\title{
Initial Assessment
}

Electromagnetic Compatibility Aspects of Proposed SPS

Microwave Power

Transmission System (MPTS)

Operations

February 1978

Prepared for the

Division of Solar Energy

U.S. Department of Energy

under Contract EY-76-C-06-1830 


\title{
NOTICE
}

This report was prepared as an account of Nork sponsored by the United States Government. Neither the United States nor the Department of Energy, sor any of their employees, nor any of their contractors. subcontractors, or their employees, makes any warranty, express or implied, or assumes any legal liability or responsibility for the accuracy, completeness or usefulness of any information, apparatus, product or process disclosed, or represents that its use would not iniringe privately owned rights.

The views, opinions and conclusions contained in this report are those of the contractor and do not necessarily represent those of the United States Coyerament or the United States Department of Energy.

\author{
PACIFIC NORTHWEST LABORATORY \\ operated by \\ BATTELLE \\ for the \\ UNITED STATES DEPARTMENT OF ENERCY \\ Under Contract EY-76-C-06-1830
}
Printed in the Unired States of America Available from
Nations! Technical Information Service United Stases Department of Commerce
5285 Pors Royal Ruad Springrieid Virginia 22151

Price: Printed Coms S___-: Microfiche $\$ 33.00$

-Paser Selling Price

90:-a25

$020-050$

$051-055$

$976-100$

$10 i+25$

$125-150$

131.175

$176 \cdot 200$

$201-203$

$226-2 \% 0$

251.275

$256-3 \% 0$

3.50

$\leq ., 90$

$\$ 5.50$

55,00

56.50

57.0

57.75

S8. 5$)$

ia.

59.00

51000

510.25 
PNL -2482

UC-97a

\title{
INITIAL ASSESSMENT \\ ELECTROMAGNETIC COMPATIBILITY ASPECTS OF \\ PROPOSED SPS MICROWAVE POWER \\ TRANSMISSION SYSTEM (MPTS) OPERATIONS
}

\begin{abstract}
(Including Radio Frequency Interference, Electromagnetic Interference and the Effects of Possible Ionospheric Modification on Communications and Other Electronic Systems)

February -- 1978
\end{abstract}

Prepared By:

Pacific Northwest Laboratory

Richland, Washington 99352

for

Division of Solar Energy

DEPARTMENT OF ENERGY

DOE Contract EY-76-C-06-1830 
TABLE OF CONTENTS

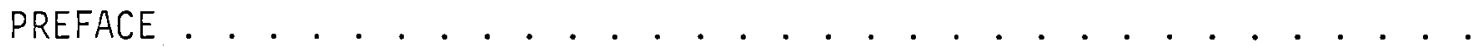

SPS EMC "POINTS"

I.

I I.

I I .

IV.

SPS EMC "DISCUSSION OF POINT I" ............. 6

Figure A: SPS Microwave Energy Distribution (after R-39) . . . 7

SPS EMC REFERENCES FOR POINT I. . . . . . . . . . . . 11

SPS EMC "DISCUSSION OF POINT II"............... 12

Figure B: SPS Noise Sideband Levels at Earth (after R-31). . . 13

Figure C: SPS Harmonic Levels at Earth (after R-31). . . . . 15

SPS EMC REFERENCES FOR POINT II . . . . . . . . . . . . 19

SPS EMC "DISCUSSION OF POINT III" . . . . . . . . . . . 20

SPS EMC REFERENCES FOR POINT III. . . . . . . . . . . . . . 24

SPS EMC "DISCUSSION OF POINT IV". . . . . . . . . . . . . . . 25

SPS EMC REFERENCES FOR POINT IV . . . . . . . . . . . . . . 27

SPS EMC "RESEARCH PLAN" ................... . . . . 28

APPENDIX I. . . . . . . . . . . . . . . . . . . 32

SPS BIBLIOGRAPHIC NOTES . . . . . . . . . . . . . . 35

REFERENCES. . . . . . . . . . . . . . . . . . 38

BIBLIOGRAPHY. . . . . . . . . . . . . . . . 56 


\section{PREFACE}

This presentation is intended to provide the general reader with an analysis of major concerns raised by the proposed SPS Microwave Power Transmission System (MPTS) with regard to other radio and electronic systems. No attempt has been made to present a comprehensive technical analysis of the various points. Extensive technical discussions of most of the points raised can be found in the references. 
SPS EMC "POINTS"

- I. Incidental energy from a SPS microwave power transmission which falls outside the rectenna area could produce harmful effects on some electronic systems throughout the hemisphere from which the SPS is visible.

- This appears to be an unavoidable result of any practical SPS microwave power transmission system due to fundamental limitations on the confinement of the transmission beam.

- Power levels produced throughout a hemisphere could degrade the performance of microwave receivers. The degree of degradation would range from negligible to catastrophic.

- Affected receivers could be modified to mitigate the problem but the cost and effectiveness of the modifications have not been determined.

- Effects on a variety of other electronic systems are expected within a radius of 20 to $30 \mathrm{~km}$ from the center of rectenna and may occur at much larger distances. Modifications to subject systems may be required.

- The severity of the problems increases as the total power transmitted from SPSS is increased and if SPSS are allowed to operate with substantial faults in their microwave power transmission control systems. 
SPS EMC "POINTS" (Continued)

I. - This incidental energy could provide secondary benefits if it could be used for limited communications purposes such as distribution of standard time and frequency information or as a navigational aid.

Further evaluation of this point will require a detailed determination of the consequences to potential victim systems, including the cost and effectiveness of possible modifications. 
SPS EMC "POINTS"

II. Spurious emissions, at frequencies outside a band presumed to be allocated to SPS microwave power transmission, could cause harmful interference to existing or planned uses of the microwave spectrum.

- Spurious emissions are strongly dependent upon engineering details which are not yet determined.

- Available estimates indicate that some limits set by existing international rules and recommendations for the prevention of interference might be exceeded.

- Control of spurious emissions may have a significant effect on the design and cost of the microwave power transmission system.

- The severity of the problem increases directly with total transmitted SPS power.

- The impact on potential victim systems has not been evaluated in detail.

Further evaluation of this point will require additional information on expected SPS spurious emissions and detailed study of the impact on potential victim systems. 


\section{SPS EMC "POINTS"}

III. SPS microwave power transmission operation will modify properties of the natural ionosphere and might substantialiy alter the propagation of radio signals over a wide range of frequencies.

- Possible effects include disruption of television broadcasting, shortwave and other commications, interference with some radar systems and degradation of accuracy of navigation aids.

- The occurrence of significant problems depends very strongly on the microwave power beam intensity. There may be a value at which SPS operation is practical and ionospheric effects are small.

- The interaction of microwave beams of the intensity proposed for the SPS power transmission with the ionosphere is not understood well enough to provide an adequate prediction of effects.

Further evaluation of this point will require extensive further study of interactions between the ionosphere and high power microwave beams including experiments that simulate SPS MPTS operations. Significant new facilities or additions to existing ones will probably be required for these experiments. 
SPS EMC "POINTS"

- IV. SPS microwave power transmissicn will require modification of existing international radio rules.

- There is at present no provision for MPTS operation and logical extension of existing rules might preclude it.

- Considering points I, II, and III above there may be technical objections to SPS microwave power transmission operations.

- International political considerations are involved.

Further pursuit of this point will require a careful assessment of points I, II and III, including selection of a candidate frequency band for SPS operations, and an organized effort on the part of some agency to obtain international agreement on a frequency allocation. 
SPS EMC "DISCUSSION OF POINT I"

Due to natural and technical limitations it is not possible to concentrate a11 the power transmitted from an SPS into a finite area. A small faction of the power will inevitably be transmitted in undesired directions. This represents a loss from the microwave power transmission system and is to be minimized for economic and other reasons. Because of the very high total power transmitted by an SPS the incidental sidelobe or scatter radiation may have a significant effect on microwave receiving equipment throughout the area from which the SPS is visible, nearly an entire hemisphere. Figure $A$ shows the power levels computed for a typical current SPS design (from Reference R-39) for a single $5 \mathrm{GW}$ system. At the edge of the earth as seen from the SPS the power level is approximately $0.3 \mathrm{microwatts} / \mathrm{cm}^{2}$. Figure $A$ is to some degree idealized. Details of the pattern would vary due to smal1 design changes or tolerances in an actual transmitting antenna assembly and partial failures of the transmission control system could result in higher power levels outside the main lobe. An increase in the total power transmitted from SPSS, either by the addition of more stations or an increase in power per station, would increase the average power level throughout the hemisphere. In the case of many SPSS using a common frequency, the actual distribution of stray energy would be quite complex and would vary with time as relative satellite positions changed slightly.

The power levels predicted in Figure A are sufficient to degrade the performance of a wide range of microwave receiving systems operating at frequencies removed from the SPS transmitting frequency due to overload and 


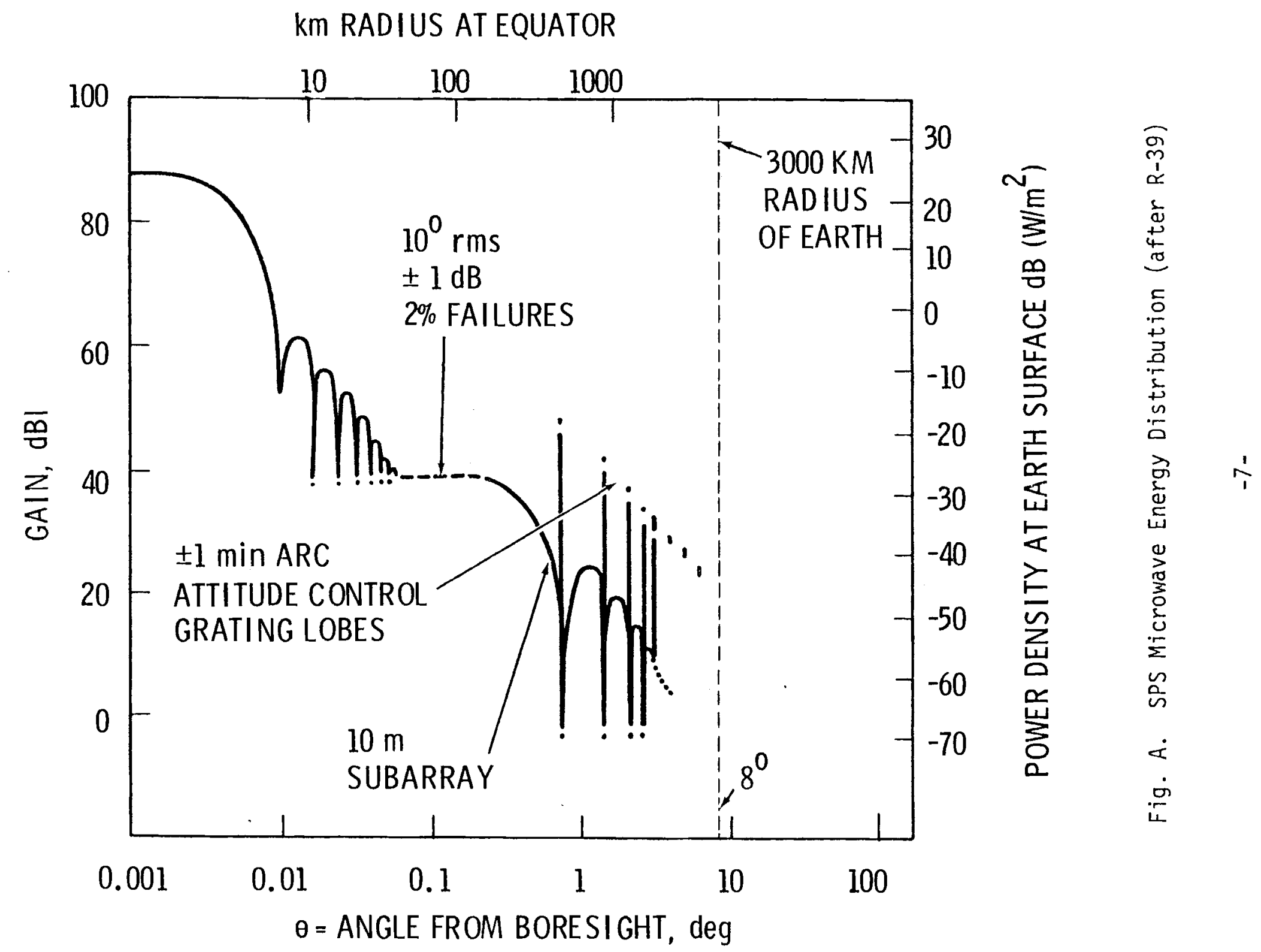


SPS EMC "DISCUSSIONS OF POINT I" (Continued)

nonlinear effects. The degree of degradation could vary from negligible to catastrophic depending on such factors as the type and orientation of receiving antenna, receiver frequency and details of the receiver design.

At one extreme, a low-altitude satellite or airborne system passing through the main beam peak power density of $23 \mathrm{MW} / \mathrm{cm}^{2}$ would be severely affected. A low-gain omnidirectional antenna designed for any frequency near the MPTS main beam frequency will intercept and deliver to the receiver approximately $1 / 4$ watt of power. This is above the damage level for many microwave components, and can be expected to interfere with or damage any receiver not specifically designed to reject the MPTS frequency.

Even at the edge of the hemisphere from which the SPS satellite is visible, where the power density from a single satellite is expected from Fig. A to be 0.3 microwatt $/ M^{2}$, a $2 M$ diameter antenna pointed toward the satellite would intercept and deliver to a receiver one microwatt, enough to overload a low noise parametric amplifier.

In principle it would be possible to add filters to affected receivers to reject the SPS power frequency, but in practice the rejection may not be completely effective in all cases and may introduce other problems, e.g., increased noise temperature in very low noise receivers or phase distortions.

The subject of responsibility of potentially affected systems for rejection of interference from the SPS power transmission frequency will be 
SPS EMC "DISCUSSION OF POINT I" (Continued)

significant in obtaining the necessary international agreements for SPS microwave power transmission operation (see Point IV).

Detailed evaluation of the total impact of SPS stray power and the effectiveness and cost of means for mitigating this impact will be a very large task considering the number of potential victim systems and the complexity of the evaluation and testing that will be required.

The overall impact, and cost of mitigating it, may depend on the exact frequency chosen for SPS transmission so this point should be evaluated as part of the SPS frequency selection process.

Power levels at and near the rectenna area will be sufficient to affect the operation of a variety of electronic equipment, including, but not limited to, receiver systems. This Electromagnetic Interference (EMI). or "High Power Effects" should be no more than a nuisance if adequately anticipated.

Prediction of the type and severity of effects to be expected on equipment which was not designed to interact with electromagnetic radiation is extremely difficult due to the large number of variables involved. The susceptibility of systems can vary widely due to minor details of a particular device or installation. We have calculated that typical computer circuits might malfunction if exposed directly to the microwave intensities expected (from Figure A) at 20 to $30 \mathrm{~km}$ from the center of the 
SPS EMC "DISCUSSIONS OF POINT I" (Continued)

rectenna. Effects have been noted from radar systems at similar intensities (Reference B-3*). In general, electronic systems would be shielded to some degree by their usual metallic enclosures and would thus be expected to function properly in higher intensity fields. The sensitivity of a number of systems and types of equipment must be investigated to assess the potential for important EMI problems at larger distances from the rectenna.

A considerable body of knowledge is available for dealing with EMI and, with proper precautions and appropriate modifications, it should be possible to operate virtually any desired equipment, except possibly microwave receivers, in the highest intensity fields SPS will produce on or near the earth.

Transmissions from the SPS will be easily detectable throughou.t roughly a hemisphere. The frequency of these transmissions must be closely controlled for proper operation of the transmitting antenna system and so might be used as a standard frequency. If suitable modulation could be applied the power transmissions might also provide a time reference. Either of the above, or other possible limited communications' uses, which might be compatible with the prime purpose of SPS could provide significant secondary benefits. This point has apparently not been explored in detail.

* Pan American Special Investigation Report 508 as quoted in B-3, p. 29-38. 
SPS EMC REFERENCES FOR POIIT I

The detailed plot of power beam intensity as a function of angle is from R-39. R-10 provides details on design considerations for the transmitting antenna and other components of the microwave power transmission system. R-31 and R-24 also consider antenna design. Power beam propagation is considered in R-31, including scatter due to weather or the ionosphere. 


\section{SPS EMC "DISCUSSION OF POINT II"}

The SPS MPTS will inevitably radiate power at frequencies other than the intended power transmission frequency. Exactly what the extent of these spurious emissions will be and what power spectral densities will be produced at the surface of the earth depend strongly on engineering details which are not yet determined. Preliminary estimates, based on components similar to those proposed for SPS DC to microwave converters, antenna system designs representative of those now planned and the use of filters believed to be practical for SPS have indicated problems in complying with current international rules limiting interference with other uses of the microwave spectrum. Interference radiated by an SPS transmitter would be particularly significant as it would affect most of a hemisphere.

The spurious emissions expected from a SPS MPTS transmitter are of two basic kinds. Random noise sidebands will be produced at frequencies adjacent to the nominal transmission frequency and, due to non-linearities, appreciable power will be produced at harmonics of the transmission frequency. The spurious emissions seen at the earth depend strongly on the choice of $D C$ to microwave converter, use of microwave filters, and overall system design.

Figure $B$ indicates the spurious power spectral flux density in noise sidebands expected at the ground for two candidate systems as calculated in R31. Also shown are limits, established by international rules and recommendations, to prevent interference to various systems. (The interference limits shown differ in some cases from those of R31, in part because of different assumptions about receiving antennas of victim systems.) 


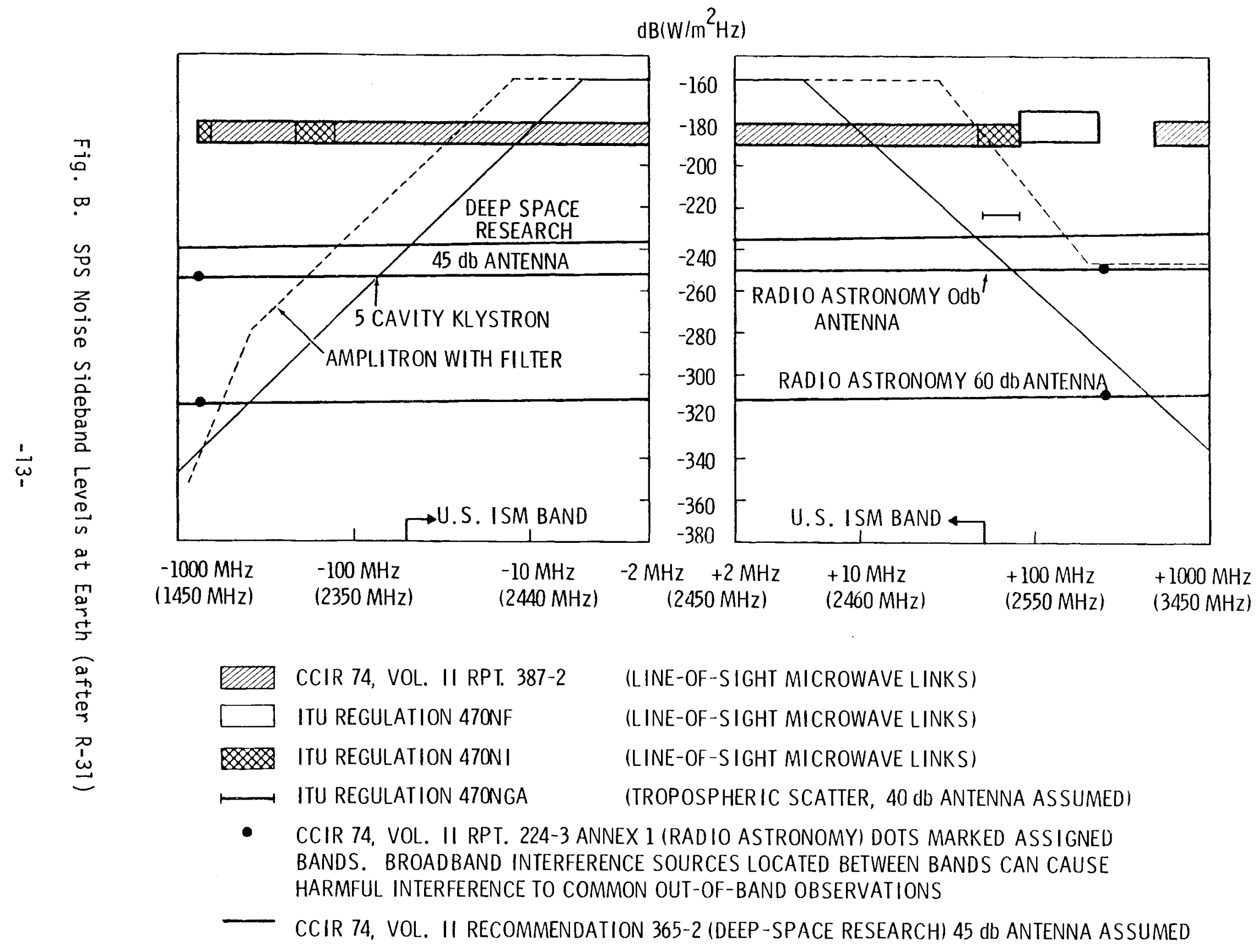


SPS EMC "DISCUSSION OF POINT II" (Continued)

An assumption generally made in evaluating radio frequency interference that might be produced by SPS is that a frequency band $100 \mathrm{MHz}$ wide will be allocated for microwave power transmission and that only interference outside this frequency band need be considered. In Figure $B$ it has been assumed that 2400 to $2500 \mathrm{iHz}$, which is available for Industrial, Scientific and Medical (ISM) uses in the United States, will be allocated. In fact there is no present frequency allocation which would allow SPS operation (see Point IV). Even with this assumption the noise sidebands shown in Figure B would exceed acceptable interference levels for low noise receiving systems especially in cases where receiving antennas might be pointed toward or near a SPS. In particular, Radio Astronomy, Deep Space Research and Tropospheric Scatter Communications Systems are provided specific protections, in International Telecommunications Union (ITU) rules or International Radio Consultative Committee (CCIR) recommendations, which might be violated by SPS microwave power transmission.

Figure C shows estimated levels of harmonic power (from Reference R-31) with recommended interference limits. Because of uncertainties in antenna gains and appropriate bandwidths comparison of the two is not entirely straightforward. Note particularly that the vertical scale of this figure is simply power flux with no bandwidth information. (Bandwidths of $4 \mathrm{kHz}$ were assumed for communications systems and $10 \mathrm{MHz}$ radio astronomy.) The presentation is intended to be conservative-- 


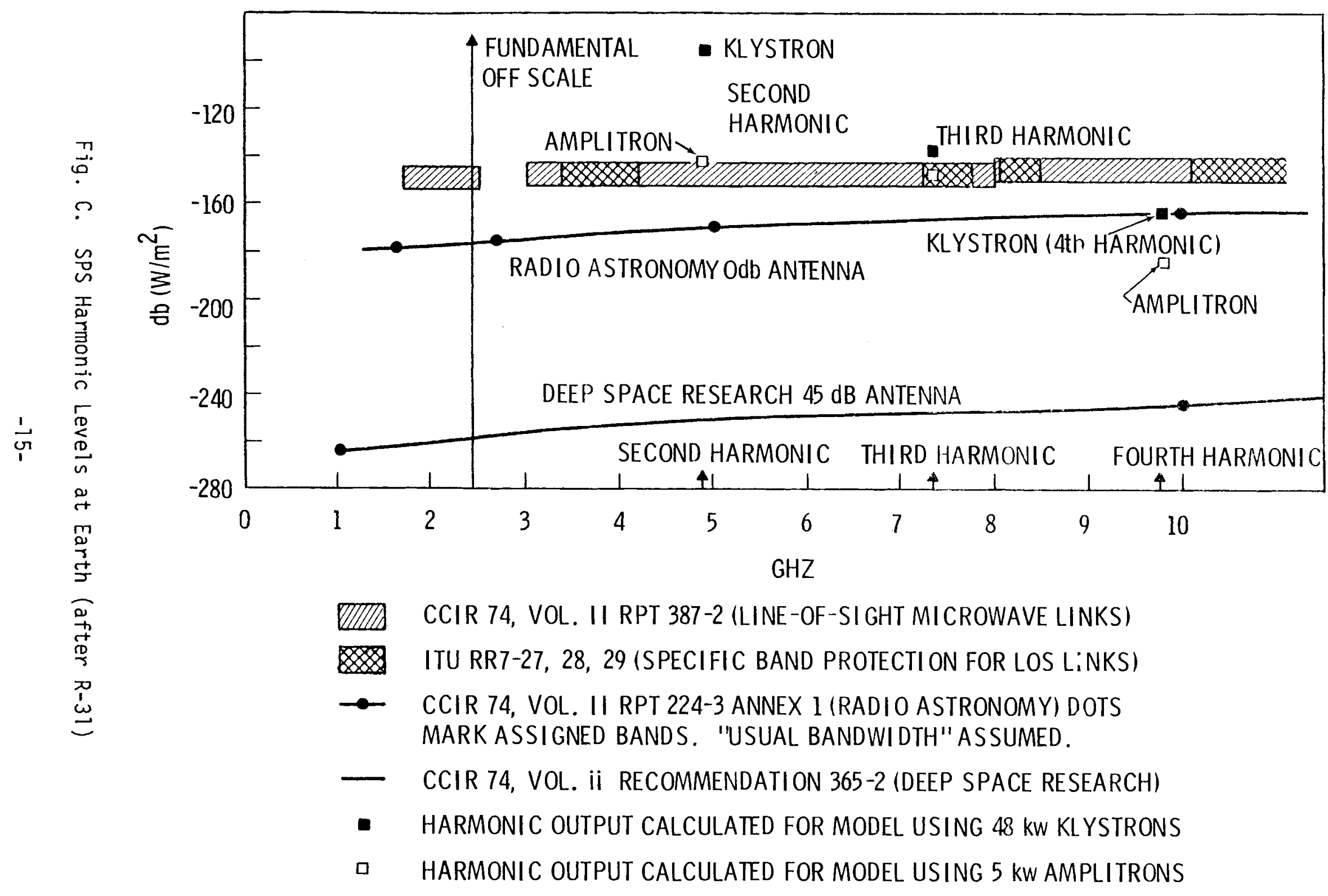


SPS EMC "DISCUSSION OF POINT II" (Continued)

interference could be experienced at levels below those shown--but indicates that, according to the preliminary estimates, SPS harmonic radiation would exceed established recommendations and in some cases (3.g., 3rd harmonic) violate ITU radio regulations.

The above does not indicate that SPS spurious emissions cannot be controlled to meet most appropriate limits, only that in the case of the preliminary design investigated in $R-3 i$ it did not. As stated above, spurious emissions are extremeiy sensitive to design details. Other estimates may be found in Appendix I, and References R-24 and R-53. All suggest interference problems.

In addition to spurious emissions from the SPS transmitter other components of the MPTS system, notably the rectenna array, may contribute harmonic radiation and possibiy noise. The rectenna elements are necessarily non-linear and will generate and radiate harmonics at levels yet to be determined and which would be expected to vary with several factors such as accuracy of matching to the rectenna load. At the power levels involved in SPS MPTS, imperfect metal-tometal junctions in any part of the system may also, due to nonlinearity of their electrical conductivity, generate significant harmonics. Spurious radiation from the rectenna system, either from rectenna elements or miscellaneous metallic structures, could be a significant source of RFI near the rectenna site. 
SPS EMC "DISCUSSION OF POINT II" (Continued)

The total of spurious emissions would be proportional to the total power provided by SPS and would thus increase as a larger number of SPS are activated.

Any spurious emissions, whether or not they exceed present regulations, would degrade the usefulness of parts of the already crowded radio spectrum. Emissions from a SPS in synchronous orbit could have an important impact on the growing number of systems which receive weak signals from space.

Communications satellites, and possibly broadcast satellites which have been assigned frequencies near those proposed for SPS, would share the limited arc of synchronous orbit accessible from the United States, so receiving antennas would be aimed in the general direction of SPS transmitters. Satellite signal strengths are limited both by regulation and basic technological considerations.

Radio and Radar Astronomy and Deep Space Research deal with signals that approach the weakest detectable, using large antennas which it may be necessary or desirable to point near SPS locations. In particular, Radio Astronomy has been assigned certain protected bands but as a matter of practice uses a wide range of other frequencies subject to existing interference. SPS spurious emissions would further limit the frequencies available for observations.

Detailed investigation of the effect of SPS MPTS emissions at unauthorized frequencies may have some influence on choice of operating frequency 
SPS EMC "DISCUSSION OF POL:IT I" (Continued)

to minimize adverse impact. No exact determination of impact is possible, however, without more extensive information on expected spurious emissions. This information will not be available until representative components, which in some cases do not exist yet, have been tested and SPS system design and testing have proceeded further. The extent of spurious emissions will presumably have an important influence on the difficulty of obtaining necessary international agreement for SPS operations and further design effort toward reducing these emissions seems appropriate. 
SPS EMC REFERENCES SECTION OF POINT II

Computations of estimated SPS spurious emission are found in R-31, R-24, and R-53. Interference limits are found in ITU Radio Regulations $(S-1)$, $\therefore \quad$ in particular article 7 , footnote 470 , and in CCIR XIIIth Plenary Assembly $(B-5)$, Volumes II and IX.

A general discussion of SPS interference impacts appears in R-39. For further information on interference considerations for Radio Astronomy see $R-12, R-8$, and $R-11$. 
SPS EMC "DISCUSSION OF POINT III"

A small part of the energy in the microwave power beam will be absorbed in passing through the ionosphere. The ioss of energy will be insignificant in terms of the efficiency of the power transmission system but will result in appreciable modification of the ionosphere. This will produce, among other effects, changes in the propagation of radio waves through or reflected from the ionosphere. Present understanding of the ionosphere and its interactions with radio and microwaves is not adequate to predict the severity of all effects that might result.

Use of the radio spectrum at frequencies below several hundred $\mathrm{MHz}$ is strongly influenced by ionospheric properties which SPS MPTS operations inight modify. The situation is complicated by the fact that the minimum power densities apparently required for an economically practical SPS are thought to be approximately at the threshold for production of ionospheric irregularities caused by intense heating.

Even if irregularities are not produced, systems using frequencies normally reflected by the ionosphere, including low frequency navigation systems and shortwave communications, would be affected.

If ionospheric irregularities are produced, shortwave communications could be disrupted over some paths and undesirable ionospheric reflection of 
SPS EMC "DISCUSSION OF POINT III" (Continued)

higher frequencies, not normally reflected, including TV broadcast frequencies, could produce interference over wide areas, within a radius of perhaps $2000 \mathrm{~km}$ from the SPS receiving point.

Prediction of ionospheric modifications that might be caused by SPS, and of the consequent effects on communications and other systems is complicated by natural variability of the ionosphere.

Experiments have been conducted which produced substantial modification of the ionosphere, including irregularities, by means of absorption of radio energy in the high frequency portion of the frequency spectrum. One significant conclusion from these experiments has been that the theoretical predictions of ionospheric behavior resulting from intentional heating have not been entirely accurate.

Experiments done to date have not adequately approximated SPS MPTS operations. Significant ionospheric modification has only been produced by the use of frequencies specifically chosen for maximum energy transfer to the ionosphere, i.e., in the high frequency band. These frequencies are much lower than those proposed for SPS, and because they were chosen to correspond to ionospheric plasma resonances (plasma frequency) the experimental conditions do not approximate SPS operations. Experiments using frequencies which better represent SPS operations have not been able to provide more than a small fraction of energy that SPS would deposit in the ionosphere. 
SPS EMC "DISCUSSION OF POINT III" (Continued)

Ionospheric modification experiments which literally duplicate SPS operation would require equipment and total power levels approximating those of an actual SPS and thus would be very expensive. Simulation of SPS effects on the ionosphere should be possible however with much lower power levels due to the fact that energy absorption in the ionosphere is strongly dependent upon frequency. For frequencies far enough removed from the plasma frequency power absorption scales as one over frequency squared. Thus, for example, at a frequency of $24 \mathrm{MHz}$ energy could be transferred to the ionosphere at a rate simulating SPS operations at $2450 \mathrm{MHz}$ from a beam on only 1/10,000th the intensity and total energy of an actual SPS. Details of the interactions between the ionosphere and radio waves have other subtle frequency dependencies however so that extrapolation of results of low frequency experiments to SPS operation is not trivial.

There is general agreement that ionospheric modification experiments are needed which appropriately simulate SPS operations. There is not complete agreement as to details of the experiments required, what frequency or frequencies to use, and exactly what measurements need to be made. One would, for example, like to use a high frequency which would closely approximate SPS effects but the amount of power required, and hence cost, rises rapidly with frequency. It also appears that SPS modification of the ionosphere could have other important effects, in 
SPS EMC "DISCUSSION OF POINT III" (Continued)

addition to those on radio profagation, and plans for experiments should include consideration of other appropriate measurements.

In view of the above, and the substantial cost of the required experiments (\$4 million is the lowest figure quoted, Reference R47), extensive additional planning is required for research in this area. 
SPS EMC REFERENCES FOR POINT III

A basic analysis of SPS microwave power transmission interaction with the ionosphere is begun in $\mathrm{R} 31$ and expanded in $\mathrm{R} 36$ to provide theoretical predictions of ionospheric modification expected, qualitative estimates of effects on radio propagation, and recommendations for further study. R47 describes a recent series of experiments in ionospheric modification performed for SPS evaluation, qualitatively describes possibie impacts of SPS ionospheric modifications, and makes specific recommendations for further work.

For further information on ionospheric modification experiments and consequences see $R 9$, $R 62$, and $R 45$. 
SPS EMC "DISCUSSION OF POINT IV"

Use of the radio spectrum is controlled by international and national regulations. At present there is no provision for SPS microwave power transmission. The closest approximation currently recognized is for Industrial, Scientific and Medical (ISM) purposes. The International Telecommunications Union (ITU), a specialized agency of the United Nations, provides for ISil operations in Article 5, footnote 357 of the International Radio Regulations as follows:

"The frequency $2450 \mathrm{MHz}$ is designated for industrial, scientific and medical purposes except in Albania, Bulgaria, Hungary, Poland, Roumania, Czechoslovakia and the U.S.S.R., where the frequency $2375 \mathrm{MHz}$ is used. Emissions must be confined within $\pm 50 \mathrm{MHz}$ of the frequencies designated. Radiocommunication services operating within these limits must accept any harmful interference that may be experienced from the operation of industrial, scientific and medical equipment."

The United States Federal Communications Commission (FCC) Rules and Regulations also allocate this band, among others, for ISA purposes and defines ISM equipment (in 18.3(f)) as "Devices which use radio waves for industrial, scientific, medical, or any other purpose including the transfer of energy by radio and which are not used nor intended to be used for radio communication" (emphasis added).

The FCC further notes that "Equipment operating on an ISM frequency may be operated with unlimited radiation on that frequency." (18.102 (b)) but that "No harmful interference shall be caused to authorized communications services from spurious or harmonic radiation" (18.14 (c)). 
SPS EMC "DISCUSSION OF POINT IV" (Continued)

It has been tentatively assumed in SPS microwave power transmission design studies and radio frequency evaluations that the ISM band from 2400 to $2500 \mathrm{MHz}$ would be allocated to SPS operations. Such an allocation does not now exist. Two important point must be noted. First the $2400-2500 \mathrm{MHz}$ band is not allocated to ISM purposes throughout the world. Second, SPS microwave power transmission would be a substantial departure from conditions foreseeable when the existing allocation was made. The area of interference produced from an ISM installation at the surface of the earth is limited by line of sight propagation characteristics at microwave frequencies whereas an SPS would cover roughly a hemisphere. There are communication services presently using this band, some but not all of which are in countries where it is not allocated to ISil.

Existing regulations could be changed at a World Administrative Radio Conference (WARC), one of which is scheduled for 1979, to explicitly permit SPS microwave power transmission. In view of the substantial impact SPS could have on radio communications, as outlined in points I, II and III above, approval of a request for such changes could hardly be regarded as assured. Convincing demonstrations would be required that consequences would be acceptable.

The proposed SPS microwave power transmission system raises concerns in a number of areas, beyond radio spectrum allocation, which may well influence any decisions on necessary International Radio Regulation 
changes. In particular there is a great deal of sensitivity and concern over possible undesirable modifications of the earth's atmosphere, including the ionosphere, and over the possibility of biologically harmful effects from electromagnetic radiation.

Modification of the international Radio Regulations would require the approval of a majority of the world's nations and it is conceivable that approval might be denied for reasons not directly related to technical concerns.

\section{SPS EMC REFERENCES FOR POINT IV}

International rules governing usage of the radio spectrum are contained in ITU Radio Regulations (S-1). See in particular articles 5 and 7 . These regulations are principally based on CCIR recommendations. See in particular Volumes II and IX of the XIIIth Plenary Assembiy (B-5). United States regulations are contained in Federal Communications Commission Rules and Regulations (S-2). See in particular Parts 2 and 18. 
SPS EMC "RESEARCH PLAN"

Further work on points I and II will require assessment of the impact of microwave radiation from the SPS power transmission system, both at the intended power transmission frequencies and all expected spurious emissions on existing radio communications, radar, radio astronomy services and other electronic systems. This assessment should include a determination of optimum SPS operating frequency to minimize harmful effects and an evaluation of the need for control of spurious emissions. A detailed assessment will require more highly refined estimates of the emissions expected from al1 parts of the SPS system, estimates which in many cases cannot be made until SPS design and testing are further advanced. Sufficient information is available now however to begin useful basic evaluation. The processes of impact assessment and design refinement are expected to proceed interactively to a technical optimum. Assessment of SPS impacts is closely related to the general concept of efficient radio spectrum utilization, a topic which is of substantial continuing interest. The U.S. Department of Commerce, Office of Telecommunications has played a leading part in work in this area and could be expected to provide substantial assistance in SPS interference assessment.

It is expected that SPS design and testing will be supervised by NASA and that they will be able to provide all, or most, of the data required to estimate emissions from the SPS MPTS. Some additional specific tests for interference assessment may be required from time to time but nothing is 
SPS EMC "RESEARCH PLAN" (Continued)

- foreseen that would be a major perturbation of overall schedules or budgets.

Specific tests may be desirable to determine the susceptibility of representative electronic apparatus and systems to electromagnetic interference from SPS. There does not seem to be an immediate pressing need for such tests but they could be simple and inexpensive to perform. As part of a detailed assessment it may be necessary to make both laboratory and field measurements of the severity of overloading problems in microwave receivers and the effectiveness of means for mitigating any problems found. This might require a substantial effort but its scope cannot be planned until the problems to be expected have been assessed in more detail.

The questions raised in point II w wll require a substantial research effort because basic scientific knowledge is not now adequate to evaluate the potentially very serious consequences of SPS ionospheric modification.

Experiments will be required to simulate ionospheric modifications that would be expected during SPS MPTS operation and extensive measurements will be needed to determine the consequences for radio communications and other systems. Existing facilities are not adequate to perform these experiments and the necessary construction will be expensive. Costs have been estimated at from $\$ 4$ million for additions to an existing facility 
SPS EMC "RESEARCH PLAN" (Continued)

(in Reference R47) to $\$ 34$ to $\$ 126$ million for construction of new facilities (in Reference R36). There is at present some divergence of opinion as to details of appropriate experiments. In view of the cost and importance of the work further efforts should be made to reach a consensus before developing detailed plans. A meeting of experts in this area seems highly desirable to define as well as possible the course of appropriate experiments. Measurements of consequences beyond those to communications should also be considered. In view of the schedule of the SPS evaluation this meeting should be scheduled for early 1978.

Further work on resolution of point IV will consist in some sense of efforts directed toward obtaining international agreement on a frequency allocation for SPS MPTS. Studies undertaken for points I, II and III will substantially develop the necessary technical assessment of consequences and could, with relatively little additional effort, provide the needed support in this area. Some agency wi1l, however, have to undertake the advocacy of the required allocation, with due sensitivity to all the considerations involved. It would seem to be desirable that the impact evaluation and advocacy roles be kept well separated.

The cost of research on ionospheric modification effects on radio propagation, responsive to point II, cannot be adequately estimated until details 
SPS EMC "RESEARCH PLAN" (Continued)

of the necessary work are determined and the division of effort between these studies and those on other ionospheric effects has been clarified. 
APPENDIX I

Notes on the SPS Noise Calculation of R-31

Two frequency-dependent effects neglected in the noise calculation of R-31 will, if included, substantially alter the noise spectrum obtained.

The first is beam scanning and/or breakup for radiated frequency components away from the carrier. The effective off-frequency gain depends crucially upon antenna feed details, and these could be chosen to minimize spurious radiation. In another context Section 6.6 .1 of the report calculates for the slotted waveguide radiator proposed a frequency scanning sensitivity of 1 arc minute per $612 \mathrm{~Hz}$ frequency deviation. This indicates that a deviation of $300 \mathrm{kHz}$ will scan the main lobe off the earth. Larger deviations will eventually scan a degraded beam back on. At any given location in the beam's scan path there would be particular narrow frequency ranges where noise could be observed possibly as intense as that calculated below, but most of the spectrum would be much quieter.

The second effect is the frequency dependence of coherence in an amplitron cascade. The report's calculation treats the antenna as a collection of independent 10-tube cascades. Antenna gain for each 10-tube coherently radiating assembly is estimated at $33.7 \mathrm{~dB}$ based on its share of the array area and an assumed coherence factor of .5. The total power output of the cascade is taken to be ten times as noisy as one tube to account for fedthrough noise being cumulative along the cascade. Coherence is taken to be 
SPS EMC APPENDIX I (Continued)

frequency independent, and the radiated spectrum shape is assumed to be the same as that of a single tube.

Power density result is $-160 \mathrm{dBW} / \mathrm{M}^{2} \mathrm{~Hz}$ at band center falling off as the singletube spectrum does.

The coherence length in an infinite cascade depends strongly on the stage gain, and at the $-3 \mathrm{~dB}$ point is just one tube. From this arise two separate calculations:

A) For out-of-band noise, each tube-and-radiator is treated as an independent noise source whose antenna gain and pattern are that of a single slotted waveguide section, and whose noise output is that of a single tube. The gain is estimated at $21 \mathrm{~dB}$ based upon detailed consideration of a center-of-antenna fully dense guide section. This gives for a uniformly illuminated antenna a power density result of $-183 \mathrm{dBW} / \mathrm{M}^{2}-\mathrm{Hz}$ at band center falling off as the single-tube spectrum does, plus the in-band contribution below. Corrected for $11.5 \mathrm{~dB}$ illumination taper it is $-178 \mathrm{dBW} / \mathrm{M}^{2}-\mathrm{Hz}$, or $18 \mathrm{~dB}$ less noisy than the report's result.

B) For in-band noise, the noise originating in any tube is assumed to be present at the same $S / N$ and completely coherent in the outputs of all tubes downstream. A tree is assumed driving 128 8-tube cascades which make up the subarray. If amplitrons are used in the tree, the first one dominates the array noise output and tree 
SPS EMC APPENDIX I (Continued)

details are unimportant. Four-way branching was assumed for the first three levels, and a 2-way branch for the fourth stage. The first tree stage's noise appears in all 1024 of the radiating guide sections (a multiplicity gain of 1024) and these sections are a11 coherent, giving an antenna gain of $1.2 \times 10^{5}$ or $51 \mathrm{~dB}$. Other contributions are all smaller, the next tree stage contributing $1 / 4$ as much because of the smaller area over which coherence is maintained, and so on. The power density result is $-151.4 \mathrm{dBW} /$ $\mathrm{M}^{2} \mathrm{~Hz}$ at band center. Away from band center the received noise power density will fall rapidly due to loss of coherence, and due to beam breakup induced by the lumped phase shift of the amplitrons and filters, and eventually become negligible compared with calculation $A$.

The net effect of considering the frequency dependence of coherence is to increase the predicted noise density near the carrier by about $9 \mathrm{~dB}$, and decrease the predicted noise far from the carrier by about $18 \mathrm{~dB}$. 


\section{SPS BIBLIOGRAPHIC NOTES}

General Information on Microwave Power Transmission:

R-28 provides a brief, overa 11 review of microwave power transmission technology and potential.

Extensive studies done for a space-to-space microwave power link are documented in R-54, R-60, and R-61.

Studies of microwave power transmission systems for SPS (or similar projects) are found in R-24 and R-53 with R-37 being perhaps the most comprehensive.

In addition, R-65 discusses expected atmospheric effects on an SPS microwave power beam.

Measurements of microwave power transmission efficiency, with particular consideration of the rectenna system are found in R-18 and R-37 which describe laboratory tests and R-20 and R-5 which describe field tests of a $30 \mathrm{KW}$ rectenna.

R-10 provides a wealth of detail on engineering considerations in SPS including microwave power transmission.

R-39 provides a comprehensive, up-to-date, summary of the impacts and benefits of SPS microwave power transmission as currently envisioned. 
SPS BIBLIOGRAPHIC NOTES (Continued)

Specific Topics in Microwave Power Transmission:

For general information about microwave to DC conversion tube technology see $R-15$, for amplitrons $R-41, R-54, R-68$, for klystrons $R-0$.

For tubes discussed for particular application in SPS see R-41, R-24, $R-31$, and $R-53$.

Antenna designs for the SPS power transmitter are described in R-10 and R-31. R-39 provides a detailed diagram of expected sidelobe levels for a well developed design.

For discussion of propagation of a power beam through the atmosphere, including scatter see R-65, R-31, and R-34. Information about atmospheric effects on microwave propagation in general may be found in $R-64, B-4$, $R-19, R-29$ and $R-30, R-17$, and $B-3$.

Detailed discussions of rectenna systems are found in R-18, R-37, and field tests are described in R-20 and R-5.

Radio frequency interference that might result from SPS microwave power transmission is estimated in R-31, R-24, and $R-53$ with a recent assessment of the impact in R-39. For information on radio spectrum usage for radio astronomy see $R-12$ and $R-8$.

International radio regulations appear in S-1. B-5 provides the technical basis for many of these rules and includes additional recommendations. S-2 contains U.S. domestic radio rules and regulations. 
SPS BIBLIOGRAPHIC NOTES (Continued)

The effects of the SPS microwave power beam on the ionosphere and their consequences for radio propagation are considered in $R-31, R-36$, and R-47 with a review in $R-39$.

Modification of the ionosphere by radio waves and resulting effects on radio communications are discussed in $R-62$ and $R-45$.

For further information on ionospheric modification and consequences thereof see $R-6, R-9, R-11, R-46, R-66, R-69$, and $R-70$. 


\section{REFERENCES}

$\underline{B O O K S}$

$\underline{B \text { 年 }}$

B-1 Deleted; now R31.

B-2 "Solar Power Satellite System Definition Study," VOL I - Executive Summary (June 28, 1977); VOL II - System Requirements and Energy Conversion Options (JuTy 29, 1977); VOL III - Construction, Transportation and Cost Analyses (August 8, 1977); VOL IV - SPS Transportation System Requirements (August 1, 1977); and VOL V - SPS Transportation: Representative System Descriptions (July 28, 1977). NAS9-15196.

B-3 "Radar Handbook," Merrill I. Skolnik, 1536 pages, copyrighted 1970.

B-4 "Radar Observations of the Atmosphere," L. J. Batten, 1973, University of Chicago Press.

B-5 "XIIIth Plenary Assembiy, Geneva, 1974," VOL I - Spectrum Utilization and Monitoring (Study Group 1); VOL II - Space Research and Radioastronomy (Study Group 2), VOL IV - Fixed Service Using Communication Satellites (Study Group 4); VOL V - Propagation in Non-Ionized Media (Study Group 5); VOL VI - Ionospheric Propagation (Study Group 6); VOL VIII - Mobile Services (Study Group 8); VOL IX - Fixed Service Using Radio-Relay Systems (Study Group 9); and VOL XI - Broadcasting Service (Television) Including Video-Recording and Satellite Applications (Study Group 11). Published by the ITU - CCIR Documents. 


\section{REFERENCES}

LETTERS

$\underline{L}$

L-1 "Force Resulting from the Electromagnetic Radiation of Energy from the SSPS Antenna," D. Cermignani, GAC Inter-Office Memo, 1 September 1972.

L-2 "SSPS Microwave Antenna Deflections due to Temperature," W. Besendorfer, GAC Inter-Office Memo, 31 July 1972.

L-3 "SSPS Microwave Antenna Temperatures," L. Royce, GAC Inter-Office Memo, 27 JuTy 1972.

L-4 "Solar Power from Satellites--Some Questions," Peter Glaser, Physics Today, pp. 9-15 and 66-69, July 1977.

L-5 "International Telecommunications. Union," contains Organization and Technical Cooperation, current as of September 1976. 


\section{REFERENCES}

\section{MICROFICHE}

$\underline{M+1}$

M-1 "Satellite Power System: Engineering and Economic Analys is Summary," NASA-TM-X-73344, 282 p, November 1976.

M-2 "Space-Based Solar Power Conversion and Delivery Systems Study. VOLUME 1: Executive Summary," Interim Report, G. A. Hazelrigg, Jr., 38 p, June 30, 1976 (ECON, Inc., Princeton, NJ).

M-3 "Space-to-Earth Power Transmission System," G. H. Stevens, et al, NASATM-X-73489, 143 p, November 1976.

M-4 "Microwave Power Transmission System Studies. VOLUME 1. Executive Summary," 0. E. Maynard, et al, 231 p, December 1975 (Raytheon Co.).

M-5 "Microwave Power Transmission System Studies: VOLUME 2. Introduction, Organization, Environmental and Spaceborne Systems Analyses," 0. E. Maynard, et al, 262 p, December 1975 (Raytheon Co.).

M-6 "Microwave Power Transmission System Studies. VOLUME 3. Section 8: Mechanical Systems and Flight Operations," 0. E. Maynard, et al, 234 p, December 1975 (Raytheon Co.).

M-7 "Microwave Power Transmission System Studies. VOLUME 4. Sections 9 through 14 with Appendices," 0. E. Maynard, et a1, 235 p, December 1975 (Raytheon Co.). 
MICROFICHE REFERENCES

$\underline{M}$

M-8 "Atmospheric Propagation Constraints on Microwave Power Transmission," W. O. Brown, 22 p, April 1977 (Sandia Labs, Albuquerque, New Mexico).

M-9 "Critical Areas: Satellite Power Systems Concepts," NASA-TM-X-74694, $168 \mathrm{p}, \mathrm{July} 1975$. 


\section{REFERENCES}

\section{REPORTS AND ARTICLES}

$\underline{R=}$

R-0 "Analytical Designs of a Space-Borne Magnetically-Focused Klystron Amplifier," DR. G. M. Branch and DR: T. G. Mihran, NASA CR-72461, Contract NAS3-11514, October 25, 1968.

R-1 "Commercial Applications of Microwave Energy, The Canadian Effort," W. Wyslouzi1, Microwave Journal, pp. 51-54, May 1975. Author is with National Research Council, Ottawa, Canada.

R-2 "Committee on Radio Frequencies," National Research Council. Contents are 1) Terms of Reference: a) Functions and Tasks and b) Organization and 2) Membership: a) Committee on Radio Frequencies, b) Subcommittee on Radio Astronomy and c) Subcommittee on Space Science.

R-3 "Electromagnetic Compatibility, An Overview," R. F. Ficchi, Microwave Journal, pp. 39-43, January 1975.

R-4 "Energy Deposition in Artificial Ionospheric Heating Experiments," J. Alex Thomson, J. Geophys. Res. \& Space Phys.75, No. 31 , p. 6446, 1 November 1970. Author: Research Institute for Engineering Sciences, Wayne State University.

R-5 "Evaluation of a Microwave High-Power Reception-Conversion Array for Wireless Power Transmission," R. M. Dickinson, Technical Memorandum 33-741, 1 September 1975, NASA CR-145625. Author is with JPL. 
$\underline{\text { R\# }}$

R-6 "Evidence for Precipitation of Energetic Particles by Ionospheric 'Heating" Transmission," J. W. Wright, J. Geophys. Res. 80, No. 31, p. 4383, September 1, 1975. Author is with NOAA-ERL.

R-7 "Final Report of the ERDA Task Group on Satellite Power Stations," ERDA76/148, Office of the Administrator, ERDA, November 1976.

R-8 "Frequency Allocations for the Radio Astronomy Service," National Academy of Sciences, in preparation for the World Administrative Radio Conference - 1979, 1st Revision - November 1975.

R-9 "Heating of the Lower Ionosphere by Powerful Radio Waves," Lowel1 H. Holway, Jr. and Gerald Meltz, J. Geophys. Res. $\underline{78}$, No. 34, p. 8402, December 1, 1973.

R-10 "Initial Technical, Environmental and Economic Evaluation of Space Solar Power Concepts," two volumes - VOL I: Summary and VOL II: Detailed Report, both dated August 31, 1976. NASA TM X 74389 (JSC-11568).

R-11 "Ionospheric Heating by Power Radio Waves," G. Meltz, L. H. Holway, Jr. and N. M. Tomljanovich, Radio Science 9, No. 11, pp. 1049-1063, November 1974.

R-12 "List of Radio and Radar Astronomy Observatories (1974)," and "Supplement," The National Research Council, Committee on Radio Frequencies, Assembly of Mathematical and Physical Sciences, 1974. 
REPORTS AND ARTICLES REFERENCES

$\underline{\mathrm{R} \#}$

R-13 "Man-Made Noise in the Microwave Frequency Range, An RFI Problem Area Identified and Analyzed," Edward N. Skomal, Microwave Joumal, pp. 44-47, January 1975. Author is with Aerospace Corporation, El Segundo, CA.

R-14 "Microwave Power Sources," Microwave Joumal, pp. 18-22, 1975, Principal and Collaborating Contributors: (Tube Sources) Jacques Collard [Varian Associates] et a1.; (Multiplier Sources) Al Kenrick [California Microwave] et al.; (Bulk Effect Sources) Wes Matthei, Microwave Assoc.; (YTO, VCO Sources) Harry Fowler [Watkins-Johnson] et a].

R-15 "Microwave Tube Technology Review," Dr. Stanley F. Kaisel, Microwave Joumaz, pp. 23-42, Ju1y 1977.

R-16 "Observations by Radio Astronomers of ATS-6 Satellite Transmissions, June 18-22, 1974," National Academy of Sciences, Report of the Subcommittee on Radio Astronomy of the Committee on Radio Frequencies, National Research Council.

R-17 "Propagation Phenomena Affecting Sate11ite Communication Systems Operating in the Centimeter and Millimeter Wavelength Bands," R. K. Crane, Proceed. IEEE 59, p. 173, 1971.

R-18 "Radiated Microwave Power Transmission System Efficiency Measurements," R. M. Dickinson and W. C. Brown, NASA Technical Memorandum 33-727 (NASA (R-142986), May 15, 1975. Authors are with JPL. 
REPORTS AND ARTICLES REFERENCES

$\underline{\mathrm{R}} \underline{\underline{\underline{H}}}$

R-19 "Rainfa11 Attenuation of Centimeter Waves: Comparison of Theory and Measurement," Richard G. Medhurst, IEEE Transactions on Antennas and Propagation, p. 550, July 1965. Author is with Telecommunications Research Labs, Hirst Research Centre, General Electric Co., Wembley, England.

R-20 "Reception Conversion Subsystem (RXCV) for Microwave Power Transmission System, Final Report," Raytheon Company, JPL Contract No. 953968, NASA CR-145917, dated 1 September 1975.

R-21 "Initial Standards and Guidelines (CS\&G) for Satellite Power Station (SPS) Development," DOE-NASA Workshop on same, October 18, 1977, Working Draft Co-Chairmen: Fred A. Koomanoff (DOE) and Ralph LaRock (NASA), held at Huntsvilie, Alabama.

R-22 "Solar Power from Satellites," Peter E. Glaser, Physics Today, p. 30, February 1977. (See L-4 for comments on this article.)

R-23 "Some Recent Trends in EMC Tests and Measurements," W. S. Lambdin, Microwave Joumal, pp. 49-51, March 1975. With Electrometrics, Division Penril Corporation, Amsterdam, New York.

R-24 "Space-to-Earth Power Transmission System," Grady H. Stevens and Richard Schuh, NASA TM X 73489, NASA Technical Memorandum, November 1976.

- R-25 "Space-Based Solar Power Conversion and Delivery Systems Study: VOLUME II: Interim Summary Report," dated 3-31-76 (NASA-CR-144289).

R-26 "A Survey of Satellite Power Stations," Charles E. Bloomquist, PRC R-1844, PRC Systems Sciences Company, September 1976. ERDA Report SE-2071/1. 


\section{REPORTS AND ARTICLES REFERENCES}

$\underline{\mathrm{R}} \stackrel{\|}{\underline{\pi}}$

R-27 "SPS Concept Development and Evaluation Program Plan, Volume 1 and Volume 2 (July 1977-August 1980)," prepared jointly by the Division of Solar Energy, ERDA, and the Office of Energy Programs, NASA. Reviewed and approved by Alan M. Lovelace, Deputy Administrator, NASA, and Robert W. Fri, Deputy Administrator, ERDA. Report dated May 1977.

R-28 "The Technology and Application of Free-Space Power Transmission by Microwave Beam," William C. Brown, Proceed. of the IEEE 62, No. 1, p. 11 , January 1974.

R-29 "Virginia Precipitation Scatter Experiment - Experiment Description (August 1972)," Goddard Space Flight Center, X-750-73-54 (preprint).

R-30 "Virginia Precipitation Scatter Experiment - Data Analysis (November 1972)," Goddard Space F1ight Center, X-750-73-55.

R-31 "Microwave Power Transmission Studies," Volumes I through IV, December 1975, Contract No. NAS3-17834, NASA Report No. NASA-CR-134886.

R-32 "Space-Borne Power Conversion into a Microwave Beam and Its Impact on the Environment of the Upper Atmosphere," 0. E. Maynard and A. H. Katz of Raytheon (Wayland, MA) and W. E. Whitacre of NASA Marshal Space Flight Center (Huntsville, AL), Proceed. of the 12th IECEC, held in Washington, DC, August 28 through September 2, 1977, Report \#779241, pp. 1445-1452, presented by the American Nuclear Society. 
REPORTS AND ARTICLES REFERENCES

$\underline{R=1}$

R-33 "Solar Power Satellite Concepts and Potential Related Space Systems," Tony E. Redding of NASA Lyndon B. Jonnson Space Center (Houston, TX), Proceed. of the 12th IECEC, held in Washington, DC, August 28 through September 2, 1977, Report \#779236, resented by the American Nuclear Society.

R-34 "Solar Power Satellites-A System Overview," G. Woodcock of Boeing Aerospace Company, Proceed. of the 12th IECEC, held in Washington, DC, August 28 through September 2, 1977, Report \#779233, pp. 1391-1398, presented by the American Nuclear Society.

R-35 "Space-Based Solar Power Conversion and Delivery Systems Study VOLUME II: Engineering Analysis of Orbital Systems (Final Report)," Rudolph J. Adornato, Contract NAS8-31308, March 1977.

R-36 "Space-Based Solar Power Conversion and Delivery Systems Study VOLUME III: Microwave Power Transmission Study," March 1, 1977, subcontract ECON-0003.

R-37 "Electronic and Mechanical Improvement of the Receiving Terminal of a Free-Space Microwave Power Transmission System," W. C. Brown, August 1, 1977, Contract NAS3-19722, NASA-CR-135194.

R-38 "Systems Definition Space Based Power Conversion Systems," Final Performance Review Briefing, NAS8-31628, dated December 2, 1976. 


\section{REPORTS AND ARTICLES REFERENCES}

$\underline{R \#}$

R-39 "Satellite Power System (SPS) Microwave Subsystem Impacts and Benefits," Richard M. Dickinson, JPL, 28 September 1977.

R-40 "SPS Environmental Assessment Plan (SEAP)," Charles E. Bloomquist and Lloyd L. Philipson, November 1976, prepared for ERDA Division of Solar Energy.

R-41 "High Power Microwave Generators of the Crossed-Field Type, "William C. Brown, J. of Microwave Power 5, No. 4, 245 (1970), paper presented at IMPI 5th Symposium, The Hague, October 7-9, 1970.

R-42 "Progress in the Design of Rectennas," W. C. Brown, J. of Microwave Power 4, No. 3, 168 (1969), IMPI Symposium paper E5, presented at the 4th International Symposium on Microwave Power, Edmonton, May 22, 1969.

R-43 "Space-Based Solar Power Conversion and Delivery Systems Study - VOLUME II: Engineering Analysis of Orbital Systems (Second Interim Report)," 30 June 1976, Contract NAS8-31308.

R-44 "The Potential of Satellite Solar Power," Peter E. Glaser (Invited Paper), Proceed. of the IEEE 65, No. 8, pp. 1162-1176, August 1977.

R-45 "Ionospheric Modification Induced by High-Power HP Transmitters--A Potential for Extended Range VHF-UHF Communications and Plasma Physics Research," William F. Utlaut, Proceed. of the IEEE 63, 1022-1043 (1975). 
REPORTS AND ARTICLES REFERENCES

R节

R-46 "Thermal Self-Focusing of Electromagnetic Waves in Plasmas," F. W. Perkins and E. J. Valeo, Phys. Rev. Letters 32, 1234 (1974).

R-47 "Final Report, Ionospheric Microwave Beam Interaction Study, September 1977," L. Duncan and W. E. Gordon, NASA Contract NAS9-15212.

R-48 "Limits of Radio Interference and Leakage Currents According to CISPR and National Regulations," Publication 9, Third Edition, 1976. Section One: "CISPR Limits of Radio Interference and Report of National Limits" and Section Two: "Maximum Permissible Values of Leakage Currents and Limiting Values of Capacitance and Energy for Radio Interference Suppression Capacitors."

R-49 "IEC Catalog of Publications," 1977, ANSI.

R-50 "IEC Pub7ication \#50-902 (1973), Group 902-Radio Interference," affiliated to the International Organization for Standardization-ISO, advance edition of International Electrotechnical Vocabulary.

R-51 "The IEC, What It Is, How It Works, What It Does, Its Origins," December 1969, Central Office and Seat of the Commission, Geneva, Switzerland.

R-52 "Advances in Klystron Amplifiers, A Tutorial Treatment Emphasizing Efficiency, Bandwidths, and Applications," Erling L. Lien, The Microwave Journal 16, No. 12, 33 (December 1973). 
$\underline{\mathrm{R}} \underline{\underline{H}}$

R-53 "Feasibility Study of a Satellite Solar Power Station," Peter E. Glaser, Owen E. Maynard, John Mackovciak, Jr., and Eugene L. Ralph, NASA, Washington, DC, February 1974, NASA-CR-2357.

R-54 "The Super Power CW Amplitron," J. F. Skowron, W. C. Brown and G. H. MacMaster, The Microwave Journal, p. 65, October 1964.

R-55 "Electromagnetic Field Immunity--A New Parameter in Receiver Design," Tomás Dvorák, IEEE Transactions on Electromagnetic Compatibilití VOL EMC-16, No. 3, p. 149 (August 1974). Author is with the Institute of High Frequency Electronics, Federal Institute of Technology, Zurich, Switzerland.

R-56 "A Preliminary Study of Possible Weather Effects due to Solar Power Satellite Rectenna Operation," Environmental Effects Office Internal Note, JSC 12519, NASA Lyndon B. Johnson Space Center, Houston, Texas.

R-57 "Microwave Power Generation Analysis," Lawrence R. Burdette, AD-774 818, December 1973 (NTIS).

R-58 "Characteristics of Magnetically Focused Large-Signal Traveling-Wave Amplifiers," Harry K. Detweiler, Technical Report \#RADC-TR-68-433, October 1968, Air Force Systems Command, Griffins Air Force Base, NY.

R-59 "Free-Space Microwave Power Transmission Study, a Microwave Beam Power Transfer and Guidance System for Use in an Orbital Astronomy Support 


\section{REPORTS AND ARTICLES REFERENCES}

$\underline{R *}$

Facility," W. C. Brown, Final. Report, Report Period DEC 9, 1969 to DEC 70, dated December 9, 1969, and amended June 11, 1970. Contract NAS8-25374.

R-60 "Free-Space Microwave Power Transmission Study, A Microwave Beam Power Transfer and Guidance System for Use in an Orbital Astronomy Support Facility," W. C. Brown, Final Report - Phase II: Report Period APR 71 to AUG 72. Contract NAS8-25374, PT-3539.

R-61 "Free-Space Microwave Power Transmission Study," W. C. Brown, Report Period: DEC 69 to JUL 74, dated 10 September 1975, Combined Phase III and Final Report. Contract NAS8-25374, PT-4601.

R-62 "Ionospheric Fodification by High Power Transmitters," Radio Science 9 , No. 11, November 1974. Special Issue. (Also Reference S-3)

R-63 "Microwave Energy Conversion," E. M. Sabbagh, part III, dated May 1962, WADD Technical Report \#WADD-TR-61-48, Contract No. AF 33(616)-7355.

R-64 "Forward Scatter from Rain," Radio and Electrical Engineering Division, National Research Council, Ottawa, Canada, PGAP, p. 414 (July 1960).

R-65 "Atmospheric Attenuation of Microwave Power," Vincent J. Falcone, Jr., J. Microwave Power 5, No. 4 (1970).

R-66 "An Atlas of the Midlatitude F-Region Response to Geomagnetic Storms," M. Mendi110 and J. A. Klobuchan, 6 February 1974. AD-778 069 (NTIS). 
REPORTS AND ARTICLES REFERENCES

$\underline{R=}$

R-67 "Density Variations in the Lower Thermosphere, "Wiliiam F. Johnson, Scientific Report \pm 2 , February 19, $1974($ CO0-2195-12), U.S. AEC Contract AT(11-1)-2195, Principal Investigator Reginald E. Newe 11.

R-68 "The Continuous-Cathode (Emitting-Sole) Crossed-Field Amplifier," John F. Skowron (Invited Paper), Proceed. Ot the IEEE 61, No. 3, pp. 330356 (March 1973).

R-69 "The Effect of a Time Varying Collision Frequency on a Radio Wave Obliquely Incident on the Lower Ionosphere," N. M. Masiin (Cavendish Laboratory, University of Cambridge), Eroc. P. Soc. Lond. A. 348, $245-$ 263 (1976). Printed in Great Britain.

R-70 "Combination Frequencies in the Interaction Between High-Power Short-Wave Radiation and Ionospheric Plasma," G. G. Getmantsev, N. A. Zuikov, D. S. Kotik, L. F. Mironenko, N. A. Mityakov, V. O. Rapoport, Yu. A. Sazonov, V. Yu. Trakhtengerts and V. Ya. Eidman, JETP Lett. 20, No. 4, 101-102 (August 20, 1974). (ZhETF Pis. Red. 20, 229-232, August 20, 1974).

R-71 "Microwave Power: A Far-Out System?," W. N. Agosto, IEEE Spectrum 13, No. 5, pp. 48-50 (May 1976).

R-72 "Satellite Solar-Power Stations," R. B. Aronson, Machine Design 47 No. 28, pp. 18-20 and 23 (27 November 1975). 


\section{REPORTS AND ARTICLES REFERENCES}

$\underline{R \#}$

R-73 "Space Power Systems: What Environmental Impact?,"B. K. Ching, Astronaut. \& Aeronaut. 15, No. 2, pp. 60-65 (February 1977).

R-74 "IEC Report on Activities for 1976," ANSI.

R-75 "IEC HANDBOOK (ANNUAIRE 1977)," ANSI.

R-76 "Limits and Methods of Measurement of Radio Interference Characteristics of Industrial, Scientific, and Medical (ISM) Radio-Frequency Equipment (Excluding Surgical Diathermy Apparatus)," Publication 11, 1975 CISPR Report. ANSI.

R-77 "Microwave Transmission System for Space Power," R. M. Dickinson, RAUMEAHRTFORSCHUNG 20, No. 5, pp. 238-241, September 1976.

R-78 "Preliminary Models for Determining Instantaneous Precipitation Intensities from Available Climatology," Robert W. Lenhard, Allen E. Cole and Norman Sissenwine, Environmental Research Papers, No. 350, 5 March 1971 , AFCRL-71-0168 (NTIS).

R-79 "Nonlinear Wave Optics of Parametric Pump Radiation in an Inhomogeneous Plasma," Donald F. DuBois, Martin V. Goldman and Dean McKinnis, The Physics of Fluids 16, No. 12, pp. 2257-2269, December 1973.

R-80 "Magnetic Field Effects on Electrons during Ionospheric Modification," Dwight R. Nicholson, J. of Geophys. Res. 82, No. 13, pp. 1839-1845, 1 May 1977. 
$\underline{\mathrm{R}} \underline{\underline{4}}$

R-81 "Review of Nonlinear Theory of Ionospheric Modification," Martin V. Goldman, UC-1003, Department of Astro-Geophysics, University of Colorado at Boulder.

R-82 "Low Frequency Radio Astronomy Through an Artificially Created Ionospheric Window," Michael D. Papagiannis and Michael Mendi110, Nature 255, pp. 42-43, 1 May 1975.

R-83 "A Large-Scale Hole in the Ionosphere Caused by the Launch of Skylab," Michael Mendi110, Gerald S. Hawkins and John A. Klobuchar, Science 187, pp. 343-345, 31 January 1975 .

R-84 "Electron Dynamics and Energy Conversion in 0-Type Linear Bean Devices," Harry K. Detweiler and Joseph E. Rowe, Advances in Microwaves 6 , 1971. 


\section{REFERENCES}

SUBSCRIPTIONS

$\underline{S+1}$

S-1 "Radio Regulations of the ITU," VOL 1 - Radio Regulations, Additional Radio Regulations and VOL 2 - Appendices to the Radio Regulations, Resolutions and Recommendations. Edition of 1976, Published by the General Secretariat of the International Telecommunication Union, Geneva, 1976. ISBN: 92-61-00181-5.

S-2 "FCC Rules and Regulations," VOL II, August 1976; VOL III, August 1976; VOL IV, March 1977; VOL V, December 1974, VOL VII, March 1974; VOL VIII, March 1971, VOL IX, June 1976; and VOL XI, August 1976. Federa1 Communications Commission, Washington, DC., Superintendent of Documents, U.S. Government Printing Office, Washington, DC 20402.

S-3 "Radio Science," $\underline{9}$, No. 11, November 1974, Journal of the United States National Committee, International Union of Radio Science. Published by the American Geophysical Union. 


\section{BIBLIOGRAPHY - CATEGORIES}

0-a MISCELLANEOUS

b BIBLIOGRAPHIES.

c SPS GENERAL INFORMATION

d SPS STUDY PLANS

1-a MICROWAVE POWER TRANSMISSION, GENERAL AND SYSTEM STUDT:?

b MICROWAVE GENERATORS OF INTEREST

c SPS ANTENNA CHARACTERISTICS (Transmitting)

d LINEAR (Non-Frequency Converting) SCATTER OF MICRONA:

e NON-LINEAR (Frequency Converting) SCATTER

f RECTENNA

2-a RADIO RULES, REGULATIONS, POLICIES, Etc. (Includes Frequency Ass:- ts)

b RFI GENERAL INFORMATION

c RFI IMPACTS ON SPECIFIC SYSTEMS USERS OR SERVICES

d SPS/RFI STUDIES

3-a IONOSPHERIC MODIFICATION BY RADIO/MICROWAVES

b IONOSPHERIC MODIFICATION EFFECTS ON SPECIFIC SERVICES, SYSTEMS OR USERS

c IONOSPHERIC PROPAGATION (Radio/Radar, EtC.)

d SPS IONOSPHERIC MODIFICATION STUDY

e PROPAGATION EFFECTS IN ARTIFICIALLY HEATED IONOSPHERE

4-a EMI 
MISCELLANEOUS--0-a

Future Projects of High-Power Transmission

Hubner, R.

Elektro-Monteur/24/8/NDV , 1973

Methods for the Transmission of Energy Over Long Distances

Bockris, J. D.

John Wiley and Sons, Inc., New York, 1975

Threshold Limit Values for Physical Agents Adapted by ACGIH for 1975

ANSI C 95.1, Safety Level of Electromagnetic Radiation with Respect to Personnel, 1974

Charts, The Satellite Solar Power Station (SSPS), August 1974, prepared by Arthur D. Little, Inc.

Excerpt, EPA/ORP 73-2, Environmental Exposure to Non Ionizing Radiation, USEPA, May 1973

X-Ray Measurements Near High-Power K1ystrons

Lenman, R. L.

MIT, Cambridge, USA

Science (USA), Vol. 169, No. 3940, 52-4, Ju1y 3, 1970

Non Ionizing Radiation Standards Rules and Regulations for Exposure, Federal Register, Vol. 36, No. 105 Sat, May 29, 1971,

Par 1910.97

Experiments Involving a Microwave Beam to Power and Position a Helicopter, IEEE Trans. Aerospace Electron, Syst., Vo1. AES 5, pp. 692-702, Sept. 1969

Electromagnetic Compatibility Analys is Center, Annapolis, MD DDC Report Bibliography, Search Control No. A0030A

Rept. No. ECAC-DAS-1-69, Mar. 69, 43p

World Distribution and Characteristics of Atmospheric Radio Noise

International Telecommunications Union, Geneva (Switzerland)

International Radio Consultative Committee

C7063D2 Fld: 17B, 20N, 4A GRAI7619 


\section{BIBLIOGRAPHIES--0-b}

Congressional Hearings and Committee Prints When Glaser Testified or Was Quoted

SDC International Search Service, P8121542, $10 \mathrm{p.}$

Satellite Power Stations

SDC International Search Service, P8120, 718, 3 p.

Sun Energy Satellite

NTIS Search Satellite Solar Power Stations

89 references from German study.

SDC International Search Service, P8120, 813.

Satellite Power Stations authors contributing to $9 p$.

Microwave Electric Power Transmission (A Bibliography with

Lehmann, E. J.

National Technical Information Service, Springfield, VA (USA), Jun 1976/NTIS, \$25.0.

References SPS, with addition, Helms, I. USERDA, April 1976

(This is a selection of the most pertinent iteris in $H$ through $H 5$ above).

NASA Literature Search \#37033. Space Power Systems, March 25, 1976 , Part 1, References Pertinent to Reference Subject ( 830 references).

Part 2 Limited Distribution References ( 118 references).

Solid State Solar to Microwave Energy Converter System and Apparatus Dudley, K. W./Macmaster, G. H., (Patent), US Patent 3,933,323, Mar 20, 1974.

Defence Scientific Information Service Ottawa (Ontario) DDC Report Bibliography, Search Control No. AOR25E Rept. No. DSIS-B14, Dec. 70, 213 p.

Searle, W. M. 
SPS GENERAL INFORMATION--0-C

Aeg-Telefunken, Considerations on the Feasibility and Technology of Solar Energy Satellites and Energy Transfer Satellites, Backnang (West Germany); Dornier-Sys tem G.M.B.H., Friedrifchshafen (West Germany): Technische Univ., Berl in (West Germany). (Fachbereich Weitverkehr und Kabeltechnik). Avail issuing activity.

Prepared jointly with Dornier System and Tech. Univ. Berl in

Solar Power From Satellites. Hearings Before the Subcommittee on AER Committee on Aeronautical and Space Sciences, United States, Senate, Ninety-Four.

Committee on Aeronautical and Space Sciences, Washington, DC, 1976, GPD, $\$ 2.70$.

Solar Energy Via Microwave (Solenergi Via Mikrrovagor)

DDC Report Bibliography, Search Control No. AOR25E

Rept. No. FSTC-HT-23-594-72, 72, 7p.

Bergstrom, Sigge

Microwave Power Transmission from An Orbiting Solar Power Station (Microwave Power Transmission from Orbiting Solar Power Station to Earth, Discussing Design Optimization Problems)

G. Goubau (U. S. Army, Inst. for Exploratory Research for Monmouth, $\mathrm{NJ}$ ), Journal of Microwave Power, Vol. 5, pp. 223-231.

Electric Power Generation in Space, National Aeronautics and Space Administration (NASA Educational Facts on Present and Future Electric Power Sources for Space Application), Washington, DC.

Analys is of Technological Development Problems Posed by the U.S. and Transfer in and from Space. Final Report. Koehn, D./Jesche, K./Rath, J./ Teichmann, D./Wirths, G. Jun 1976, NTIS, $\$ 12.50$.

Space Power Systems: What Environmental Impact

Ching, B. K.

(Aerospace Corp., El Segundo, CA)

As tronaut. Aeronaut., 15, 2, Feb 1977, 60-65.

Solar Power from Satellites

Glaser, P. E.

Arthur D. Little Inc., Cambridge, MA, USA

Phys. Today (USA), Vol. 30, No. 2, 30-2, 34, 36-8, Feb. 1977, Coden: PHTOAD

Excerpts 1976 NASA Authorization

Subcommittee on Space Science and Applications

Committee on Science and Technology, U. S. House of Representatives, V.II, Pt. 4. 
SPS GENERAL INFORMATION--0-C

Solar Satellite Power System Concepts. Hearings Before the Subcommittee Subcommittee on Energy Research, Development and Demonstration of the Committeee Representatives, ilinety-Fourth Congress, Second Session, Committee on Science and Technology, Washington, DC, 1976, GPO.

Status of Satellite Solar Power Development Glaser, P. E.

(Arthur D. Little, Inc., Cambridge, MA)

American Section of the International Solar Energy Society, Cape Canaveral, $\mathrm{FL}$

Sharing the Sun: Solar Technology in the Seventies. Volume 1

Bdeer, K. W. (Ed.)

Feasibility Study of a Satellite Power System Concept, Rockwell International Report Prepared for NASA/MSFC, Contract No. NAS8-32161, November 1976.

Feasibility of a Satellite Solar Power Station (SSPS)

Glaser, P. E.

(Arthur 0. Little, Inc., Cambridge, Mass)

ASHRAE J./18/11/Nov 1976/36-40.

Application of Station-kept Array Concepts to Satellite Polar Power Station Design, Aerospace Corporation Report, Prepared for NASA/MSFC, Contract No. NAS8-31842, November, 1976.

High-Power Microwave Transmission from Solar Space Stations

Arndt, G. D.: Leopold, L.

Lyndon B. Johnson Space Center, NASA, Houston, TX, USA ISA

Advances in Instrumentation, Vol. $31677 / 1-61976$

II 11-14 0ct. 1976 Houston, TX, USA

Derivation of a Low Cost Satellite Power System

Drummond, J. E.; Drummond, R. N.

Maxwel1 Labs. Inc., San Diego, CA, USA

American Inst. Chem. Engrs., American Nucl. Soc., Soc. Automotive

Engrs., et a 1. 11th Intersociety Energy Conversion Engineering Conference

$64-72,1976$.

Evolution of the Satellite Solar Power Station (SSPS) Concept

Glaser, P. E.

(Arthur D. Little, Inc., Cambridge, MA)

J. Spacecr. Rockets/13/9/Sept 1976/573-576

Survey of Satellite Power Stations

Bloomquist, C. E.

PRC Systems Science Co., Los Angeles, CA (USA), Sep 1976

Dep. NTIS $\$ 10.00$ 
SPS GENERAL INFORMATION--0-C

Space Solar Power - An Available Energy Source

Ferdman, S.; Kline, R. L.

Grumman Aerospace Corp., Bethpage, NY, USA

J. Astronaut. Sci. (USA), Vol. 24, No. 3, 243-55.

July-Sept. 1976.

Coden: JALSA6

Space Based Power Conversion and Power Relay Systems, Preliminary

Analysis of Alternate Systems, Fourth Performance Review, Boeing

Aerospace Company, Report No. NASA 8-31628, August 11, 1976.

The Development of a Satellite Solar Power Station

Glaser, P. E.

Arthur D. Little, Inc., Cambridge, MA, USA

Selvage, C., Soc. Photo-0ptical Instrumentation Engrs., American Acad.

Microbiology, et al

SBN 0892521120

Proceedings of the Society of Photo-optical Instrumentation Engineers, Vol. 85. Optics in Solar Energy UtTization II IX-SSVI 1977

24-25 Aug. 1976 San Diego, CA, USA

Soc. Photo-optical Instrumentation Engrs. Bellingham, WA, USA

National Prospects for Solar Energy Use

Eng., Corne11 Q. 11/3/Aut 1976/27-29

Space-Based Solar Power Conversion and Delivery Systems Study, Interim Report, ECON, Inc., Report No. 76-145, Prepared for NASA/MSFC, Contract No. NAS8-37308, June 30,1976

Satellite Power Systems, Program Definition Effort, Environmental Impact, Johnson Space Center Presentation, June 3-4, 1976

Development of a Satellite Solar Power Station

Glaser, P. E.

(Arthur D. Little, Inc., Cambridge, MA)

Spacef1 ight/18/6/Jun 1976/198-208.

SPS Briefing to ERDA Task Force, NASA Marshal1 Space Flight Center, May $12,1976$.

Satellite Power Systems Technical Briefing for the Administrator, ERDA, April 6, 1976.

The Future of Solar Satellites, Wall St. Journal, March 23, 1976.

Interim Study, Space Based Solar Power Conversion and Delivery Systems Study, ECON, Inc., Report No. 76-145-IB, March 31, 1976. 
Space-Based Solar Power Conversion and Delivery Systems Study. ECON, Inc., Princeton, NJ (USA), March 31, 1976, NTIS $\$ 9.00$.

Space Power Systems, NASA Literature Search $\# 37033$, March 25, 1976 , Part I, References Pertinent to Reference Subject ( 830 References), Part II, Limited Distribution Reference (118 references)

Development of the Satellite Solar Power Station Glaser, P. E. Statement before the Committee on Science and Technology, U. S. House of Representatives, February 20, 1976.

Program Review: Comparative Assessment of Orbital and Terrestrial Control Power Systems, October 1975-January 1976, Jet Propulsion Laboratory, Presentation 20 February 1976. Also previous program reviews.

Power Satellite, a Viable Polar Power Option

Statement by R. B. Taylor, Boeing Co. Before U. S. Senate Subcommittee, Aerospace Technology National Needs, January 19, 1976.

Colonies in Orbit

O'Nei1., G. R., New York Times Magazine, January 18, 1976.

Second Performance Review Briefing, Space Based Solar Power Conversion and Power Relay Systems, Boeing Aerospace Company, NAS8-31628, January 1976.

Activities in Space-Based Solar Power Development Whitacre, W. E.

(National Aeronautics and Space Administration, Huntsvilie, AL)

Univ. of Alabama/Huntsvilie, AL/1975

Application of Solar Energy, WU, S. T. (Ed.)

Geosynchronous Satellite Solar Power

Williams, J. R.

Energy Transmission to Earth (Georgia Institute of Technology, Atlanta, GA), In Solar Energy for Earth an. AIAA Assessment (A75-31267 14-44), New York, America Institute of Aeronautics and Astronautics, Inc., 1975, p. 59-71.

Satellite Solar Power Station: A New Frontier to Space Technology Schreitmoller, K. R. (DFVLR, Stuttgart)

Rassegna Internazionale Elettronica Nucleare Ed Aerospazialle/Rome/1975

(In Atti Del SV Convegno Internazionale Sullo Spazid)

Solar Energy for Earth: An AIAA Assessment

Killiam, H. J./Dugger, G. L./Grey, J. (Eds.)

American Institute of Aeronautics and Astronautics, Inc., New York, $1975, \$ 9.50$. 
SPS GENERAL INFORMATION--0-C

NASA Working Papers on Satel1ite Power System Concepts, February 1975, July 1975 and December 1975.

For Solar Power: Sunny Days Ahead

Kaplan, G.

IEEE Spectrum/12/12/Dec 1975/47-52.

Space Colonies and Energy Supply to the Earth.

$0^{\prime} \mathrm{Neill,G}$. K.

Princeton, Univ., Princeton, NJ, USA

Science (USA), Vot. 190, No. 4218, 943-7, Dec. 5, 1975.

Satellite Solar-Power Stations

Aronson, R. B.

Mach. Des./47/28/27 November 1975/18-20, 23.

Space-Based Conversion and Power Relay Systems-Preliminary Analys is of Alternate Systems, Boeing Aerospace Company, First Performance Review, Oc tober 23, 1975. (NAS8-31628)

The High Frontier

O'Neill, G.

The Co Evolution Quarterly, Fall 1975.

The Utilization of Space as a Source of Energy for the Earth

(Barcelona, Polytechnic University, Marcelona; Promar S. A., Soa in)

(International Astronautical Federation, International Astronauticai

Congress, 26th, Lisbon, Portuga1, September 21-27, 1975, Paper 21 p.)

Orbital Solar Energy Technology Advances

Woodcock, G. R.; Gregory, D. L.

(Boeing Aerospace Co., Kent, WA), In Energy 10: Annual Intersociety

Energy Conversion and Engineering Conference, 10th: Newark, Del.,

August 18-22, 1975, Record. (A75-45920 28-44), New York, Institute of

Electrical and Electronics Engineers, Inc., 1975, p. 1057-1064.

Space-Based Solar Power Conversion and Delivery Systems (Study)

Nathan, C. A.

Grumman Aerospace Corp., Bethpage, NY (USA), Aug. 6, 1975/NTIS $\$ 5.00$.

The Satellite Solar Power Station

Glaser, Peter E.

Presented at the Conference on Space Manufacturing Facilities,

Princeton University, May 7-9, 1975.

Feasibility and Engineering Studies of Solar-Energy SAT

(Summary of a Study)

Allgemeine Elektricitaets-Fesellschaft Aeg Telefunken, Berlin (F. R. Germany)/May 1975/Dept. NTIS \$5.50. 
The Adaptation of Free Space Power Transmission Technology to the SSPS Concept--Satellite Solar Power Stations (Raytheon Co., Waltham, MA). American Institute of Aeronautics and Astronautics and American Astronautical Society, Solar Energy for Earth Conference, Los Angeles, CA, Apri1 21-24, 1975, AIAA 12p.

The Satellite Solar Power. Station--An Option for Energy Production on Earth (Arthur D. Little, Inc., Cambridge, MA)

American Institute of Aeronautics and Astronautics and American Astronautical Society, Solar Energy for Earth Conference, Los Angeles, CA, Apri1 21-24, 1975, AIAA 9 p.

The Satellite Solar Power Station--A New Frontier to Space Technology? Schreitmoller, K. R.

Inst. fur Energieforschung, DFVLR, Stuttgart, Germany

Internat Exhibition and Congresses on Electronics, Nuclear Energy and Space Technology

AttI Del XV Convegno Internazionale Sullo Spazio (15th International

Technical Scientific Space Meeting) 437-46 1975

17-19 March 1975 Rome, Italy

Feasibility Study of a Satellite Solar Power Station NASA CR-2357, February 1975.

Satellite Power System Concepts

NASA Working Paper, Prel iminary Technology Assessment

February 1975, based on Survey October 1974-January 1975, by

William B. Lenoir, NASA/JSC and Roy E. Currie, Jr., NASA/MSFC.

Satellite Solar Power Station Option

Glaser, P. E.

(Arthur D. Little, Inc., Cambridge, MA), 1974

The Satellite Solar Power Station Option--For Solar Energy Transmission to Earth

(Arthur D. Little, Inc., Cambridge, MA), In Remote Sensing Applied to Energy-Related Problems; Proceedings of the Symposium-Course, Miami, $\mathrm{FL}$, December $2-4,1974$.

Solar Energy. III. Illusion or Actuality?

Kohler, H. W.

Tech. Rundsch. (Switzerland), Vol. 66, No. 53, 17-18, 24 Dec. 1974.

Coden: TCRUAU

Project Independence, Task Five Report, Solar Energy, Nov. 1974.

National Science Foundation, Washington, DC.

An Overview of Solar Energy Applications

Glaser, P. E.

(Arthur D. Little, Inc., Cambridge, MA). In Herem 74: Northeast Electronics Research and Engineering Meeting, Boston, MA, October 28-31, 1974, Record. Part 1 (A75-39191 19-32 Newton, MA, Institute of Electrical and Electron Engineers, Inc., 1974, p. 45-50. 
SPS GENERAL INFORMATION--0-C

The Colonization of Space

O'Nei11, G. K., Physics Today, September 1974.

Economics Analyses of Solar Energy Utilization (Boeing Co., Seattle, WA)

In Intersociety Energy Conversion Engineering Conference, 9th, San

Francisco, CA, August 26-30, 1974, Proceedings. (A75-10476 01-44)

New York, American Society of Mechanical Engineers, 1974, p. 306-316.

Engineering Evaluations of Three Electric Power Generating Proposals

That Utilize Satellite Space Systems

Yi Cheng, Douglas Glasson, Vladimir Hruby, Phillippe Roesch, Steven

Schneider, Kari Seppanen, Roy Setterlund, and Kevin Slimak

Massachusetts Institute of Technology, May 1974.

Power Relay Satellite

Rockwe11 Report E74-31, March 1974.

Space Satellite Power System

P. E. Glaser; Little (Arthur D.) Inc., Cambridge, MA, 28 March 1974,

$24 \mathrm{p}$; Subm-Sponsored by NASA. Conf - Presented at the Solar Energy

Lecture 3. Washington, DC, March-May 1974; Sponsored by IEEE. Washington

Acad. of Sci. and Washington Soc. of Eng.

Feasibility Study of a Satellite Solar Power Station

Glaser, Peter, et al.

NTIS: U. S. Department of Commerce, February 1974.

Performance Evaluation and Parametric Sizing Study of the Baseline SSPS, Grumman Corporation, ASP-611-M-1019, 2 January 1973.

Comparison and Evaluation of Power Plant Options for GEDSYN Solar Power. Final Report.

Williams, J. R., Georgia Inst. of Tech. Atlanta (USA), School of Mechanical Engineering, 1973/NTIS \$5.50.

Energy Research and Development and Space Technology. Hearing Before the Sub. and Subcommittee on Energy, May 7, 22, and 24, 1973.

Committee on Science and Astronautics (U. S. Congress. House), Washington, DC Committee on Science and Astronautics, Washington, DC, 1973, GPD.

Adapting Microwave Techniques to Help Solve Future Energy Problems Brown, W. C., (Raytheon Co., Wal tham, MA)

IEEE Trans. Microwave Theory Tech./MTT-21/12/Dec 1973/753-63.

Terrastar: Terrestrial Application of Solar Technology and Research, Auburn Univ., AL (USA), September 1973/NTIS \$19.25.

The Satellite Nuclear Power Station--An Option for Future Power Generation Williams, J. R.; Clement, J. D.

American Inst. Aeronautics and Astronautics, et al. 8th Intersociety Energy Conversion Engineering Conf. Proceedings, 566-73, 1973.

August 13-16, 1973, Philadelphia, PA, USA 
SPS GENERAL INFORMATION--O-C

Feasibility of Large-Scale Orbital Solar/Thermal Power Generation (Feasibility Analysis of Satellite Solar/Thermal Power Generation and Transmission to Earth, Describing Brayton Cycle Heat Engine for Initial Energy Conversion) (Boeing Co., Seattle, WA).

Patha, J.T.; Woodcock, G. P. In Intersociety Energy Conversion Engineering Conference, RTH, Philadelphia, PA, August 13-16, 1973, Proceeding (A73-38386 19-03z), Ven fork, American Institute of Aeronautics and Astronautics, Inc., 1973, p. 312-379.

Satellite Solar Power Stations to Meet Future Energy Demands Glaser, P. E. (Arthur D. Little, Inc., Cambridge, MA) Ind. At. Spatiales/17/July-Aug 1973/77-95 (in English and French)

Space Solar Power--Satellite-Borne Generators for Earth Consumption Glaser, P. E. (Arthur D. Little, Inc., Cambridge, MA), In Photovoltaic Power and Its Applications in Space and On Earth: International Congress on the Sun in the Service of Man, Paris, France, July 2-6, 1973, Proceedings. (A74-24901 10-03) Bretigny-Sur-Orge, Essonne, France, Centre National D Etudes Spatiales, 1973, p. 599-618.

Satellite Solar Power Stations to Meet Future Energy Demands Glaser, P. E.

Ind. At. and Spat. (France), Vol. 17, No. 4, 77-95, July-Aug. 1973

Coden: IAQSBL

The Satellite Solar Power Station

Glaser, P. E.

Arthur D. Little, Inc., Cambridge, MA, USA; Maley, S. W.;

IEEE 1973 IEEE G-MTT International Microwave Symposium, Digest of

Technical Papers 186-8 1973.

4-6 June 1973, Boulder, CO, USA

IEEE, New York, USA

Feasibility of a Satellite Solar Power Station

Glaser, P. E.

Indian and East Eng. Vol. 115, No. 6, 289-92, June 1973. Coden: IEAEAS.

Solar Power Via Satellite

Glaser, P. E.

Arthur D. Little Inc., Cambridge, MA, USA, IEEE

1973 IEEE International Convention and Exposition, Vol. III 6.4/10 p. 1973

26-30 March 1973, New York, USA, IEEE New York, USA

Solar Power from Satellites--A Reality in 1990?

Brady, M. M.

TEK, UKEBL. (Norway), Vol. 120, No. 12, 23-4,6 22 March 1973 (Coden: TUGEAJ)

Solar Energy Systems

MITRE Corporation, March 1973, Frank R. Eldridge, Author 


\section{SPS GENERAL INFORMATION--0-C}

Satellite Nuclear Power Station, An Engineering Analys is

J. R. Williams and J. D. Clement

NASA Grant NGR-11-002-145 Report

Georgia Institute of Technology, March 1973.

Satellite Power Stations - A New Source of Energy

(Near-Equatorial Synchronous Orbit Satellite Solar Power Station

System with Photovoltaic Cell Arrays Energy Conversion into Microwave

Power for Transmission to Earth)

W. C. Brown (Raytheon Co., Lexington, MA)

IEEE Spectrum, Vol. 10, March 1973, pp. 38-47.

Feasibility of a Satellite Solar Power Station

Glaser, P. E.

(Arthur D. Little, Inc., Cambridge, MA)

Institute of Electrical and Electronics Engineers, Inc., Newton MA, 1972 NEREM 72.

The Potential of Power from Space

Glaser, P. E.

Arthur D. Little, Inc., Cambridge, MA, USA

IEEE, General Electric Co., Texas Instruments, Inc., American Telephone and Telegraph Co.

Electronics and Aerospace Systems Convention 1972 Record 34-31, 1972

16-18 0ct. 1972, Washington, DC, USA

IEEE New York, USA

Systems Engineering Overview of the Satellite Power Station

Mockovciak, J., Jr.

(Grumman Aerospace Corp., Bethpage, NY)

Amer. Chem. Soc., Washington, DC, 1972, Intersociety Energy Conversion

Engineering Conference, 7th, San Diego, CA, September 25-29, 1972

Proceed ings

The Use of the Space Shuttle to Support Large Space Power Generation Sys tems

(Arthur D. Little, Inc., Cambridge, MA)

Glaser, P. E.

In Space Shuttle Payloads; Proceedings of the Symposium, Washington, DC, December 27, 28, 1972. (A74-14102 03-311 Tarzana, CA, American Astronautical Society, 1973, p. 167-191.

Briefings before the Task Force on Energy of the Subcommittee on Science, Research and Development of the Committee on Science and Astronautics, U. S. House of Representatives, 92nd Congress, Second Session, Series Q, March 1972, U. S. Government Printing Office, Washington, 1972.

A Systems Engineering Overview of the Satellite Power Station Mockovciak, J., Jr., Grumman Aerospace Corp., Bethpage, NY, USA ASME, IEEE, American Chem Soc., American Inst. Aeronautics and Astronautics, American Inst. Chem. Engrs. American Nuclear Soc., Soc. Automotive Engrs. Proc. of 7 th Intersociety Energy Conversion Engineering Conf. Sept. 25-29, 1972, San Diego, CA, USA. 
Solar Power Generating Systems as Sources of Non-Polluting Energy (Power Generation in Space and Power Generation on the Ground)

Tani, T.; Horigome, T.

Kanner (Leo) Associates, Redwood City, CA/(NASA, Washington)

Denki Gakkai ZASSMI/92/12/Dec 1972/31-24/NTIS \$3.25.

Solar Energy as a National Energy Resource

Glaser, P. E.

NSP/NASA Solar Energy Panel, Dept. of Mechanical Engineering, University of Maryland, College Park, MD, December 1972.

Satellite Solar Power Station--An Option for Power Generation Glaser, P. E.

Arthur D. Little, Inc., Cambridge, MA, USA

ASME, IEEE, American Chem Soc., American Inst Aeronautics and Astronautics, American INST. Chem Engrs., American Nuclear Soc., Soc. Automotive Engrs., Proceedings of the 7 th Intersociety Energy Conversion Engineering Conference 507-13, 1972; 25-29 September 1972, San Diego, CA, USA

American Chem. Soc., Washington, DC, USA

Solar Era. 1. Practical Promise

Gaucher, L. P.

Mech. Eng. 94/8/Aug 1972/9-12.

Solar Satellite Power Station, Tech Memoranda, Grumman Aerospace Corporation, Bethpage, NY, January-June 1972.

Satellite Solar Power Station, Master Program Plan Development. Grumman Aerospace Corporation, ASP-611-R-12, June 1972.

Satellite Solar Power Station, Configuration Status Report, Grumman Aerospace Corporation, ASP-583-R-10, June 1972.

Grumman Report ASP-583-R-11, Satellite Solar Power Station - Technical Memoranda, June 1972.

A Look at the Future of Free-Space Microwave Power Transmission Brown, W. C.

Raytheon Co., Wal tham, MA, USA

Internat. Microwave Power Inst.

7 th Annual Microwave Power Symposium (Abstracts), 7, 1972

24-26 May 1972, Ottawa, Canada

Internat. Microwave Power Inst., New York, USA

Progress in the Efficiency of Free-Space Microwave Power Transmission Brown, W. C.

Raytheon Co., Wal tham, MA, USA, Internat. Microwave Power Inst.

7th Annual Microwave Power Symposium (Abstracts) 181972

24-26 May 1972 Ottawa, Canada

Internat. Microwave Power Inst., New York, USA 
SPS GENERAL INFORMATION--O-C

Space Resources to Benefit the Earth

Glaser, P. E.

(Arthur D. Little, Inc., Cambridge, MA)

New York Acad. Sciences, Annals/187/25, Jan 1972/406-19.

Microwave Power Transmission in the Satellite Solar Power Station System Brown, E. C.; Maynard, O. E.

Raytheon Co., Lexington, MA (Equipment Div.) Tech. Report, ER72-4038.27, January 1972.

Power Without Pollution

Glaser, P. E.

(Arthur D. Little Co., Cambridge, MA)

Intern. Microwave Power Inst./Edmonton, A1berta, Canada, 1971

Papers presented at the 1971 Symposium on Microwave Power.

Power for Space, Technology Transfer for Human Survival

Glaser, P. E.

(Arthur D. Little, Inc., Cambridge, MA)

Amer. Astronaut. Soc. $/ 1971$

Technology Utilization Ideas for the 70's and Beyond. Proceedings of Special AAS/AIAA Technical Event, 30 Oct 1970. AAS Science Technology Series, Vol. 26.

Satellite Solar Power Station - Systems Engineering Report Grumman Report ASP-583-R-8, November 1971 .

Satellite Solar Power Station, Spectrolab, Technical Report, November 1971.

Satellite Solar Power Station - Solar Photovoltaic Array Report, Spectrolab/Heliotek Divisions of Textron, Inc., November 1971.

Power in the Year 2001. III. Solar Power

Walters, S.

Mech. Eng./93/11/Nov 1971/33-6.

Concept for a Satellite Solar Power System

Glaser, P. E.

Chem. Technol. (USA) 606-14 0ct. 1971.

Comments on Glaser's Concept for a Satellite Solar Power Station Mills, W. A.

J. Microwave Power/6/1/Apr 1971/55-7.

Power Without Pollution

Glaser, P. E.

Satellite Solar Power Station for Microwave Generation, Transmission and Energy Conversion to Electrical Power on Earth

Arthur D. Little, Inc., Cambridge, MA/Journal of Microwave Power,

Vol. 5, p. 210-222, December 1970 . 
SPS GENERAL INFORMATION- -0-C

Power Without Pollution. Dream That Must Come True Stuhlinger, $E$.

J. Microwave Power/5/4/Dec 1970/207-9.

Space Resources to Benefit the Earth

Glaser, P. E.

Third Conference on Planetology and Space Mission Planning. The New York Academy of Sciences, New York, October 29, 1970.

(To be published by Trans. New York Acad. Sci.)

The Space Radiation Environment at Synchronous Altitude and Its Effects on Communication Satellites

Rostron, R. W.

Radiation Environmental Model of Synchronous Communication Satellites

Solar Cell Degradation by Particle Fluxes, Comsat Labs., Clarksburg, MD, Members - $\$ 1.00$, Nonmembers - $\$ 1.50$. New York, American Inst. of Aeronautics and Astronautics, American Inst. of Aeronautics and Astronautics, Communications Satellite Systems Conference, 3rd, Los Angeles, CA, April 6-8, 1970.

Satellite Solar Power Station

Glaser, P. E.

Arthur D. Little, Inc., Cambridge, MA

Solar Energy/12/3/May 1969/353-61.

The Future of Power from the Sun

Glaser, P. E.

IECEC 1968 Record; IEEE Publication 68C21-Energy, 1968, pp. 98-103.

Power from the Sun; Its Future

Glaser, P. E.

Amer. Assn. Adva. Sci., Vol. 162, 22 November 1968, pp. 857-61.

Stuhlinger, E., and Bucher, G. C.

A Concept for An Orbiting Astronomical Station

R-SSL, MSFC, Working Paper, August 1967. 


\section{CONGRESSIONAL HEARINGS}

AN - 75-J801-22.7

ARE - Solar Energy Research Projects

ARS - 1304

WI

WITNESS: Lustig, Harry, prof. of physics and dean of Col1. of Liberal Arts, City Coll. of N.Y. p. 50-72: Glaser, Peter E., vp., Arthur D. Little Co. p. 78 101; Greeley, Richard S.; assoc. technician dif. systems dev. div. Mitre Corp. p. 101-125: Heiss, Klause P., pres. Econ., Inc. p. 125-165; Comly, James B., mgr. therma 1 br. Gen. Electric Corporate R\&D Center, P. 166-170; Cetron, Marvin J., pres. Forecasting Int1. Ltd. p. 170-197; Ralph, Eugene L. vp. for R\&D, Spectrolab. Inc., p. 259-266; Agnew, Harold, dir. Los Alamos Scientific Lab; ACC. BY: Balcomb, John D. P., p. 266-285.

AN - 75-H702-24

MTI - Future Space Programs, 1975, Vol. 2

MRE - Sept. 1975, V+983, p. 11

Glaser, Peter E. (vp.Arthur D. Little, Inc.), "The Satellite Solar Power Station: A Focus for Future Space Activities," July 22, 1975, with numerous charts and diagrams ( $p$. 437-459).

AN - 74-\$441-66.5

ARE - June 27,1974, p. $126-148$

ARS - 456

WI

WITNESS; Glaser, Peter E., vp., engineering sciences, Arthur D. Little, Inc., Cambridge, Mass.

TY

STATEMENT AND DISCUSSION: Overview of solar energy application; extent of solar energy development abroad; need for Federal participation in introducing solar technology.

AN - 74-S441-66

MTI - Solar Energy Research Act of 1974.

MRE - June 27, 1974; iv+300 p. il.

Committee Serial No. 93-47 (92-82), Hearing on S. 3234 (text. p. 3-15), the Solar Energy Research Act of 1974, to authorize funding for solar energy R\&D and to provide incentives for commercial use of solar technology.

Includes introductory (p. 275-303) contains correspondence, statements, and "The Silicon Ribbon Solar Ce11: A Way to Harness Solar Energy" by A. I. Mlavsky (Tyco Labs. Wal tham, Mass.), June 1974 (p. 293-306). 


\section{CONGRESSIONAL HEARINGS}

AN - 74-S541-40.2

ARE - Mar. 27, 1974, p. 149-160

ARS - 436

WITNESS: GTaser, Peter E., vp. Engineering sciences, Arthur D. Little, Inc., Cambridge, Mass.

TY

STATEMENT AND DISCUSSION: Recommendations for Federal encouragement of solar energy R\&D; predictions regarding solar heating and cooling use and costs.

AN - 73-H701-15

MTI - Energy Research and Development and Space Technology

MRE - May 7, 22, 24, 1973; i i i+5.0 p. il.

Appendices ( $p$. 502-570) contain additional submitted statements and:

a. Moore School of Elect ical Engineering "Nonionizing Radiation Hazards: paper on biological hazards which may result from exposure to microwaves (p. 539-548).

b. "Major NASA Energy Systems, Programs, and Potential Applications," table (p. 559).

c. Williams, J. R., "Satellite Nuclear Power Station," rpt. (p. 563-570).

AN - 74-H701-15

MTI - Solar Heating and Cooling Demonstration Act

MRE - Nov. 13-15, 1973; vii+502, i1.

WITNESS: GTaser, Peter E., vp. engineering sciences, Arthur D. Little, Inc.

STATEMENT: Assessment of industry's technological ability to develop solar heating and cooling systems; description of typical solar climate control system. (p. 128-158)

DISCUSSION: Problems with H. R. 10952 funding (p. 158-163)

INSERTION: Project Plan for a Program to Develop a Solar Climate

Control Industry, Mar. 16, 1973, Arthur D. Little (p. 139-157).

Space Solar Power

Glaser, P. E.

(Arthur D. Little, Inc., Cambridge, MS)

Centre National D'Etudes Spatiales/Bretigny-Sur-Orge, Essonne, France/1973/

Photovoltaic Power and Its Applications in Space and on Earth 


\section{CONGRESSIONAL HEARINGS}

AN - 74-S121-3

MTI - Space Shuttle Payloads, Part 2

MRE - Oct. 31, 1973; iv+101, p. 11

Continuation of hearings on plans for the space shuttle era. This volume considers potential use of space shuttle for missions relating to energy production and transmission, and to industrial production in space.

WITNESS: Glaser, Peter E., vp. engineering sciences, Arthur D. Little, Inc.

TY

STATEMENT AND DISCUSSION: STides presentation and explanation of operations of a satellite solar power station (SSPS) including microwave generation and transmission system; planned space shuttle transportation system for SSPS; estimated cost of program over next ten years.

AN - 74-H441-20

MTI - National Energy Research

MRE - May 16, 23, June 13, Dec. 10, 18, 1973, Jan. 31, Feb. 1, 19

AN - 74-H441-20.7

ARE - June 13, 1973, p. 206-220

ARS - 464

WI

WITNESS: Glaser, Peter E., vp. and head of engineering sciences, Athur D. Little Co., Inc.

TY

STATEMENT AND DISCUSSION: Review of U. S. and foreign applications of solar energy; status of, and importance of further development on, satellite solar power stations.

AN - 73-H701-15.12

ARE - May 24, 1973, p. 257-501

ARS - 1708

TY

Statements and Discussion: Explanation, with slides, of satellite solar power stations (SSPS) concept and microwave beam radiation effects (technical memo of dev. plans, p. 281-284), analys is of problem areas and requirements; economic factors in evaluating and developing energy options; feasibility of satisfying peak energy demands from space power stations.

Evaluation of space shuttle program and possibility of Apollo mission in geosynchronous orbit possible uses of SSPS for support of space activities; potential consequences of energy sources vulnerability.

Briefing papers, prepared for subcom. including charts, photos, tables, titled: a. "Power from the Sun via Satellite" by P. E. Glaser; assessment of SSPS feasibility, including technical principles, economic considerations, environmental issues, and list of references. (p. 298-373).

b. "Space Technology and Energy" by K. A. Ehricke, focusing on space relaying by microwave beam transmission and power relay satellites (p. 329-373). 


\section{CONGRESSIONAL HEARINGS}

$A N=72-H 702-10$

MRI - Briefings Before the Task Force on Energy, Volume I I

MRE - Mar. 1972; viii+179 p. il.

c. Glaser, Peter E. (vp. Arthur D. Little, Inc. et al), "Satellite Solar Power Station: An Option for Power Generation" prepared with Joseph G. Gavin, Jr. (Grumman Aerospace Corp.), Willianl C. Brown (Raytheon Co.), and Eugene L. Ralph (Textron, Inc.) (p. 144-179). 
MICROWAVE POWER TRANSMISSION, GENERAL AND SYSTEM STUDIES--1-a

Atmospheric Propagation Constraints on Microwave Power Transmission Brown, W. 0. Sandia Labs., A1buquerque, NM (USA) Apr 1977/Dep.NTIS, PC AD2/MF A01.

Microwave Transmission System for Space Power Dickinson, R. M.

Jet Propulsion Lab., Pasadena, CA (USA)/Raumfahrtforschung/20/5/Sep 1976/ 238-241.

Free Space Microwave Power Transmission Technology and Applications-Present and Future

Brown, E. C.

Raytheon Co., Wal tham, MA, USA.

1976 IEEE MTT-S International Microwave Symposium 3521976

N. Eberhardt

14-16 June 1976, Cherry Hi11, NJ, USA

IEEE New York, USA

Abstract

Microwave Power: A Far-out System

Agos to, W. N.

IEEE Spectrum/13/5/May 1976/48-50.

Space-Based Solar Power Conversion and Delivery Systems

ECON, Inc.

NASA/MSFC Contract No. 8-31308, Final Report; April 1976.

Space-Based Solar Power Conversion and Delivery Systems (Study) Nathan, C. A.

GAS-NSS-P-75-001, Grumman Aerospace Corp.; NAS8-31308,

NASA $\mathrm{Cr}-144252,1975$.

Microwave Power Transmission System Studies. Vol. 2: Introduction, Organization, Environmental and Spaceborne Systems Analyses

Maynard, 0. E., et al.

(ER75-4368-Vo1. 2, Raytheon Co., ; NAS3-17835),

NASA CR-134886, Vol. 2, 1975.

Microwave Power Transmission System Studies. Volume 3, Section 8:

Mechanical Systems and Flight Operations.

Maynard, 0. E., et al.

(ER75-4368-Vol. 3, Raytheon Co.; NAS3-17835), NASA CR-134886, Vo1. 3, 1975.

Microwave Power Transmission Studies, Volumes I through IV, Raytheon Company, Report No. ER75-4368, Prepared for NASA/Lewis Research Center, Contract No. NAS3-17835, NASA Report No. NASA CR-134886, December 1975. 
MICROWAVE POWER TRANSMISSION, GENERAL AND SYSTEM STUDIES--1-a

Microwave Power Transmission System Studies

NASA CR-134886, December 1975. (NAS3-17835)

Wireless Power-Transmission Test Aims at Harnessing Sun One Day

Mason, J. F.

Electron. Des. (USA), Vol. 23, No. 25, 32, 346 Dec. 1975.

Free-Space Microwave Power Transmission Study, Phase 3. Final

Brown, W. C.

Raytheon Co., Wal tham, MA (USA)

10 Sep 1975/NTIS $\$ 6.00$.

Survey on the Wireless Power Transmission by Microwave

Sogawa, T.

Electrotech. Lab., Tokyo, Japan

Circ. Electrotech. Lab. (Japan) No. 183 1-90 May 1975.

Radiated Power Transmission System Efficiency Measurements

R. M. Dickinson, W. C. Brown

Tech Memo 83-727 Jet Propulsion Laboratory, California Institute of

Technology, 15 May 1975.

Summary Data - Structural Analys is Microwave Power Transmission System;

4 October 1974

GAC Memo MPTSS-74-013.

The Technology and Application of Free-Space Power Transmission by Microwave Beam

Brown, R. C.

Raytheon Co., Waltham, MA, USA

Proc. IEEE (USA) Vol. 62, No. 1 11-25 Jan. 1974 Coden: IEEPAD.

Regional and Global Energy Transfer Via Passive Power Relay

Satellites

Ehricke, K. A.

(Rockwell International Corp., Space Div., Downey, CA)

Canaveral Council of Technical Societies/Cape Canaveral, FL/1973/

Technology Today and Tomorrow.

Comments on the Beam Transmission Efficiency in Microwave Power Transmission Via Space

Goubau, C.

U. S. Army Electronics Command, Fort Monmouth, $\mathrm{NJ}$; Prepared for the Subcommittee on Space Science and Applications, House of Representatives (published in Congressional Record 1973). 
MICROWAVE POWER TRANSMISSION, GENERAL AND SYSTEM STUDIES--1-a

Adapting Microwave Techniques to Help Solve Future Energy Problems

Brown, E. C.

Raytheon Co., Wal tham, MA, USA

IEEE Trans. Microwave Theory and Tech. (USA) Vol. MTT-21, No. 12

753-63, Dec. 1973 Coden: IETMAB

Future Projects of High-Power Transmission

Hubner, R.

Elektro-Monteur/24/B/NDV 1973/43-48/(In German)

High Power, Efficient, Free-Space Microwave Power Transmission Systems

Brown, W. C.

Raytheon Co., Waltham, MA, USA

Belgium Assoc. Metalworking, Mech. and Electrical Industries, et al.

1973 European Microwave Conference, Vol. II C15.4/4 pp. 1973

4-7 Sept. 1973 Brussels, Belgium

Univ. Ghent, Ghent, Brussels.

Cavities of the Future

Menga, P.

(Enel/Cre, Milan)

Elettrificazione/9/Sep 1973/459-466.

Status of the Cost and Technology of the Microwave Power Transmission

System in the Satellite Solar Power Station

Brown, W. C.

Raytheon Technical Report, PT-8738, 13 March 1973.

Transportation of Energy by Microwave Beam

Brown, W. C.

Soc. Automotive Engrs., American Chem. Soc., American Inst.

Aeronautics and Astronautics, American Soc. Mech. Engrs., IEEE

American Inst. Chem. Engrs., American Nucl. Soc., American

Power Conference, Marine Technology Soc

Proceedings of the 1971 Intersociety Energy Conversion

Engineering Conference, 5-14 1971

3-5 Aug. 1971, Boston, MA, USA

Soc. Automotive Engrs., New York, USA

Status of the Technology and Applications of Free-Space Microwave Power

Transmission

Brown, W. C.

Raytheon Co., Waltham, MA, USA

Reggia, F.; IEEE

1971 IEEE-GMTT International Microwave Symposium Digest of Technical Papers $144-51971$

16-19 May 1971, Washington, DC, USA

IEEE, New York, USA 
MICROWAVE POWER TRANSMISSION, GENERAL AND SYSTEM STUDIES--i-a

Advanced Applications of Microwave to Propulsion and Power Transmission

Voss, W. A. G.

Univ. Alberta, Edmonton, Canada

IEEE

1971 IEEE International Convention Digest 460-1 1971

22-25 Mar 1971 New York, USA

IEEE, New York, USA

Wireless Power Transmission in a Space Environment

Robinson, W. J., Jr.

Marshall Space Flight Center, AL, USA

J. Microwave Power (Canada), Vol. 5, No. 4, 233-43 Dec. 1970 Coden: JLMPAB

Satellite Solar Power Station and Microwave Transmission to Earth

J. Microwave Power, Vo1. 5, Dec. 1970.

Microwave Power Transmission From an Orbiting Solar Power Station

Goubau, G.

J. Microwave Power (Canada), Vo1. 5, No. 4, 223-31 Dec. 1970

Coden: JLMPAB

Atmospheric Attenuation of Microwave Power

Falcone, V. J., Jr.

J. Microwave Power (Canada), Vo1. 5, No. 4, 269-78, Dec. 1970.

Coden: JLMPAB

Diffractional Field Distortion and Cross Talk in Guided Optical Multibeam Transmission

Christian, J. R., Goubau, Go, Mink, J. W., Schwering, F.

Research and Development Technical Report, Army Electronics Command, Fort Monmouth, N. J., Dec. 70, 29 p.

Non-Conventional Methods of Electricity Transmission

Weiss, A.

Elektrotech. Z. (ETZ) B (Germany), Vo1. 22, No. 17, 403-7, 21 Aug. 1970.

Microwave Power Transmission

Broome, K. R., D. J. Goertz and J. W. Hankin

The Journal of Microwave Power, May 1970, p. 171.

Power Transmission of the Future Microwaves or Superconductors

Paul, $H$.

Electron. Power/16/May 1970/171-175.

Very High Power Transmission Over Large Distances With the Aid of Microwaves and Supraconductive Lines

Paul, $H$.

Int. Elektron. Rundsch./24/4/Apr 1970/87-90/(in German). 
MICROWAVE POWER TRANSMISSION, GENERAL AND SYSTEM STUDIES $--1-a$

Principles and Limits on Electrical Power Transmission

Oeding, D.

(Brown, Boveri and Cie, AG, Mannheim, Ger.)

Elektrotech.Z./91/1/16 Jan 1970/29-36/(in German).

Experiments Involving a Microwave Beam to Power Position a Helicopter Brown, W. C.

IEEE Trans. on Aerospace and Electronic Systems, Vol. AES-5, No. 5, pp. 692-702, Sept. 1969.

Power Transport at Microwave Frequencies

Krul, L.

Electrotechniek (Netherlands), Vol. 47, No. 18, 417-20, 4 Sept. 1969.

Long Distance Heavy Power Transmission by Microwaves

Paul, $H$.

Bu11.Schweiz.Elektrotech.Ver./60/14/5 Jul 1969/609-621/(In German).

Microwave Power Engineering

G. Goubau and F. Schwering; Editor, E. C. Okress

Vol. 1, New York: Academic Press, 1968, pp. 241-255.

Experimental System for Automatically Positioning a Microwave-Supported

Platform

Brown, W. C.

Tech. Rept. RADC-TR-68-273, 1968.

Performance, Analysis and Selection of Balldon Electrical Power Systems Hamilton, R. C.

Institute for Defense Analyses, Arlington, VA (USA), Science and Technology Div. $/ 200$ and $4000 \mathrm{~W} /$ Comparison of Cable System, Microwave Rectenna System,

Fuel Cells, Dec. 1968/NTIS.

Feasibility Study of Wireless Power Transmission Systems

Robinson, W. J., Jr.

Aug. 1968/NTIS.

Experimental Airborne Microwave Supported Platform

Brown, W. C.

Technical Report No. RADC-TR-65-188, Dec. 1965

Contract AF30 (602) 3481.

Experiments in the Transportation of Energy by Microwave Beams Brown, W. C.

1964 IEEE Intersociety Conference Record, Vol. 12, Pt. 2, 1964, pp. 8-17. 
MICROWAVE POWER TRANSMISSION, GENERAL AND SYSTEM STUDIES--1-a

A Survey of the Elements of Power Transmission by Microwave Beam Brown, W. C.

1961 IRE International Convention Record, Vol. 9, Part 3, pp. 93-105.

Transmission of Power by Radiation

Ryan, A. H.

California Inst. of Tech., Pasadena (USA), 1958. 
MICROWAVE GENERATORS OF INTEREST--T-b.

Final Development Report for Design Studies of CFA Using Samarium Cobalt Magnets

Anon., Raytheon Company, Microwave and Power Tube Division, Report No. PT-3339.

A High Efficiency $15 \mathrm{Mw}, 400 \mathrm{Mc} / \mathrm{s}$ Pulsed Klystron

Clough, L. D., Dix, J. F., Monk, A. J. and Rowcroft, P.

Jour. of Electronics and Control, pp. 105-118.

Axial Space-Charge Modes in a Crossed-Field Amplifier

Bondartsov, G. I.; Sominskii, G. G.

M. I. Kalinin. Leningrad Polytech. Inst., Leningrad, USSR

Zh. Tekh. Fiz. (USSR), Vol. 45, No. 8, 1654-8. Coden: ZTEFA3

Starting in the Cold Cathode Distributed Emission Crossed Field Amplifier Shaw, E. K.

Varian Eastern Tube Div., Union, NJ, USA

IEEE Trans. Electron Devices (USA), Vol. ED-24, No. 1, 22-6, Jan. 1977. Coden: IETDA I

Study of the Near-Cathode Current in Crossed Electric and Magnetic Fields Petrochenko, V. I.

Izv. vuz Radioelektron. (USSR) Vol. 19, No. 10, 125-6, Oct. 1976. Coden: IVUZB5

High Efficiency, CW, High Power Klystrons for Storage Ring Applications Kinrad, G. T.

Stanford Linear Accelerator Center, Stanford Univ., Stanford, CA, USA IEEE, American Phys. Soc., et al.

IEEE Trans. Nucl. Sci. (USA), Vol. NS-22, No. 3, 1249-52, June 1975 Coden: IETNAE

1975 Particle Accelerator Conference, 12-14 March 1975, Washington, DC, USA

Amplitron in Dual-Frequency Regime

Mikhalevskii, V. S.; Makhno, V. I.

Pis'ma V Zh. Tekh. Fiz. (USSR), Vol. 1, No. 11, 529-31, 12 June 1975.

Coden: PZTFDD

A High-Power Klystron for Industrial Processing Using Microwaves

Maloney, E. D.; Faillon, G.

Thomson-CSF, Paris France

J. Microwave Power (Canada), Vol. 9, No. 3, 231-9 Sept. 1974

Coden: JLMPAB

Noise Measurements on Pulsed High-Power M/W Amplifiers

Riedl, G.

- $\quad$ Siemens $A G$, Munich, Germany

Microwave J. (USA), Vol. 17, No. 8, 29-33 Aug. 1974

Coden: MCWJAD 
MICROWAVE GENERATORS OF INTEREST-- $1-b$

Evaluation of Charge Distribution in a Crossed-Field Device from Ion Bombardment of the Cathode

Malyugin, V. I.; Sominskii, G. G.

M. I. Kalinin Leningrad Polytech. Inst., USSR

Zh. Tekh. Fiz. (USSR), Vol. 44, No. 7, 1511-16 July 1974 Coden: ZTEFA3

Crossed Field Amplifiers in Radar Transmitters

Singh, L.; Mukherjee, B. K.

Defence Electronics Res. Lab., Hyderabad, India

Electro-Technol. (India), Vol. 18, No. 2, 64-9 June 1974

Coden: ELTEAQ

Low Cost S-Band Transmitter Tube for Phased Array Radars

Varian Associates Palo Alto, Calif., Palo, Alto Microwave Tube Div.

Semiannual Rept. 1 Jul-31 Dec 73, Apr 74 39p Scott, A.W.

Contract: DAAB07-73-C-0244

Monitor: ECOM 0244-1-73

Analysis of the Energy Spectrum of Ions Bombarding the Cathodes of M-Type Tubes

Malyugin, V. I.; Sominskii, G. G.

Fiz. Elektion. Trudy LPI (USSR), No. 329, 105-B, 1973

The Crossed-Field Amplifier Computational and Exparimental Results

Cooke, M. L.; Shaw, E. K.; Yarrington, L. I.

Warnecke Electron Tubes Inc., Des Plaines, I11., USA

IEEE

1973 International Electron Devices Meeting Technical Digest 278-81, 1973

3-5 Dec. 1973, Washington, DC, USA

IEEE, New York, USA

Three-Dimensional Evaluation of Energy Extraction in Output Cavities of Klystron Amplifiers

Kosmahl, H. G. and Albers, L. V.

IEEE Trans. on Electron Devices, Vol. ED-20, No. 10, 11, 883-890; October 1973

C.F.A. or T.W.T.? Which Valve Will Best Meet Your Transmitter Output Stage Requirements?

Barker, G. G.

IEE, et al

SBN $085296112 \times$

International Conference on Radar-Present and Future, 189-94, 1973

23-25 Oct. 1973, London, England

IEE, London, England

Charging and Stabilising System for a Pulsed Crossed-Field Amplifier Using an SCR-Switched UItrasonic Inverter

Crowfoot, T. P.; Whalley, G.W.

Admiralty Surface Weapons Establ., Portsmouth, England

IEEE, 197311 th Modulator Symposium, 176-83, 1973

18-19 Sept. 1973, New York, USA

IEEE, New York, USA 
MICROWAVE GENERATORS OF INTEREST $--1-b$

UHE Power Klystron YK 1151 for 20-KV Television Transmitter Final Stages

Schmidt, W.

Valvo GMBH, Hamburg, Germany

Int. Elektron. Rundsch. (Germany), Vol. 27, No. 9, 187-91

Sept. 1973 Coden: IELRAK

Quench Modulator for Cold-Cathode Crossed-Field Amplifier

Smith, W. I.

RCA Corp., Moorestown, NJ, USA

IEEE

197311 th Modulator Symposium, 153-5, 1973

18-19 Sept. 1973, New York, USA

IEEE New York, USA

CFA's and TWTA's for ECM Systems

Moats, R. R.

Warnecke Electron Tubes Inc., Des Plaines, IL, USA

Microwave J. (USA), Vol. 16, No. 9, 33-8, Sept. 1973

Coden: MCWJAD

The Effects of Load Mismatch on the High-Power Multicavity Klystron

Tallerico, P. J.

Univ. Cal ifornia, Los Alamos, NM, USA

Hoffman, G.

Belgium Assoc. Metalworking, Mech. and Electrical Industries, et al

1973 European Microwave Conference, Vol. II, C11.6/44 pp.

1973

4-7 Sept. 1973, Brussels, Belgium

Univ. Ghent, Ghent, Brussels

CFA Tube Enables New-Generation Coherent Radar

Smith, W.; Wilczek, A.

RCA, Moorestown, $\mathrm{NJ}$, USA

Microwave J. (USA), Vol. 16, No. 8, 39-42 Aug. 1973

Coden: MCWJAD

Experimental Study of the Degradation of the Amplifying Condition in a Device with a Secondary-Emission Cathode

Makarov, V. N.

Izv. vuz Radjoelektron. (USSR), Vol. 16, No. 7, 74-6 July 1973

Coden: IVUZB5

The Fluctuation Characteristics of a Continuous-Operation Amplitron, Fluctuation Relationships

Kornilov, S. A.

Radiotekh. and Elektron. (USSR) Vol. 19, No. 6 1232-42 June 1974

Coden: RAELA4 
MICROWAVE GENERATORS OF INTEREST--1-b

Six-Month $R$ and D Study for 1-10 MW Microwave Device from 1-10 GHz MacMaster, George A.

Raytheon Microwave and Power Tube Division, 8 June 1973.

High Efficiency High-Power Klystrons

Ogura, K.; Shimada, T.; Zushi, T.; Ohya, K.; Miyake, S.; Endo, K.

Toshiba Rev. (Int. Ed.) (Japan) No. 81 28-32 May 1973 Coden: TRIEAB

High-Power Linear-Beam Tubes

Staprans, A.; William McCune, E.; Ruetz, J. A.

Varian Associates, Palo Alto, CA, USA

Proc. IEEE (USA) Vol. 61, No. 3 299-330 March 1973

Coden: IEEPAD

The Continuous-Cathode (Emitting-Sole) Crossed-Field Amplifier Skowron, J. F.

Raytheon Co., Wal tham, MA, USA

Proc. IEEE (USA), Vol. 61, No. 3 330-56 March 1973 Coden: IEEPAD

McCune, E. and Misuhara, A.

$X$-Band PPM-Focused Wide-Band Klystron

Paper presented at the Electron Devices Meeting, Washington, DC;

December 1972.

Stability of the Amplitron

Prokof'vev, L. V.; Skobelkin, V. I.

Radiotekh. and Elektron. (USSR) Vol. 17, No. 1 119-26 Jan. 1972

Coden RAELA4

High Power Klystron

Heynisch, H.; Bittorf, $H$.

Patent No. USA 3688152 Assignees: Siemens, AG Filed: 3 March 1971

Original Patent App1. No.: Germany P2010480.7

Priority Date: 5 March 1970

29 Aug. 1972

A Method of Designing the Amplitron Slow-Wave Structure

Ambrozhevich. V.; Raevski, L.

Prace Przemysl. Inst. Telekomun. (Poland), Vol. 21, No. 72

15-23 1971 Coden: PPITAT

High Power Microwave Tubes

Arnett, H. D., et al.

1971 IEEE Region Z Conference, Washington, DC,

Technology Forecasting and Assessment of Technology Digest.

Design Considerations for the High-Power Multicavity Klystron

Tallerico, P. J.

Univ. California, Los Alamos, NM, USA

IEEE Trans. Electron Devices (USA), Vol. ED-18, No. 6

374-82 June 1971 Coden: IETDAI 


\section{MICROWAVE GENERATORS OF INTEREST--1-b}

High Performance Klystrons for Accelerator Applications

Tallerico, P. J.

Univ. California, Los Alamos, NM, USA

IEEE, Nucl. Sci. Group, Nat. Bur. Stand., Centre for Radiation Res.,

Nat. Sci. Found., US Atomic Energv Commission

IEEE Trans. Nucl。Sci. (USA), Vol. NS-18, No. 3 257-9 June 1971 Coden: IETNAE

1971 Particle Accelerator Conference, Accelerator Engineering and Technology

1-3 Mar 1971 Chicago, IL, USA

Coupled-Mode Analysis for Nonuniform Crossed-Field Drift Beams

EL-Shandwily, M. E.; Saleh, M.A.

Nat. Res. Center, Dokki, Cairo, UAR

IEEE Trans. Electron Devices (USA) Vol. ED-18, No。6

359-64 June 1971 Coden: IETDAI

Surface Wave Transmission Line for a Balloon-Elevated Antenna System;

Final Rept.; Army Electronics Command, Fort Monmouth, NJ; Sept. 70; 27 p.;

Distribution Limitation Now Removed.

High Power Microwave Generators of the Crossed-Field Type

Brown, W. C.

Raytheon Co., Wal tham, MA, USA

J. Microwave Power (Canada), Vol. 5, No. 4 245-59 Dec. 1970

Coden: JLMPAB

High Power Linear Beam Tube Devices

Guenard, P.

(Thomson - CSF, ORSAY, ESSONE, FRANCE)

J. Microwave Power/5/Dec 1970/261-7.

High Power Klystron Development at the Stanford Linear Accelerator Center Lebacqz, J. V. Stanford Univ., CA, USA

NERG Nederlands Electronica En Radio Genootschap, Royal Institution of Engineers in the Netherlands, IEEE, Benelux Section

MOGA 70 8th International Conference on Microwave and Optical Generation and Amplification (Summaries) $1 \mathrm{pp} .1970$

7-11 Sept 1970 Amsterdam, Netherlands

MOGA Eindhoven, Netherlands

A High Power, High Efficiency Injected Beam Crossed Field Amplifier Jones, C. L.; Herriott, R. W.

Litton Industries, San Carlos, CA, USA

NERG Nederlands Electronica En Radio Genootschap, Royal Institution of Engineers in the Netherlands, IEEE, Benelux Section

MOGA 70 8th International Conference on Microwave and Optical Generation and Amplification (Summaries) $1 \mathrm{pp} .1970$

7-11 Sept 1970 Amsterdam, Netherlands

MOGA Eindhoven, Netherlands 


\section{MICROWAVE GENERATORS OF INTEREST--1-b}

High Efficiency Klystron Amplifiers

Lien, E. L.

Eighth Int. Conf. on Microwave and Optical Generation and Amplification, pp. 11-21 to 11-27; September 1970 .

Periodic Electrostatic Focusing of High-Perveance Electron Beams for High-Power Klystrons

Shimada, T.

Tokyo Shibaura Electric Co. Ltd., Kawasaki-Shi, Japan

Electron and Commun. Jap. (USA) Vol. 53, No. 8 76-9 Aug. 1970

Coden: ECJAB4

$X$-Band CW Generator Development

Mann, Joe

RADC (EMATE) GAFB, 15 Apri1 1970.

Characteristics of an RF-Keyed Crossed Field Amplifier

Vaughan, J.R.M.

IEEE

1970 IEEE International Convention Digest 348-9 1970

23-26 Mar 1970 New York, USA

IEEE New York, USA

Linear Beam Tube Having a Beam Collector Cooled by Radiation through an Infrared Window

Lien, E. L.

U. S. Patent No. 3448325; 1969.

One Megawatt C.W. X-Band Klystron

Mann, J.; Robinson, $D$.

Varian Associates, Palo Alto, CA, USA

IEEE, Electron Devices Group

International Electron Devices Meeting 1001969

29-31 Oct 1969 Washington, DC, USA

IEEE, New York, USA

Abstract

The CFA as a Modern Radar Element

Hollis, E. E.; Griffin, W. J.

Sanders Associates, Bedford, MA, USA

IEEE, Electron Devices Group

International Electron Devices Meeting 1201969

29-31 Oct 1969 Washington, DC, USA

IEEE New York, USA

High Power Klystron Design and Analys is

Tallerico, PJ

Univ. California, Los Alamos, NM, USA

IEEE, Electron Devices Group

International Electron Devices Meeting 96-8 1969

29-31 0ct 1969 Washington, DC, USA

IEEE, New York, USA 
MICROWAVE GENERATORS OF INTEREST--]-b

Ultra High Power Amplitron

Anon.

Vol. II I, CW Amplitron Development RADC-TDR-64-389, May 1969

(CONFIDENTIAL)

Self-Modulating, Partially Reentrant Crossed Field Amplifier

Hess, P. N.

Patent No.: USA 3560867 Assigness: Litton Precision Products, Inc.

Filed: 22 April 1969

Original Patent Appl. No.: USA 818279

2 Feb. 1971

The Use of Amplitrons as Microwave Amplifiers in High Power Radar

Systems with Frequency Agility

Chieco, G. A.; Scerch, G.

Radar Management Group, Selenia, Rome

Internat. J. Electronics (GB), Vol. 26, No. 3 237-52 March 1969.

Crossed-Field Amplifier Electron Discharge Device

Patent No.: UK 1223091 Assignees: General Electric Co.

Filed: 28 Jan. 1969

Original Patent Appl. No.: USA 703728

Priority Date: 7 Feb 1968

24 Feb. 1971

Kilowatt $\mathrm{CW}$ Klystron Amplifiers at $\mathrm{Ku}$ and $\mathrm{Ka}$ Bands

James, B. G., and Zitelli, L. T.

Microwave Journal, November 1968, pp. 53-57.

Research and Experimental Study for the Development of a 1000-Watt CW Space

Environmental S-Band Power Amplifier

Nelson, R. B., Abraham, W. G., Lien, E., et al.

NASA Contractor Report CR-66648, Varian Associates, Palo Alto, CA

September 1968.

Electromagnetic Wave Change Interaction in Crossed Fields

Fox, K. A.; Meyer, M. A.; Swierkowski, S.; Turner, C. W.; Van Duzer, T.; et al

Report No.: ECOM-0227-2; Issued by: CA, USA

USGRDR No.: AD-668690

March 1968.

Experimental Analysis of the Biased-Gap Klystron

Walder, J. and McIsaac, P. R.

IEEE Trans. on Electron Devices, Vol. ED-13, No. 12, 11.

950-955 December 1966.

Cross-Field Amplifier Having a Beam of Electrons Flowing Through the Interaction Region Orthogonally to Microwave Power Flow

Farney, G. K.

Patent No.: USA 3868539 Assigness: Varian Associates

Filed: 28 June 1966. 


\section{MICROWAVE GENERATORS OF INTEREST $--1-b$}

Power Travelling-Wave Tubes

Gittins, J. F.

Elsevier Pub1. Co., Inc., New York; 1965.

Super Power Amplitron Test and Evaluation

MacMaster, G. H., Nichols, L. J.

RADC-TR-65-165, November 1965

(CONFIDENTIAL).

Description and Operating Characteristics of the Platinotron

W. C. Brown

Proc. IRE, Vol. 45, No. 9, Sept. 1957, pp. 1209-1222.

Ultra High Power Amplitron

Tech. Report No. RADC-TR-65-165, November 1965, p 16.

Super Power Tubes: Their Capabilities and Limitations

Eastman, L. F.

Electronics, July 13, 1965, pp. 48-54.

Ultra High Power Amplitron

Anon.

Volume 1, CW Amplitron Development, RADC-TDR-64-389, May 1965.

The Super Power CW Amplitron

Skowron, J. F., MacMaster, G.H., and Brown, E. C.

Microwave J., Vol. 7, October 1964.

Large Signal Analysis

Ruden, $T$.

Twenty-second Quarterly and Final Report, Contract No. NObsr-77590,

September 7, 1964. Raytheon Report No. SP0-012, Section 2.3, pp 41-60.

A Two-Cavity Extended Interaction Klystron Yielding 65 Percent Efficiency

Priest, D. H. and Leidigh, W. J.

IEEE Trans. on Elec. Dev., Vol. ED-11, pp. 369-373; August 1964.

Twenty-kilowatt $890 \mathrm{Mc} / \mathrm{s}$ Continuous-Wave Magnetron

Twisleton, J.R.G.

Proc. IEE, Vol. III, No. 1, January 1964, pp. 51-56.

High Power Tube Program, Final Report

Anon.

MIT Lincoln Laboratory, 30 November 1963.

Experiments with High Power CW Klystrons with Extended Interaction Catchers

Priest, D. H. and Leidigh, W. J.

IEEE Trans. on Elec. Dev., Vol. ED-10, pp. 201-211; May 1963. 


\section{MICROWAVE GENERATORS OF INTEREST--1-b}

High Power Microwave Converter

Thomas, J.

Tech. Rept. No. ASDTR61-476, Pt. II, February 1963, ASTIA,

Document No. AD-402975.

High Power Program, High Power Project, Project DELILAH

Anon.

Semi-annual Report, Calspan Report No. UB-1309-P-107, July 1962.

Properties of Focused Apertures in the Fresnel Region

Sherman, John $W$.

IEEE Trans. Antennas Propag., Vol. AP-10, No. 4, July 1962, pp. 399-498.

Microwave Energy Conversion

Sabbagh, E. M.

Rept. WADD-61-48, Pt. III. Air Force Systems Command, Wright-Patterson

Air Force Base, Ohio, May 1962.

Crossed-Field Microwave Devices

Okress, E.

Vols. 1 and 2, Academic Press, 1961.

A High Efficiency Klystron with Distributed Interaction

Chobrow, M.

IRE Transactions on Electron Devices, January 1961, pp. 44-55.

Crossed-Field Microwave Tubes

Brown, W. C.

Electronics, Apri1 29, 1960.

A 3-Megawatt, 15-Kilowatt, S-Band Amplitron

Smith, W. A., and Zawada, F. A.

Microwave J., Vo1. 2, October 1959.

Theory of the Amplitron

G. E. Dombrowski

IRE Trans. on Electronics Devices, Vol. ED-6, Oct. 1959, pp. 419-428.

General Design Procedure for High-Efficiency Traveling-Wave

Amplifiers

Rowe, J. E. and Sobol, H.

IRE Trans. on Electron Devices, Vol. ED-5, No. 4, pp. 288-300;

October, 1958.

A High-Power Periodically Focused Traveling-Wave Tube Purl, 0. T., et al.

Proc. IRE, Vol. 46, No. 2, pp.441-448; February 1958. 


\section{MICROWAVE GENERATORS OF INTEREST--1-b}

Magnetic Focusing of Electron Beams

Mende 1, J. T.

Proc. IRE, Vol. 43, No. 3, pp. 327-331; March 1955.

Microwave Magnetrons

Collins, G. B.

Radiation Lab. Series, McGraw-Hi11 Book Co., 1951.

Microwave Magnetrons

G. B. Collins, ed.

New York: McGraw-Hi11 Book Co., Inc. 1948.

KTystrons and Microwave Triodes

Hami 7 ton, D. R., Knipp, J. K. and Kuper, J. B. H. pp. 73-80, McGraw-Hi11 Book Co., New York, 1948. 


\section{SPS ANTENNA CHARACTERISTICS (TRANSMITTING) $--1-\mathrm{C}$}

Manufacturing Methods for Dimensionally Stabie Composite Microwave Composites

Keller, L. B. and Raech, H.

Hughes Aircraft Report, May 1974.

Developments of a Unique Graphite/Epoxy Antenna Subreflector

Robinson, E. Y., Stonier, R. A., Lofgren, C. L.

Composite Materials (Third Conference, 1973), ASTM, pp. 632-650.

A Supersynthesis Radio Telescope for Neutral Hydrogen Spectroscopy at the Dominion Radio Astrophysical Observatory

Roger, Robert S., et al.

Proc. IEEE, Vol. 61, No. 9, Sept. 1973, pp. 1270-1276.

Satellite Power Stations: A New Source of Energy?

Brown, W. C.

IEEE Spectrum, Vo1. 10, No. 3, pp. 38-47, March 1973.

Progress Report - Feasibility Study of Satellite Solar Power Station Spectrolab 6011-02 1 September 1972.

Sensitivity of Attitude Control Propellant Requirements to SSPS Deviation Angle Limits

GAC Memo ASP-611-M-1004; 21 August 1972.

Advanced Composite Material Study for Millimeter Wavelength Antennas AFML-TR-71-105, Vol. II; Oct. 1971.

A Novel Directivity Expression for Planar Antenna Arrays

Foreman, B.

Radio Science Vol. 5 No. 7, p. 1077; 1970.

Atmospheric Attenuation of Microwave Power

Falcone, V. J., Jr.

(USAF, Cambridge Res. Labs., Bedford, MA)

Transmission from Satellite Solar Energy Station to Earth, Discussing Attenuation and Power Density Optimization

J. Microwave Power 5 Dec 1970 269-78.

The Effect of Random Amplitude and Phase Errors of Continuous Apertures Schanda, E.

IEEE Trans. Antennas Propag., Vol. AP-15, No. 3, May 1967, pp. 471-473.

Antenna Tolerance Theory - A Review

Ruze, John

Proc. IEEE, Vol. 54, No. 4, April 1966, pp. 633-640.

Microwave Scanning Antennas

R. C. Hansen, Editor

Academic Press 1964, Vo1. 1, Chapter 1, pp 33-40. 
Array Antennas: New Applications for an 01d Technique

J. L. Allen

IEEE Spectrum, p. 125, November 1964.

The Reflecting Beam Waveguide

J. E. Degenford, M. D. Sirkis, and W. H. Steier

IEEE Trans. Microwave Theory Tech., MTT-12, pp. 445-453, July 1964.

Special Issue on Active and Adaptive Antennas

IEEE Trans. Antennas Propagat., Vol. AP-12, March 1964.

Self-Focusing Array Research Model

Sichelstiel, B. A.

IEEE Trans. Antennas Propag., Vo1. AP-12, No. 2, March 1964, pp. 150-154.

Retrodirective Array Using the Heterodyne Technique

Pon, Chuck Y.

IEEE Trans. Antennas Propag., Vol. AP-12, No. 2, March 1964, pp. 176-180.

Self-Phasing Array Antennas

Skolnik, M. I.

IEEE Trans. Antennas Propag., Vo1. AP-12, No. 2, March 1964, pp. 142-149.

A New Horn Antenna with Suppressed Sidelobes and Equal Beamwidths

P. D. Potter

The Microwave Journa1, June 1963, pp. 71-78.

Microwave Antenna Theory and Design

Silver, S.

MIT Rad. Lab. Series, Vo1. 12, Dover (reprint), New York, 1949. 


\section{LINEAR (NON-FREQUENCY CONVERTING) SCATTER OF MICROWAVES--1-d}

Antenna Resolution as Limited by Atmospheric Turbulence Ruina, J. P. and J. M. Angulo.

An Experimental Study of the Temporal Statistics of Radio Signals Scattered by Rain

Hubbard, R. W.; Hull, J.; Wells, P.; and Rice, P. L.

ITS Tech Rept. OT/TRER-33, Inst. Telecommun. Sci., to be published.

Statistics of the Radiated Field of a Space-to-Earth Microwave Power

System

Stevens, Grady H.; Leninger, Gary

Proposed TM.

The Howls Radar Sky-Clutter Environment

Reedy, Edward K.; Cutler, Timothy D.

Technical Rept., Sep 75 45 p.

Massachusetts Inst. of Tech. Lexington Lincoln Lab

$A D-8010605 L$

Contract: F19628-76-C-0002

Proj: GIT-A-1667

Monitor: ESD TR-75-319

A Review of Clutter, 1974

Warden, M. P.; Dodsworth, E. J.

Royal Radar Establishment Malvern (England)

AD-A014 421 17/9

Technical Note, Sep 7436 p.

Rept. No. RRE-TN-783

Monitor: DRIC BR-44348

Quiet and Disturbed Electron Density Profiles in the Auroral Zone Ionosphere Bates, H. F.; Hunsucker, R. D. Univ. Alaska, Fairbanks, USA

Radio Sci. (USA) Vol. 9, No. 4 455-67 April 1974 Coden: RASCAD

Feasibility Study of a Satellite Solar Power Station

Lewis Research Center - NASA CR-2357; Feb. 1974.

Proceedings of the IUCRM Colloquium on the Fine Scale Structure of

Precipitation and EM Propagation, Nice, 23-31, October 1973.

A Method of Providing Rain Margins for 18/30 GHZ Communications

Satellites Without Increasing the Solar Power Requirement (Bell Telephone Laboratories, Inc., Holmdel, $\mathrm{NJ}$ ), In International Conference on Communications, Seattle, WA, June 11-13, 1973, Conference Record. Volume I. (A73-38713 20-07), New York, Institute of Electrical and Electronics Engineers, Inc., 1973, p. 12-13 to 12-18. 


\section{LINEAR (NON-FREQUENCY CONVERTING) SCATTER OF MICROWAVES--1-d}

Analysis of Data from the Avon-to-Westford Experiment

Crane, R. K.

Tech. Report 498, MIT Lincoln Laboratory, January 1973.

Determination of Ionospheric Electron Content from the Faraday Rotation of Geostationary Satellite Signals

Titheridge, J. E.

Planet. Space Sci. 20:353-369, 1972.

Feasibility Study of Satellite Solar Station (SSPS)

Spectrolab Report 6011-03, 4 October 1972.

Results of Precipitation Backscatter Measurements at $1.8 \mathrm{~cm}$ with a Polarization Diversity Radar

McCormick, G. C. and A. Hendry.

Preprints 15th Weather Radar Conference, 35-38. Amer. Meteorol. Soc. October 1972.

Measurement of Wind Gradients in Convective Storms by Doppler Radar Donaldson, R. J., Jr., G. M. Armstrong, K. J. Banis, and R. M. Dyer. Preprints 15th Weather Radar Conference, pp. 22-26.

Amer. Meteorol. Soc., October 1972.

On Some Photochemical and Meterological Factors Determining the Distribution of Ozone in the Stratosphere: Effects of Contamination by $\mathrm{NO}_{\mathrm{x}}$ Emitted from Aircraft

Crutzen, P. J.

Report AP-6, Institute of Meteorology, University of Stockholm, 1971.

The Role of Chemistry and Air Motions on Stratospheric Ozone as Affected by Natural and Artificial Oxides of Nitrogen Johnston, $H$.

Sci., Vol. 173, 1971, p. 517

Paper presented at Autumn Meeting of NAS, Washington, DC, 1971.

A Semi-empirical Determination of the Shape of Cloud and Rain Drops Pruppacher, H. R. and R. L. Pitter

J. Atmospheric Sci. 28, 86-94. 1971.

EDS. Climatological Data, Virginia, Annual Summary. Environmental Data Service, U. S. Dept. of Commerce, Vol. 80, No. 131970 and Vol. 81, No. 131971 .

Salmeda, H. A., Sissenwine, N., and Lenhard, R. W. Environmental Research Paper No. 374, Preliminary Atlas of 1.0, 0.5, and Percent Precipitation Intensities for Eurasia. AFCRL-71-0527, 7 October 1971.

NASA. Interference Due to Rain

NASA/GSFC X-750-71-211 (Rev.). August 1971. 


\section{LINEAR (NON-FREQUENCY CONVERTING) SCATTER OF MICROWAVES--1-d}

Some Statistics of the Small Scale Distribution of Precipitation Austin, P. M. NASA-GSFC Document X-751-72-149, Ju1y 1971.

Description of the Avon-to-Westford Experiment

Crane, R. K.

Tech. Report 483, MIT Lincoln Laboratory, Apri1 1971 .

Preliminary Models for Determining Instantaneous Precipitation

Intensities from Available Climatology

Lenhard, R. W., Cole, A. E., and Sissenwine, N., Environmental Paper

No. 350, AFCRL-71-0168, 5 March 1971.

Precipitation-Scatter Measurement at 6,12 , and $18 \mathrm{GHz}$.

Buige, A.; and Rocci, B.

Tech. Memo CL-55-70, Comsat Laboratories, Dec. 1970.

EDS. Climatological Data, National Summary, Annual. Environmental

Data Service, U. S. Dept. of Commerce, Vols. 14-21, 1963-70.

Weather Effects on Radar

Bean, B. R., Dutton, E. J., and Warner, B. D.

Radar Handbook, McGraw-Hi17 Book Co., New York, 1970, Ch 24, pp. 1-40.

Detailed Analysis of Precipitation Data

Carey, R. B., and G. S. Kalagian

FCC/USAF POPSI Project. Report R-7003, Research Division, Federal

Communications Commission, December 1970.

A Comparison Between Monostatic and Bistatic Scattering from Rain and Thin Turbulent Layers

Crane, R. K.

Tech. Note 1970-29, MIT Lincoln Laboratory, Oct. 1970.

Interpretation of the Fluctuating Echo from Randomly Distributed Scatters, Part 4.

Rogers, R. R.

Scientific Report MW-63, Stormy Weather Group, McGil1 University, September 1969.

Ionospheric Phase Distortion and Faraday Rotation of Radio Waves Murahami, T., Wickizer, G. S.

RCA Review, Vot. 30, Sept. 1969, pp. 474-503.

Experiments Regarding Temporal, Spatial, and Frequency Correlation Characteristics of Radar Precipitation Clutter

Nathanson, F. E. and J. P. Reiliy

Memo MRT-0-124, Applied Physics Laboratory, Johns Hopkins University, 1967.

Distribution of Radar Echoes Over the United States

Granthan, D. D., and Kantor, A. J.

Air Force Surveys in Geophysics No. 171, AFCRL-67-0232, Apri1 1967. 


\section{LINEAR (NON-FREQUENCY CONVERTING) SCATTER OF MICROWAVES--1-d}

Raindrop Distributions at Franklin, North Carolina

Mueller, E. A. and A。L. Sims

Tech. Report TR-ECOM-02071-RR3, I11inois State Water Survey, (Urbana), September 1967a.

Raindrop Distributions at Island Beach, New Jersey

Mueller, E. A. and A. L. Sims

Tech. Report TR-ECOM-02071-RR2, I11inois State Water Survey, September $1967 b$.

Radio Scattering Cross Sections of Thunderstorms

Culnan, D. E., Guirand, F. O., and Skerjanec, R. E.

NBS Rept. 8816, U. S. Dept. of Commerce, June 1965.

Z-R Relationships Deduced from Forward Scatter Doppler Measurements Doherty, L. H.

J. Atmos. Sci. 21:683-697, 1964.

Advances in Radio Meteorology

Atlas, D.

Advan. Geoph., 10:317-478, 1964.

The Study of Precipitation Backscatter at $1.8 \mathrm{~cm}$ with a Polarization

Diversity Radar

McCormick, G. C. and A. Hendry

Preprints 14th Weather Radar Conference, 225-230. Amer. Meteoro1. Soc. November 1970.

The Scattering of SHF Radio Waves by Hail and Wet Snow Dennis, A. S.

Final Rept. (NASA Contract NASr-49(02)), Stanford Res. Inst., June 1964.

Forward Scatter from Rain

Doherty, L. H., and Stone, S. A.

IRE Trans. Antennas Propagat. 8:414-418, 1960.

A Statistic Survey of Atmospheric Index-of-Refraction Variation Crain, C. M. , et al.

IRE Trans. Antennas and Propagation Vol. AD-1, No. 2; 1953.

A Comparison of Radio Scattering by Precipitation and by a Turbulent Atmosphere

Gordon, W.

Proc. Weather Radar Conf. 3d 1959, pp. F17-F24.

The Relationship of Raindrop-Size to Intensity

Laws, J. 0. and D. A. Parsons

Am. Geophys. Union Trans. 24, 452-460. 1943. 
NON-LINEAR (FREQUENCY CONVERTING) SCATTER--1-e

Detection of Combination Frequencies as a Powerful Shortwave Radiation Interacts with an Ionospheric Plasma

Getmantsev, G. G.; Zuikov, N. A.; Kotik, D. S.; Mironenko, L. F.; Mityakov, N. A.; Rapoport, V. 0.; Sazonov, Yu.A.; Trakhtengerts, V.Yu.; Erdman, V.Ya. Zh. Eskp. and Teor. Fiz. Pis'ma (USSR), Vol. 20, No. 4 229-32

20 Aug. 1974 Coden: ZFPRAU

Trans of: JETP Letters (USA) Coden: JTPLA2 
RECTENNA SYSTEMS $--1-f$

Evaluation of a Microwave High Power Reception-Conversion Array for Wireless Power Trans.

NASA TM 33-741.

Final Report, Simulation and Experimental Studies of Microwave-to-DC Energy Conversion Sys tems

J. Nahas

Prepared for NASA, Lewis Research Center, under Grant No. NSG-3070.

Thermionic Diode Rectifier

Brown, W. C.

In Okress, Microwave Power Engineering, Vol. 1, pp. 295-298,

Academic Press.

Solid-State Power Rectifier

George, R. H.

In Okress, Micorwave Power Engineering, Vol. 1, pp. 275-294, Academic

Press.

Crossed-Field Rectifier

Brown, W. C.

In Okress, Microwave Power Engineering, Vol. 1, pp. 309-311,

Academic Press.

Performance of a High-Power, 2.388-GHz Receiving Array in Wireless Power

Dickinson, R. M.

Jet Propulsion Lab., California Inst. of Technol., Pasadena, CA, USA

Eberhardt, $N$.

IEEE, 1976 IEEE MTT-S International Microwave Symposium 139-41 1976

14-16 June 1976, Cherry Hi11, NJ, USA

IEEE New York, USA

Optimization of the Efficiency and Other Properties of the Rectenna Element

Brown, W. C.

Raytheon Co., New Products Center, Wal tham, MA, USA

Eberhardt, $N$.

IEEE

1976 IEEE MTT-S International Microwave Symposium 142-4

1976

14-16 June 1976, Cherry Hill, NJ, USA

IEEE, New York, USA

Advanced Mixer Technology

K. J. Linden

Technical Report, AFAL-TR-76-107, Jan. 1976

Modeling and Computer Simulation of a Microwave-to-DC Energy Conversion

Element

J. Nahas

IEEE Trans. On Microwave Th. and Tech., Vol. MTT-23, pp. 1030-1035,

Dec. 1975 


\section{RECTENNA SYSTEMS--l-f}

RXCV Power Meter Calibration

J. C. Parr

Raytheon Memo JCP-82, dated 19 November 1975.

RXCV RF Field Measurements - Final Results of Calibration

J. C. Parr

Raytheon Memo JCP-91, dated 14 January 1975.

Recent Progress in Power Reception Efficiency in a Free-Space Microwave Power Transmission System

Brown, W. C.; Kim, C. K.

Raytheon Co., Wal tham, MA, USA

IEEE, Microwave Symposium, Digest of Technical Papers 332-3, 1974.

Recent Progress in Power Reception Efficiency in a Free Space Microwave Power Transmission System

Brown, E. C., and Kim, C. K.

Presented at the IEEE-MTT International Microwave Symposium,

Atlanta, GA, May 1974.

Conversion of Electromagnetic Radiation to Electrical Power

Woodal1, J. J.

Pat. 3,675,026, issued Ju7y 4, 1972.

New Incentives for Underground Transmission

Power Eng. 75-12, December 1971 26-31.

A Cyclotron-Wave Rectifier for S-Band and X-Band Watson, D. C., Grow, R. W., and Johnson, C. C.

IEEE Trans. Electron Devices, Vol. ED-18, No. 1, January 1971.

The Receiving Antenna and Microwave Power Rectification

Brown, W. C.

(Microwave Receiving Antenna with Solid State Power Rectified for

Converting Energy from Space Solar Cell Array Into DC Power on Earth), Journal of Microwave Power Inst., Symposium 5th, The Hague, Netherlands, October 7-9, 1970.

Microwave Power Rectification with Commercial Schottky-Barrier Diodes

MacPherson, A. C., Cohen, E. D., and Herndon, M.

Journal of Microwave Power, Vol. 4, No. 4, December 1969.

Progress in the Design of Rectennas

Brown, W. C.

Raytheon Co., Waltham, MA, USA

J. Microwave Power (Canada) Vo1. 4, No. 3, 168-75 Oct. 1969 Coden: JLMPAB 


\section{RECTENNA SYSTEMS--1-f}

W. C. Brown, et a 1 .

U. S. Patent No. 3,434,678, March 25, 1969.

Solid-State Microwave Rectification

Smith, Paul H.

Tech. Rpt. No. RADC-TR-67-334, July 1967.

Solid State Microwave Power Rectifiers

George, R. H.

Rept. RADC-TR-65-224, Rome Air Develop. Center, Griffis Air Force Base, NY. August 1965.

Atmospheric Water Vapor Divergence: Measurements and Applications Barnes, A. A., Jr.

AFCRL-65-501, Specia1 Reports No. 28, July 1965.

Rectification of Microwave Power

Brown, W. C. and George, R. H.

IEEE Spectrum, Vo1. 1, pp. 92-97, October 1964.

Microwave Power Engineering

E. C. Okress, W. C. Brown, T. Moreno, G. Goubau, N. I. Heenan and R. H. George

IEEE Spectrum, October, 1964, pp. 76-96.

An Efficient Means of Converting Microwave Energy To Do Using Semiconductor Diodes

George, R. H. and Sabbagh, E. M.

IEEE Intern. Conv. Record, Electron Devices, Microwave Theory Tech., Vo1. II, Pt. 3, pp. 132-141, March 1963.

Microwave Rectifier Tube

Dench, E., and Osepchuk, J.

ETectronic Design, pp. 58-59, August 7960. 
RADIO RULES, REGULATIONS, POLICIES, ETC. (INCLUDES FREQUENCY ASSIGNMENTS)--2-a

Direct Satellite Broadcasting

AD-A042 921 17/2 22/2 Office of Naval Research London (England)

Descriptive Note: Conference Rept., Jul 77 16p Blachman, Nelson M.

Rept. No. ORNL-C-5-77

Operating Frequencies for the Navstar/Global Positioning System

AD-A030 164 17/7 22/2 Aerospace Corp El Segundo Calif Systems Engineering Operations

Descriptive Note: Final Rept., Jul 7656 p Butterfield, Frank E.

Rept. No. TR-0076(6474-01)-1

Contract: F04701-75-C-0076

MOnitor: SAMSO TR-76-197

General Characterisitics of the Contemporary Svstems of Radio Communication

AD-B008 458L 17/2.1 Foreign Technology Div Wright-Patterson AFB Ohio

Dec. 7534 p Gusyatinskiy, I. A.; Pirogov, A. A.

Rept. No. FTD-ID(RS)T-2305-75

Communication Satellites

AD-4017 $900 \quad 17 / 2.1 \quad 22 / 2 \quad 5 / 2$

Defense Documentation Center Alexandria VA

Descriptive Note: Report Bibliography Jan 63-May 75. Nov 75 373p

Rept. No. DDC/BIB-75/75

The Preparations for and the Implications of the General World Administrative Radio Conference of 1979

AD-A017 531 17/2.1 Naval Postgraduate School Monterey Cal if

Descriptive Note: Master's Thesis, Sep 75 83p Wheaton, Martha Jane,

Unclassified Report

Review of RF and Microwave Hazards in the United States and Research on the Biological Effects of Microwaves at Piny

Rosenthal, S. W.

Fifth Colloquium on Microwave Communications, Proceedings; Vol. III;

Budapest 1974.

An Electromagnetic Compatibility Program for the 1970 (Selected Issues)

AD-784 939 9/3 Rand Corp Santa Monica Calif

Descriptive Note: Interim Rept., Aug $74294 p$ Hiebert, A. L.; Scharff, S. A.

Rept. No. R-1114/1-PR

Contract: F44620-73-C-0011

Frequency Choice for Tactical Satellite Communications

AD-783 912 17/2.1 Massachusetts Inst of Tech Lexington Lincoln Lab

Descriptive Note: Technical Note, July $7464 p$ Schneider, Kenneth S.;

Rept. No. TN-7974-40

Contract: F19628-73-C-0002

Monitor: ESD TR-74-233 
RADIO RULES, REGULATIONS, POLICIES, ETC. (INCLUDES FREQUENCY ASSIGNMENTS) --2-a

Communications Satellites - Issues and Trends

AD-781 134 17/2.1 22/2 Aerospace Corp El Segundo Cal if

Descriptive Note: Review Rept., May 74 25p Bekey, I.

Rept. No. TR-0074(4060-01)-1

Contract: F04701-73-C-0074

Monitor: SAMSO TR-74-135

A Modest Proposal to Reform the Federal Communications Commission AD-786 866 5/4 17/2 Rand Corp Santa Monica Cal if

Apr 74 55p Geller, Henry; Rept. No. P-5209

Methods for Assigning Frequencies to Avoid Intermodulation Interference AD-880 852L 9/6 Pacific Missile Range Point Mugu Cal if

Descriptive Note: Technical Publication, Jan 71 23p Teague, D. S., Jr. Rept. No. PMR-TP-70-7

Corrections to DASA Communication Handbooks (DASA 1954, 1955, 1956)

AD-855 010 17/2 20/14 18/3 General Electric Co Santa Barbara Cal if Tempo

Ju1 $6935 p$

Rept. No. 69TMP-58

Contract: DASA01-69-C-0132

PROJ: DASA-NWER-HE-043

Monitor: DASA 2313

Troposcatter Spectrum Utilization Analysis

AD-921 742L 17/2.1 20/14 Army Electronic Proving Ground Fort Huachuca Ariz Descriptive Note: Final Rept., Dec 68 149p Mccluskey, R. L。

Rept: No. USAEPG-FR-376

Proj: RDT/E-1-S-650209-D-615, USATECOM-6-9-9056-01

Task: 1-S-650209-D-61501

Application of Channel Separation Matrices to Frequency Assignment AD-829 528L 17/2.1 9/3 IIT Research Inst Annapolis MD

Descriptive Note: Technical Rept., Feb 68 129p Lustgarten, Merri11 N.

Contract: AF 19(628)-5049

Proj: AF-649E

Monitor: ESD TR-67-11

IRIG Standards for Radio Command Systems, 4400-5000 MC/S

AD-672 254 17/2.1 9/6 16/1 Inter-Range Instrumentation Group White Sands Missile Range NM

Aug $6712 p$

Rept. No. IRIG-103-67

A Study for the Development of a Frequency Assignment System for Radio Relay Networks. Volume I.

$A D-847785$ 17/2.1 Georgia Inst of Tech At1anta Engineering Experiment Station Descriptive Note: Technical Rept., Jul 67 160p Perlin, I. E.; Bowers, A. W.; McGovern, J. P.; Duncan, G. E.; Hoenes, K. E.

Rept. No. GIT-A-878-Vol-1

Contract: DA-28-043-AMC-01551(E) 
RADIO RULES, REGULATIONS, POLICIES, ETC (INCLUDES FREQUENCY ASSIGNMENTS) --2-a

Historical Analysis of Electromagnetic Interference Limits

AD-657 014 20/14 17/2.1 Aerospace Corp El Segundo Calif Technical Operations Apr 67 49p Pearlston, C. B., Jr.

Rept. No.: TR-1001(2307)-12

Contract: AF 04(695)-1001

Monitor: SSD TR-67-127

ARMY PUBLICATIONS

Radio Frequency Authorization and Usage Reporting System; R 100-353

Army Electromagnetic Spectrum Usage Program; AR 105-63

Electromagnetic Interference and Radiation Hazards; R 100-6

Radio Frequency and Call Sign Assignments for Army Activities Within the Continental United States; AR 105-24

Radio Frequency Allocations for Equipments Under Development, Production and Procurement; AR 105-16

Radio Frequency Management Training Course; $R$ 100-53

Frequency Management and Electromagnetic Compatibility; M 100-31

Electromagnetic Compatibility Program--Reporting of U. S. Military Electronic Equipment Environmental Data; R 100-3 
RF I GENERAL IINFORMATION--2-b

Engineering Design Handbook, Electromagnetic Compatibility

AD-A038 803 20/74 Army Materiel Development and Readiness Command

Alexandria, $V A$

Mar 77 703P

Rept. No. DARCOM-P-706-410

Federal Systems Review Process

Gamble, W. D.

Office of Telecommunications, Dept. of Commerce, Washington, DC, USA

IEEE International Symposium on Electromagnetic Compatibility 13-18 1976

13-15 July 1976 Washington, DC, USA

IEEE New York, USA

Electromagnetic Interference

Foreman, $L$.

Polytech. TIJDSCHR. Elektrotech. Elektron. (Netherlands)

Vol. 31, No. 2 115-21 Feb. 1976 Coden: PTEEBR

Electromagnetic Compatibility

Stumpers, F.L.H.M.

Philips Res. Labs., Eindhoven, Netherlands

Bu11. Assoc. Suisse Electr. (Switzerland), Vol. 65, No. 16

1216-21 10 Aug. 1974 Coden: BUSEAH

Radio Interference - A Review

McLachlan, A. S.; Ainley, J. H.; Harry, R. J.

Min. Posts and Telecommunications, London, England

Wireles World (GB), Vol. 80, No. 1462 191-5 June 1974

Coden: WIWOAA

Communication/Electronic Receiver Performance Degradation Handbook AD-764 710 17/2.1 9/5 IIT Research Inst Annapol is MD

Descriptive Note: Technical Rept., Ju? 73 168P Kravitz, Frank

Contract: F19628-73-C-0031

Proj: AF-649E

Monitor: ESD TR-73-014

A Note on Radio-Frequency Interference

Dean, K. G.

AWA Tech. Rev. (Australia) Vol. 14, No. 4 335-43 1972 Coden: AWARA3

Sanguine System Environmental Compatibility Assurance Program (ECAP) AD-718 828 6/6 17/2.1 Naval Electronic Systems Command, Washington, DC Descriptive Note: Status Rept. 1967-70, Dec 70 375P Carlson, Richard E. Proj: PME-117-21 
RFI GENERAL INFORMATION--2-b

Systems Electromagnetic Compatibility Study. Volume II. Methodology. AD-869 142 20/14 17/2.1 17/9 Lockheed Electronics Co West Long Branch NJ Descriptive Note: Technical Rept。No. 12 (Annual), 1

Jan-31 Dec 69

Apr 70 126p Masnaghetti, R. K.; Deangelis, A. J.; McCaleb, M. B.; Latte, D. A.; Murphy, J. P.

Contract: DAAB07-67-C-0104

Proj: DA-1-H-662701-D-449

Task: $1-\mathrm{H}-662701-\mathrm{D}-44901$

Monitor: ECOM 0104-12B

Environmental Data Collection and Processing Facility (EDCPF), Products and Services Catalog

AD-839 030L 5/2 Bel1 Aerosystems Co Tucson Ariz Environmental Data Collection and Processing Facility

Aug 68 79p Flahie, T. J.; Jarvis, C. E.; Spurling, C. E. Rept. No. A70009-399

Contract: DAAB07-68-C-0029

Monitor: EDCPF 44

A Method for Computing Intermodulation-Free Frequency Lists AD-834 378L 20/14 17/2.1 IIT Research Inst Annapolis MD Descriptive Note: Technical Rept., Jun 68 45p Lustgarten, M. N. Contract: F19628-68-C-0130

Proj: AF-649E

Monitor: ESD TR-68-103 


\section{RFI IMPACTS ON SPECIFIC SYSTEMS, USERS OR SERVICES--2-C}

A Survey of Interference Problems and Applications to Geostationary Satellite Networks

Jeruchim, M. C.

General Electric Co., Space Div., Valley Forge Space Technol. Center, Philadelphia, PA, USA

Proc. IEEE (USA) Vol. 65, No. 3 317-31 March 1977 Coden: TEEPAD

Radiation Diagrams of Antennae for Earth Stations in the Fixed Satelite

Service for Use in Interference Studies, Report 391-2, Thirteenth

Plenary Assembly, International Radio Consultative Committee, Vol. 4, pp. 176180, Geneva, 1974.

Digital Equipment Susceptibility

AD-902 $976 \quad 20 / 3 \quad 20 / 14 \quad 17 / 2$

Descriptive Note: Final Rept. 1 Sep 70-28 May 72, Aug 72 146P

Baxter, Denmer Dix; Wilson, Jay L.,; Lecain, James F.

Rept. No. OR-11982

Contract: DAAB07-71-C-0013

Proj: DA-1-S-662701-D-449

Monitor: ECOM 0013-F

Electromagnetic Compatibility Analysis of the AN/TPN-19 Airport Surveillance and Precision Approach Radars

AD-865 026L 20/14 17/9 IIT Research Inst Annapolis MD

Descriptive Note: Technical Rept., Jan 70 74P Heinz, W.; Patrick, J.;

Stephan, M.; Mautschke, A.

Contract: F19628-69-C-0073

Proj: AF-649E

Monitor: ESD TR-70-23

Interference Analysis of the Proposed AN/TPN-19 Ground Controlled Approach

System

AD-841 467L 17/9 20/14 IIT Research Inst Annapolis MD

Oct 68 39P Gauthier, G.

Contract: F19628-68-C-0130

Proj: AF-649E

Monitor: ECAC J-12-67-3

Spectrum Utilization Analysis (TACOM)

AD-851 069L 17/2.1 Pan American World Airways Inc Patrick AFB Fla Guided Missiles Range Div

Descriptive Note: Development Rept. Mar 65 168P

Contract: DA-36-039-SC-80424

Proj: RDT/E-1-S-650209-D-615, USATECOM-64945501

Task: 1-S-650209-D-61501

Monitor: USAEPG DR-459 


\section{IONOSPHERIC MODIFICATION BY RADIO/MICROWAVES---3-a}

Magnetic Field Effects on Electrons During Ionospheric Modification Nicholson, D. R.

Dept. of Astro-Geophys., Univ, of Colorado, Boulder, CO, USA

J. Geophys. Res. (USA) Vol. 82, No. 13, 1839-45, 1 May 1977 Coden: JGREA2

Generation of Artificial Spread-F by a Collisionally Coupled Purely

Growing Parametric Instability

Cragin, B. L.; Fejer, J. A。; Leer, E.

Hax-Planck-Inst. fur Aeronomie, Katlenburg-Lindau, Germany

Radio Sci. (USA), Vol。12, No.2, 273-84, March-April 1977 Coden: RASCAD

Observations of Joule and Particle Heating in the Auroral Zone

Banks, P. M.

Dept. of Appl. Phys., Univ. of California, San Diego, LA Jolla, USA

J. Atmos. and Terr. Phys. (GB), Vol. 39, No. 2, 179-93, Feb. 1977

Coden: JATPA3

Possibility of Artificially Generating Geomagnetic Pulsations

Lyatskaya, A. M.; Lyatskiv, V. B.; Mal'tsev, Yu.P.

Polar Geophys. Inst. Kola, Acad. of Sci., USSR

Geomagn. and Aeron. (USSR), Vol. 16, No. 2, 1976 Coden: GEAEA6

Trans of: Geomagn. and Aeron. (USA), Vol. 16, No. 2, 193-5, 1976 Coden: GMARAX

Effect of Strong Radio Waves on the Formation of a Mid-Latitude E/Sub S/ Layer Ignat'yeva, Yu.A.; Krotova, Z. N.

Sci. Res. Inst. of Radio Waves, USSR

Geomagn. and Aeron. (USSR), Vol. 16, No. 41976 Coden: GEAEA6

Trans of: Geomagn. and Aeron. (USA), Vol. 16, No. 4, 381-3 1976 Coden: GMARAX

Heating of Electrons in the Lower Ionosphere by the Electromagnetic

Emission of Vertical Lightning Discharges

Nikolayenko, A. P.

Inst. of Radio Phys. and Electronics, Acad. of Sci.,

Ukrainian SSR

Geomagn. and Aeron. (USSR), Vol. 16, No. 2, 1976 Coden: GEAEA6

Heating of the Auroral Ionosphere During an Aurora

Degtyarev, V. I.; Kurulov, V. A.; Ferberg, B. A.

Inst. of Terrestrial Magnetism, Ionosphere and Radio Wave Propagation,

Acad. of Sci., USSR

Geomagn. and Aeron. (USSR), Vol. 16, No. 1, 1976 Coden: GEAEA6

Trans of: Geomagn. and Aeron. (USA), Vol. 16, No. 1, 110-11, 1976

Coden: GMARAX

Electron Density Disturbances During Local Heating of the Ionospheric F Layer Savel'yev, S. M.; Ivanov, V. B.

Geomagn. and Aeron. (USSR), Vol. 16, No. 2, 1976 Coden: GEAEA6

Trans of: Geomagn. and Aeron. (USA), Vol. 16, No. 2, 207-8, 1976

Coden: GMARAX 
The Effect of a Time Varying Collision Frequency on a Radio Wave Obliquely Incident on the Lower Ionosphere Masl in, N. M. Cavendish Lab., Univ. of Cambridge, Cambridge, England Proc. R. Soc. A (GB), Vol. 348, No. 1653, 245-63, 1976, Coden: PRLAAZ

Geomagnetic Storm Effects on the Thermosphere and the Ionosphere Revealed by In Situ Measurements from OGO 6

Marubashi, K.; Reber, C. A.; Taylor, H. A., Jr.

Lab. for Planetary Atmospheres, Goddard Space Flight Center, Greenbelt, MD, USA Planet. and Space Sci. (GB), Vol. 25, No. 11, 1031-41, Nov. 1976

Coden: PLSSAE

Discrepancy Between Electron Heating and Cooling Rates Derived from Atmosphere Explorer-C Measurements

Brace, L. H.; Hoegy, W. R.; Mayr, H. G.' Victor, G. A.; Hanson, W. B.;

Reber, C. A.; Hinteregger, H. E.

Goddard Space Flight Center, NASA, Greenbelt, MD, USA

J. Geophys. Res. (USA), Vol. 81, No. 31, 5421-9, 1 Nov. 1976

Coden: JGREA2

The Excitation of Plasma Lines in Blanketing Sporadic $E$ Gordon, W. E.; Carlson, H. C.

Rice Univ., Houston, TX, USA

J. Geophys. Res. (USA), Vol. 81, No. 22, 4016-18, 1 Aug. 1976

Coden: JGREA2

Ionospheric Heating Beneath the Magnetospheric Cleft

Titheridge, J. E.

Radio Res. Centre, Univ. of Auckland, Auckland, New Zealand

J. Geophys. Res. (USA), Vol. 81, No. 19, 3321-6, 1 July 1976

Coden: JGREA2

Enhanced 0 I 6300-AA Regions Produced by the Platteville Ionospheric Modification Experiment

Sipler, D. P.; Biondi, M. A.

Phys. Dept., Univ. of Pittsburgh, Pittsburgh, PA, USA

J. Geophys. Res. (USA), Vol. 81, No. 19, 3467-70, 1 July, 1976

Coden: JGREA2

Plasma Heating in Multiple-Resonance Excitation of a Plasma in a

Mirror Machine

Bender, A.; Siambis, J. G.

Carnegie-Mellon Univ., Pittsburgh, PA, USA

Plasma Phys. (GB), Vol. 18, No. 6, 417-27, June 1976

Coden: PLPHBZ 
IONOSPHERIC MODIFICATION BY RADIO/MICROWAVES--3-a

Formation of Three-Dimensional Langmuir Solutions in the Presence of Strong RF Waves in the Ionosphere

Petviashvili, V. I.

Fiz. Plazmy (USSR), Vol. 2, No. 3, 450-54, May-June 1976. Coden: FIPLDK

The Magnetospheric Cleft-Ionospheric Effects

Whitteker, J. H.

Communications Res. Centre, Dept. of Communications, Ottawa, Ontario, Canada

J. Geophys. Res. (USA), Vol. 81, No. 7, 1279-88, 1 March 1976 Coden: JGREA2

Analysis of Backscatter Spectrum in an Ionospheric Modification Experiment Kim, H.; Crawford, F. W.; Harker, K. J.

Inst. for Plasma Res., Stanford Univ., Stanford, CA, USA

J. Geophys. Res. (USA), Vol. 81, No. 1, 193-8, 1 Jan. 1976 Coden: JGREA2

Traveling Ionospheric Disturbances Arising as a Result of Powerful Transmitter Operation

Grigor'ev, G. I.

Izv. Vuz Radiofiz. (USSR), Vo1. 18, No. 12, 1801-5, 1975 Coden: IVYRAY

Trans of: Radiophys. and Quantum Electron. (USA) Coden: SORPAK

Theory of Heating in the Lower Ionosphere by Obliquely Incident Waves from a Powerful Point Transmitter

Maslin, N. M.

Cavendish Lab., Univ. of Cambridge, Cambridge, England

Proc. R. Soc. A (GB) Vol. 346, No. 1644, 37-57, 1975 Coden: PRLAAZ

Plasma Lamination in the Powerful Radio Wave Reflection Region in the Ionosphere

Vas'kov, V. V.; Gurevich, A. V.

Izv. Vuz Radiofiz. (USSR), Vol. 18, No. 9, 1261-72, 1975

Coden: IVYRAY

Trans of: Radiophys, and Quantum Electron (USA) Coden: SORPAK

Oxygen Emission in the Field of a Strong Electromagnetic Wave in the Lower

Ionosphere

Milikh, G. M.

State Sci. Res. Radio Inst., USSR

Geomagn. and Aeron. (USSR), Vol. 15, No. 3, 491-6, 1975 Coden: GEAEA6

Trans. of: Geomagn. and Aeron. (USA), Vol. 15, No. 3, 397-400, 1975

Coden: GMARAX

The Influence of Ionosphere Powerful Heating on Sporadic E-Region Ignat'ev, Yu.A.

Izv. Vuz Radiofiz. (USSR), Vol. 18, No. 9, 1365-9, 1975 Coden: IVYRAY

Trans. of: Radiophys, and Quantum Electron. (USA) Coden: SORPAK

Heating of the Neutral Component of the Lower Ionosphere in the Field of a Strong Radio Wave

Gurevich, A. V.

P. N. Lebedev Inst. of Phys., Acad. of Sci., USSR

Geomagn. and Aeron. (USSR), Vol. 15, No. 1, 161-3, 1975, Coden: GEAEA6

Trans of: Geomagn. and Aeron. (USA), Vol. 15, No. 1, 134-5, 1975 Coden: GMARAX 
IONOSPHERIC MODIFICATION BY RADIO/MICROWAVES--3-a

Heating of the Ionosphere by an Electromagnetic Field Under Developed

Parametric Instability

Mityakov, N. A.; Rapoport, V. 0.; Trakhtengerts, V.Yu.

Izv. Vuz Radiofiz. (USSR), Vol. 18, No. 1, 27-33, 1975 Coden: IVYRAY

Trans of: Radiophys. and Quantum Electron (USA) Coden: SORPAK

Waves and Wave-Particle Interactions in the Magnetosphere - A Review Gendrin, R.

Groupe de Recherches Ionospheriques, CNET, Issy-Les-Moulineaux, France

Space Sci. Rev. (Netherlands), Vol. 18, No. 2, 145-200, Nov. 1975

Coden: SPSRA4

Theory of Enhanced Airglow During Ionospheric Modifications

Weinstock, $J$.

Aeronomy Lab., NOAD, Boulder, CO, USA

J. Geophys. Res. (USA), Vol. 80, No. 31, 4331-45, 1 Nov. 1975 Coden: JGREA2

Self-Heating of the Partial Reflection Experiment

Kissick, W. A.; Ferraro, A. J.

Ionosphere Res. Lab., Pennsylvania State Univ., University Park, PA, USA

J. Atmos. and Terr. Phys. (GB), Vol. 37, No. 10, 1365-70, Oct. 1975

Coden: JATPA3

Current and Future Trends in Ionospheric Research

Bowhill, S. A.

Dept. of Electrical Engng., Univ. of Illinois, Urbana-Champaign, IL, USA

Consiglio Nazionale Delle Ricerche

Radio Sci. (USA), Vol. 10, N 0.7, 693-7, July 1975, Coden: RASCAD

Application of Nonlinear Plasma Physics to Space Physics

AD-A009 651 20/9 4/1 20/14 Princeton Univ NJ Plasma Physics Lab

Descriptive Note: Final Rept. 1 Jan-31 Dec. 74, May $7510 P$

Kulsrud, Russell M.; Perkins, Francis W.

Contract: F44620-73-C-0026

Proj: AF-9751

Task: 975101

Monitor: AFOSR TR-75-0661

Simulated Diffusion Scattering in Ionospheric Modification

Berger, R. L.; Goldman, M. V.; Dubois, D. F.

Univ. Colorado, Boulder, USA

Phys. Fluids (USA), Vol. 18, No. 2, 207-13, Feb. 1975 Coden: PFLDAS

Theoretical Studies of Ionospheric Heating by Powerful Radio Waves

Meltz, G. and Holway, L. H., Jr.

Final Technical Report RADC-TR-73, sponsored by DARPA, 1974.

Production of Ionospheric Striations by Thermal Self-focusing

Thome, G. D. and F. W. Perkins

Physical Review Letters 32, 1238-1240, 1974. 
IONOSPHERIC MODIFICATION BY RADIO/MICROWAVES--3-a

Analysis of the Backscatter Spectrum in an Ionospheric Modification

Experiment

Kim, H.; Crawford, F. W.; Harker, K. J.

Report No.: NASA-CR-142015; Issued by: Stanford Univ., CALIF., USA; Dec. 1974

Special Issue on Ionospheric Modification (Nov. 1974)

Radio Science Vol. 9

A Summary of Vertical Incidence Radio Observations of Ionospheric

Modification

Utlaut, W. F.; Violette, E. J.

U. S. Dept. Commerce, Boulder, CO

Radio Sci. (USA) Vol. 9, No. 11, 895-903, Nov. 1974 Coden: RASCAD

A Theoretical Model for Short-Scale Field-Aligned Plasma Density Striations Perkins, F. W.

Princeton Univ., NJ, USA Radio Sci. (USA), Vol. 9, No. 11, 1065-70, Nov. 1974

Coden: RASCAD

Suggestions for Future Research in HF Ionospheric Modification

Sweeney, L. E., Jr.

Stanford Res. Inst., Menlo Park, Cal if., USA

Radio Sci. (USA), Vol.9, No. 11, 1089-90, Nov. 1974 Coden: RASCAD

Electron Acceleration by Parametrically Excited Langmuir Waves

FEJER, J. A.; Graham, K. N.

Max-Planck-Inst. Aeronomie, Lindau/Harz, Germany

Radio Sci. (USA), Vol. 9, No. 11, 1081-4, Nov. 1974 Coden: RASCAD

Generation of Large Scale Field-Aligned Density Irregularities in Ionospheric Heating Experiments

Fejer, J. A.

Max-Planck-Inst. Physik and Astrophysik, Munchen, Germany

AGARD, AGARD Conference Proceedings No. 138 on Non-Linear Effects in

Electromagnetic Wave Propagation, $13 / 7 \mathrm{pp} ., 1974$

12-15 Nov. 1973 Edinburgh, Scotland

AGARD Neuilly Sur Sernne

A Model of the Enhanced Airglow Excited by RF Radiation

Haslett, J. C.; Megill, L. R.

NOAA, Boulder, Colo., USA

Radio Sci. (USA), Vol. 9, No. 11, 1005-19, Nov. 1974 Coden: RASCAD

Ionospheric Heating by Powerful Radio Waves

Meltz, G.; Holway, L. H., Jr.; Tomljanovich, N. M.

Raytheon Co., Sudbury, MA, USA

Radio Sci. (USA), Vol. 9, No. 11, 1049-63, Nov. 1974 Coden: RASCAD 
Ionospheric Modification Theory - Past, Present, and Future

Meltz, G.; Perkins, F. W.

Raytheon Co., Sudbury, MA, USA

Radio Sci. (USA), Vol. 9, No. 11, 885-8, Nov. 1974 Coden: RASCAD

Generation of Large-Scale Field-Aligned Irregularities in Ionospheric

Modification Experiments

Cragin, B. L.; Fejer, J. A.

Univ. California, San Diego, La Jolla, USA

Radio Sci. (USA), Vol。9, No. 11, 1071-5, Nov. 1974 Coden: RASCAD

Enhanced Airglow, Electron Acceleration, and Parametric Instabilities

Weinstock, J.

NOAA, Boulder, Colo., USA

Radio Sci. (USA), Vol. 9, No. 11, 1085-7, Nov. 1974 Coden: RASCAD

The Platteville High Power Facility

Carroll, J. C.; Violette, E. J.; Utlaut, W. F.

U.S. Dept. Commerce, Boulder, Colo.

Radio Sci. (USA), Vol. 9, No. 11, 889-94, Nov. 1974 Coden: RASCAD

ARECIBO Heating Experiments (Ionospheric Plasma Heating)

Gordon, W. E.; Carlson, H. C., Jr.

Rice Univ., Houston, Tex., USA

Radio Sci. (USA), Vol. 9, No. 11, 1041-7, Nov. 1974 Coden: RASCAD

The Ivory Coral Program on Ionospheric Modification

AD-A001 570 4/ 1 Stanford Research Inst Menlo Park Calif

Descriptive Note: Technical Summary Oct 70-Dec 73, Sep 74 149P

Vanderlind, M. R.

Contract: N00014-70-C-0413, ARPA Order-1656

Proj: NR-088 047, SRI-8727

Nonlinear Theory of High Frequency Heating of a Plasma

Ivanov, A. A.; Signov, Yu.S.; Khadyrev, Yu.V.

I. V. Kurchatov Inst. Atomic Energy, Acad. Sci., Moscow, USSR

Dok1. Akad. Nauk SSSR, Vol. 214 No. 4-6, 1291-4 of Vol. 214, No. 6, Feb. 1974

Coden: DANKAS

Trans of: Sov. Phys.-Dokl. (USA), Vol. 19, No. 2, 79-81, Aug. 1974

Coden: SPHDA9

Heating Experiments in the Ionosphere

Crawford, F. W.

Stanford Univ., Calif., USA

American Phys. Soc., IEEE, Texas Tech. Univ., et a]

2nd Topical Conference on RF Plasma Heating El/9 pp., 1974

20-22 June 1974, Lubbock, Tex., USA

Texas Tech. Univ., Lubbock, Tex., USA 
IONOSPHERIC MODIFICATION BY RADIO/MICROWAVES--3-a

The 6300A Intensity Variations Produced by the ARECIBO Ionospheric

Modification Experiments

Sipler, D. P.; Enemark, E.; Biondi, M. A.

Report No.: SRRC-203; Issued by: Univ. Pittsburgh, PA, USA

USGRDR No.: AD-779548

Contract No.: DAHCO4-73-0037

May 1974

6300-AA Intensity Variations Produced by the ARECIBO Ionospheric

Modification Experiment

Sipler, D. P.; Enemark, E.; Biondi, M. A.

Univ. Pittsburgh, PA, USA

J. Geophys. Res. (USA), Vol. 79, No. 28, 4276-80, 1 Oct. 1974 Coden: JGREA2

Parametric Instabilities and Ionospheric Modification

Perkins, F. W.; Oberman, C.; Valeo, E. J.

Princeton Univ., NJ, USA

J. Geophys. Res. (USA), Vol. 79, No. 10, 1478-96, 1 Apri1 1974 Coden: JGREA2

Lower Ionosphere Ion Chemistry

Sechrist, C. F., Jr.

Univ. Illinois, Urbana, USA

Hol tet, J. A.;

ELF-VLF Radio Wave Propagation 39-52 1974

17-27 Apri1 1974 Spatind, Norway

Reidel Dordrecht, Netherlands

Variation of Electron Density Collision Frequency in a Time-Dependent

Plasma Medium

Varshney, S. K.; Ram, V.; Chandra, A.; Sarkar, D. C.

Phys. Dept., Aligarh Muslim Univ., Aligarth, India

Indian J. Radio and Space Phys., Vol. 3, No. 4, 349-52 Dec. 1974 Coden: IJRSAK

Symposium and Aeronomy and Radio Wave Propagation, Feb. 1974, New Delhi, India

Theoretical Studies of Ionospheric Heating by Powerful Radio Waves, AD-780 553 4/1 Raytheon Co Sudbury, MA

Descriptive Note: Final Technical Rept. Jan 73-Feb 74, Feb 7467 P

Me]tz, Gerald; Holway, Lowell H., Jr.

Contract: F30602-73-C-0154

Monitor: RADC TR-74-114-PT-3

Production of Ionospheric Striations by Self-Focusing of Intense Radio Waves AD-784 683 4/1 Princeton Univ N J Plasma Physics Lab

Jan 74, 4P, Thome, G. D.; Perkins, F.W.

Rept. No. PPL-AP-71

Contract: F44620-73-C-0026

Monitor: AFOSR TR-74-1326 
IONOSPHERIC MODIFICATION BY RADIO/MICROWAVES--3-a

Response of Gravity Waves to Slowly-Varying Ionospheric Heating Holway, Jr., L. H. and Meltz, G.

(Technical Memo), 1973

Excitation of Parametric Instabilities by Non-Monochromatic HF Fields

Holway, L. H., Jr. and Meltz, G.

Proceedings of the IVORY CORAL 1973 Technical Review Meeting,

sponsored by DARPA, pp. 215-232, 1973.

Measurements of the Recombination of Electrons with $\mathrm{H}_{3} \mathrm{O}^{+} \cdot\left(\mathrm{H}_{2} \mathrm{O}\right)_{\mathrm{n}}$ Series Ions, Phys. Rev. A, 7, pp. 292-298 (1973)

Lev, M. T., Biondi, M. A., and Johnson, R.

Review of Non-Linear Theory of Ionospheric Interaction.

Goldman, M. V.

University of Colorado, Report UC1003, 1973.

Wave Interaction in the Lower Ionosphere - A Survey

AD-774 $9174 / 1$ 20/14 Office of Naval Research London (England)

Dec 73 16p Waynick, Arthur $H$.

Rept. No. ONRL-R-30-73

Heating of the Lower Ionosphere by Powerful Radio Waves

Holway, L. H., Jr.; Meltz, G.

Raytheon Res. Div., Waltham, MA, USA

J. Geophys. Res. (USA), Vol. 78, No. 34, 8402-8, 1 Dec. 1973 Coden: JGREA2

Electron Heating in the Ionosphere by Powerful Gyro-Waves

Smith, R. A.; Loch, R. G.

Univ. New England, Armidale, NSW, Australia

AGARD

AGARD Conference Proceedings No. 138 on Non-Linear Effects in Electromagnetic Wave Propagation, 29/14pp. 1974

12-15 Nov. 1973, Edinburgh, Scotland

AGARD NEUILLY SUR SEINNE

Wave Interaction Using a Partially REflected Probing Wave

Kissick, W. A.; Ferraro, A. J.

Pennsylvania State Univ., University Park, USA

AGARD

AGARD Conference Proceedings No. 138 on Non-Linear Effects in

Electromagnetic Wave Propagation 30/9pp. 1974

12-15 Nov. 1973, Edinburgh, Scotland

AGARD, Neuilly Sur Seinne

Onset, Growth and Motions of Ionospheric Disturbances Caused by High-

Intensity Electromagnetic Heating

Wright, J. W.

NOAA, Boulder, CO, USA

AGARD

AGARD Conference Proceedings No. 138 on Non-Linear Effects in

Electromagnetic Wave Propagation 6/17pp. 1974

12-15 Nov. 1973 Edinburgh, Scotland

AGÄD Neuilly Sur Seinne 
IONOSPHERIC MODIFICATION BY RADIO/MICROWAVES--3-a

Modification Effects in the Ionospheric D-Region

Jones, T. B.

Univ. Leicester, England

AGARD

AGARD Conference Proceedings No. 138 on Non-Linear Effects in

Electromagnetic Wave Propagation, 32/8pp. 1974

12-15 Nov. 1973 Edinburgh, Scotland

AGARD Neuilly Sur Seinne

Potential Applications of Ionospheric Modification to Aeronomy

Meltz, G.

Raytheon Co., Sudburgy, MA, USA

AGARD

AGARD Conference Proceedings No. 138 on Non-Linear Effects in

Electromagnetic Wave Propagation 1/26pp, 1974

12-15 Nov. 1973 Edinburgh, Scotland

AGARD Neuilly Sur Seinne

A Survey of Ionospheric Modification Effects Produced by High-Power HF Radio Waves

Utlaut, W. F.

U. S. Dept. Commerce, Boulder, Colo.

AGARD

AGARD Conference Proceedings No. 138 on Non-Linear Effects in

12-15 Nov. 1973 Edinburgh, Scotland

AGARD Neuilly Sur Seinne

Observations of Enhanced Ion Line Frequency. Spectrum During ARECIBO

Ionospheric Modification Experiment

Hagfors, T.; Zamlutti, C. J.

Nth, Trondheim, Norway

AGARD

AGARD Conference Proceedings No. 138 on Non-Linear Effects in

Electromagnetic Wave Propagation, 5/12pp. 1974

12-15 Nov. 1973 Edinburgh, Scotland

AGARD Neuilly Sur Seinne

The Saturation Spectrum of Parametric Instabilities

Fejer, J. A.; Yu-Yun Kuo

Max-Planck-Inst. Physik and Astrophysik, Munchen, Germany AGARD

AGARD Conference Proceedings No. 138 on Non-Linear Effects in

12-15 Nov. 1973 Edinburgh, Scotland

AGARD Neuilly Sur Seinne

Numerical Solution of a Problem of Non Linear Wave Propagation Through

Plasmas

De Socio, L. M.; Gaffuri, G.

Univ. Camerino, Italy

AGARD

AGARD Conference Proceedings NO. 138 on Non-Linear Effects in

Electromagnetic Wave Propagation 33/10pp. 1974

12-15 Nov. 1973 Edinburgh, Scotland

AGARD Neuilly Sur Seinne 
IONOSPHERIC MODIFICATION BY RADIO/MICROWAVES--3-a

AGARD Conference Proceedings No. 138 on Non-Linear Effects in

Electromagnetic Wave Propagation

AGARD

1974 12-15 Nov. 1973 Edinburgh, Scotland

AGARD Neuilly Sur Seinne

Radio Frequency Heating Effects on Electron Density in the Lower E Region Witlis, J. W.; Davis, J.R.

Naval Res. Lab., Washington, DC, USA

J. Geophys. Res. (USA), Vo1。78, No. 25, 5710-17, 1 Sept. 1973

Coden: JGREA2

Parametric Excitation of Electromagnetic Waves

Leer, E.

Nordlysobservatoriet, Tromso, Norway

Phys. Norv. (Norway), Vol. 7, No. 2, 102, 1973 Coden: PHNOAH

Norwegian Physical Society Annual Meeting (Abstracts Only)

18-20 June 1973 Trondheim, Norway

F-Region Movements Produced by Artificial Modification of the Ionosphere with High Power Radio Waves

Jones, T. B.

Univ. Leicester, England

Q. J. R. Astron. Soc. (GB), Vol. 14, No. 2, 198, June 1973 Coden: QJRAAK

Royal Astronomical Society Meeting on Winds in the Ionosphere, 24 Nov, 1972

London, England

Ionospheric Modification

Meltz, G.

Raytheon Co., Portsmouth, R. I., USA

European Phys. Soc., Austrian Phys. Soc.

International Congress on Waves and Instabilities in Plasmas (Abstracts Only

Received), L4/7pp., 1973

2-7 Apri1 1973 Innsbruck, Austria

Inst. Theoretical Physics, Innsbruck, Austria

Isothermal Ionization of the Lower Ionosphere Under the Effect of Radio Waves Gurevich, A. V.

P. N. Lededev Phys. Inst. Acad. Sci., USSR

Geomagn. and Aeron. (USSR), Vol. 12, No. 4, 631-40, 1972 Coden: GEAEA6

Trans of: Geomagn. and Aeron. (USA), Vol. 12, №. 4, 556-64, 1972

Coden: GMARAX

Stable Electron Density Fluctuations in a Plasma in the Presence of a

High-Frequency Electric Field

Hagfors, T.; Gieral towski, G. F.

Cornell Univ., ARECIBO, Puerto Rico

J. Geophys. Res. (USA), Vo1。77, No. 34, 6791-803, I Dec. 1972 Coden: JGREA2 
IONOSPHERIC MODIFICATION BY RADIO/MICROWAVES-3-a

Induced Enhancement of the Plasma Line in the Backscatter Spectrum by

Ionospheric Heating

Harker, K. J.

Stanford Univ., Calif., USA

J. Geophys. Res. (USA), Vol. 77, No. 34, 6904-6, 1 Dec. 1972

Coden: JGREA2

On D-Region Electron Heating by a Low-Frequency Terrestrial Line Current with Ground Return.

Row, R. V.; Mentzoni, M. H.

Symbionics, Wal tham, MA, USA

Radio Sci. (USA), Vol. 7, No. 11, 1061-6, Nov. 1972 Coden: RASCAD

Phenomena Associated with Very High Power, High Frequency F-Region Modification Below the Critical Frequency

Seliga, T. A.

Ohio State Univ., Columbus, USA

J. Atmos. and Terr. Phys. (GB), Vol. 34, No. 10, 1827-41, Oct. 1972

Goden: JATPA3

F-Region Modification Experiments Performed Near Boulder, CO

On the Generalization of the Appleton-Hartree Magnetoionic Formulas.

Sen, H. K. and Wyller, A. A.

J. Geophys. Research 65, 3931-3950, 1960

Some Radio and Optical Observations of Ionospheric Modification by Very

High Power H.F. Ground-Based Transmission

Utiaut, W. F.

ESSA, Boulder, Colo, USA

IEEE, Antennas and Propagation Group

1970 G-AP International Symposium 208-12, 1970

14-16 Sept 1970, Columbus, Ohio, USA

IEEE, New York, USA

Observation of Ionospheric Modification by Very High Power High Frequency Ground-Based Transmission

Utlaut, W. F.

Dept. Commerce, Boulder, Colo., USA

American Geophys. Union

Trans. Am. Geophys. Union (USA), Vol. 51, No. 11, 734, Nov. 1970

52nd Annual Meeting of the American Geophysical Union (Abstracts Only

Received), 12-16 Apri1 1971, Washington, DC, USA

- On the Role of Plasma Instabilities in Ionospheric Heating by Radio Waves Perkins, F. W.' Kaw, P. K.

Princeton Univ., NJ, USA

- J. Geophys. Res. (USA), Vol. 76, No. 1, 282-4, 1 Jan. 1971 Coden: JGREA2 
IONOSPHERIC MODIFICATION BY RADIO/MICROWAVES--3-a

The Ionosphere as a Plasma Laboratory

Cohen, R.

NOAA, Boulder, Colo., USA

IEEE

1971 IEEE Group on Antennas and Propagation International Symposium 28-31, 1971

22-24 Sep 1971 Los Angeles, Calif., USA

IEEE New York, USA

Variability of Plasma-Line Enhancement in Ionospheric Modification

Experiments

Fejer, J. A.

Univ. California, San Diego, La Jolla, USA

J. Geophys. Res. (USA), Vol. 77, No. 1, 273-5, 1 Jan. 1972 Coden: JGREA2

Threshold of Ionospheric Modification by Radio Waves

Weinstock, J.; Bezzerides, B.

NOAA, Boulder, Colo., USA

J. Geophys. Res. (USA), Vol. 77, No. 4, 761-4, 1 Feb. 1972 Coden: JGREA2

High Frequency Induced Enhancements of the Incoherent Scatter Spectrum at ARECIBO

Carlson, H. C.; Gordon, W. E.; Showen, R. L.

ARECIBO Obs., Puerto Rico

J. Geophys. Res。(USA), Vol. 77, No. 7, 1242-50, 1 March 1972

Coden: JGREA2

Ionospheric Interaction of VLF Radio Waves

Galejs, J.

Naval Res. Lab., Washington, DC, USA

J. A mos. and Terr. Phys. (GB), Vol. 34, No. 3, 421-36, March 1972

Coden: JATPA3

Artificial Heating of the Lower Ionosphere

Showen, R. L.

Rice Univ., Houston, Tex., USA

J. Geophys. Res. (USA), Vol. 77, No. 10, 1923-33, 1 Apri1 1972

Coden: JGREA2

Incoherent Scatter Observations at ARECIBO Using Compressed Pulses

Ioannidis, G.; Farley, D. T.

Cornel1 Univ., Ithaca, NY, USA

Radio Sci. (USA), Vol. 7, No. 7 763-6 July 1972 Coden: RASCAD

Modifying the Ionosphere with Radio Waves

Utlaut, W.

Inst. Telecommunication Sci., Boulder, Colo., USA

New Sci. (GB), Vol. 55, No. 808, 238-90, 10 Aug. 1972 Coden: NWSCAL 
IONOSPHERIC MODIFICATION EFFECTS ON SPECIFIC SERVICES, SYSTEMS OR USERS--3-b

Proceedings of the Allerton-House Conference (4th) on HF Radio Direction

Finding and Radiolocation Research

AD -888 $218 \quad 17 / 3 \quad 17 / 7 \quad 17 / 2.1$

Illinois Univ Urbana Radiolocation Research Lab

Descriptive Note: Final Rept., Sep 71, 435P, Bailey, A. D.

Rept. No. RRL-PUB-392, UILU-ENG-71-2542

Contract: N00014-71-C-0221

Modification of the Ionosphere

AD-680 $983 \quad 4 / 1 \quad 17 / 2.1 \quad 18 / 3$

Library of Congress Washington, DC Aerospace Technology Div

Descriptive Note: Surveys of Foreign Scientific and Technical Literature, Dec 68 71P Michaels, Daniel W.

Rept. No. ATD-69-11-101-1

High Altitude Tests Measurement Summary

AD-827 915L 18/3 General Electric Co Santa Barbara Calif DASA

Information and Analysis Center

Contract: DA 49-746-XZ-282

Monitor: DASA, 1970 
IONOSPHERIC PROPAGATION (RADIO/RADAR, ETC.) --3-C

Demodulation of Strong Low-Frequency Waves in the Subauroral Ionosphere in the Frequency Range of Geomagnetic Osciliations

Kopytenko, Yu.A.; Molchanov, O. A.; Mogilevskii, M. M.; Markeeva, Yu.M.;

Schchekotov, A.Yu.; Pogrebnikov, M. M.

Zh. Eksp. and Teor. Fiz. Pis'ma V Red. (USSR), Vol. 25, No. 5, 237-40

5 March 1977 Coden: ZFPRAU

Trans of: JETP Letters (USA) Coden: JTPLA2

Ionospheric Scintillation

Crane, R. K.

Lincoln Lab., MIT, Lexington, MA, USA

Proc. IEEE (USA), Vol. 65, No. 2, 180-99, Feb. 1977 Coden: IEEPAD

Anomalous Absorption of Electromagnetic Waves in a Randomly Inhomogeneous

Collisionless Magnetoactive Plasma

Ryzhov, Yu.A.

Zh. Eksp. and Teor. Fiz. (USSR), Vol. 72, No. 1, 141-50, Jan. 1977

Coden: ZETFA7

Trans. of: Sov. Phys. JETP (USA) Coden: SPHJAR

Theory of the Modulation Imposed on an 0bliquely Incident Radio Wave Reflected in a Disturbed Region of the Lower Ionosphere

Maslin, N. M.

Cavendish Lab., Univ. of Cambridge, Cambridge, England

Proc. R. Soc. A (GB), Vol. 349, No. 1659, 555-70, 1976 Coden: PRLAAZ

Anomalous Radio Wave Absorption Due to Ionospheric Heating Effect

Graham, K. N.; Fejer, J. A.

Burroughs Interactive Res. Center, La Jolla, CA, USA

Radio Sci. (USA), Vol. 11, No. 12, 1057-63, Dec. 1976 Coden: RASCAD

Ionospheric Scintillation Theory-A Mini-Review

Rino, C. L.

Stanford Res. Inst., Menlo Park, CA, USA

IEEE Trans. Antennas and Propag. (USA), Vol. AP.24, No. 6, 912-15, Nov. 1976

Coden: IETPAK

Eiscat--A New Project for Studying the High Latitude Ionosphere

Rishbeth, $H$.

SRC, Appleton Lab., Slough, England

Contemp. Phys. (GB), Vol. 17, No. 5, 483-9, Sept.-Oct. 1976 Voden: CTPHAF

Simultaneous Optical and Incoherent Scatter Observations of Two Low-

Latitude Auroras

Noxon, J. F.; Evans, J. V.

Blue Hill Obs., Harvard Univ., Cambridge, MA, USA

Planet. and Space Sci. (GB), Vol. 24, No. 5, 425-42, May 1976 Coden: PLSSAE

Diurnal Variation of the Mean Faraday Factor at Arecibo

Smith, D. H.

J. Geophys. Res. 75:823-838, 1970. 
Review of Important Problems in Wave Propagation Affecting Future Telecommunication System Performance

Utlaut, H. F.

Office of Telecommunications, Inst. Telecommunications Sci., U. S. Dept. of Commerce, Boulder, CO, USA

Internat. Telecommunication Union, Assoc. Elettrotecnica and Elettronica Italiana, IEE, IEEE, et al

World Telecommunication Forum Technical Symposium 3.1.8/1-8, 1975

6-8 0ct. 1975, Geneva, Switzerland

Internat. Telecommunication Union, Geneva, Switzerland

Scattering of an Ordinary Wave Near the Reflection Point by Small-Scale Irregularities

Mityakov, N. A.; Rapoport, V. 0.; Trakhtengerts, V. Yu. Izv. Vuz Radiofiz. (USSR), Voi. 18, No. 9, 1273-8, 1975 Coden: IVRAY

Trans of: Radiophys. and Quantum Electron. (USA) Coden: SORPAK

Evidence for Precipitation of Energetic Particles by Ionospheric "Heating" Transmissions Wright, J. W.

Space Environment Lab., NOAA, Boulder, CO, USA

J. Geophys. Res. (USA), Vol. 80, No. 31, 4383-6, 1 Nov. 1975 Coden: JGREA2

Aurora? Energy Input from Energetic Electrons and Joule Heating at Chatanika Wickwar, V. B.; Baron, M. J.; Sears, R. D.

Stanford Res. Inst., Menlo Park, CA, USA

J. Geophys. Res. (USA), Vol. 80, No. 31, 4364-7, 1 Nov. 1975 Coden: JGREA2

Around-the-World Propagation

Rumi, G. C.

Instituto Elettrotecnico Nazionale Galileo Ferraris, Torino

Italy

Consiglio Nazionale Delle Ricerche

Radio Sci. (USA), Vol. 10, No. 7, 711-18, July 1975 Coden: RASCAD

Geophysical Investigations by Scattered Radio Waves

Dieminger, $W$.

Max-Planck-Inst. fur Aeronomie, Lindau/Harz, Germany

Consiglio Nazionale Delle Ricerche

Radio Sci. (USA), Vol. 10, No. 7, 681-91, Ju1y 1975 Coden: RASCAD

The Historical Development of Forecasting Methods for Ionospheric

Propagation of HF Waves

Rawer, $K$.

Fraunhofer-Gesel1schaft, Inst. fur Phys. Weltraumforschung, Freiburg, Germany Consiglio Nazionale Delle Ricerche

Radio Sci. (USA), Vol. 10, No. 7, 669-79, July 1975 Coden: RASCAD 
IONOSPHERIC PROPAGATION (RADIO/RADAR, ETC.) $--3-\mathrm{C}$

TIDS in Equatorial Anomaly Region

Kaushika, N. D.

Inst. de Pesquisas Espacials Sao Jose Dos Campos, Brasil

Indian J. Radio and Space Phys., Vol. 4, No. 1, 86-8, March 1975

Coden: IJRSAK

Stimulated Compton Scattering in a Plasma in Magnetic Field

Spatschek, K. H.; Shukla, P. K.; Yu. M. Y.

Ruhr-Univ. Bochum, Germany

Lett. Nuovo Cimento (Italy), Vol. 12, Ser. 2, No. 10, 368-70, 8 March 1975

Coden: NCLTAX

Effect of Smal1 Ionospheric Irregularities on Radiowave Absorption

Chen, H. C.; Fejer, J.A.

Univ. California, San Diego, La Jolla, USA

Radio Sci. (USA), Vol. 10, No. 2, 167-71, Feb. 1975 Coden: RASCAD

Daily and Seasonal Variations of the Frequency of Occurrence of Traveling Disturbances in the Ionosphere

Ploshchenko, 0. S.; Chernysheva, S. P.; Sheftel', V. M.

Rostov on Don State Univ., Rostov on Don, USSR

Geomagn. and Aeron. (USSR), Vol. 14, No. 5, 910-12, 1974 Coden: GEAEA6

Trans of: Geomagn. and Aeron. (USA), Vol. 14, No. 5, 775-7, 1974

Coden: GMARAX

Ionospheric Propagation of HF and VHF Radio Waves Across the Geomagnetic Equator

Nielson, D. L.; Crochet, M.

Stanford Res. Inst., Menlo Park, CA, USA

Rev. Geophys. and Space Phys. (USA), Vol. 12, No. 4, 688-702, Nov. 1974

Coden: RGPSBL

Plasma Instabilities and Radio Aurora

Oksman, J.

Univ. Oulu, Finland

Ann. Geophys. (France), Vol. 30, No. 2, 285-90, March-May 1974 Coden: AGEPA7

Equatorial Ionospheric Absorption During Half a Solar Cycle (1964-1970)

Gnanal ingam, S.

Inst. Sci. and Industrial Res., Colombo, Sri Lanka

J. Atmos. and Terr. Phys. (GB), Vol. 36, No. 8, 1335-54, Aug. 1974

Coden: JATPA3

Incoherent Scatter Sounding of the Ionosphere

Beynon, W.J.G.

Univ. Coli. Wales, Aberystwyth

Contemp. Phys. (GB), Vol. 15, No. 4, 329-52, July 1974 Coden: CTPHAF 
IONOSPHERIC PROPAGATION (RADIO/RADAR, ETC.)--3-C

Observations of Artificially Produced Scintillations Using Satellite Transmissions

Pope, J. H.; Fritz, R. B.

NOAA, Boulder, Colo., USA

J. Geophys. Res. (USA), Vol. 79, No. 7, 1065-71, 1 March 1974 Coden: JGREA2

Comparisons of Techniques for Measurement of D-Region Electron Densities

Selchrist, C. F., Jr.

Univ. Illinois, Urbana-Champaign, USA

Radio Sci. (USA), Vol. 9, No. 2, 137-49, Feb. 1974 Coden: RASCAD

Symposium on Incoherent Scatter, 12-16 June 1973, Tromso, Norway

Characteristics of the Ionosphere and Stratosphere During the Winter Chavdarov, S. S.; Ryss, I. K.; Chernysheva, S. P.; Boldyrev, N. M. Rostov-on-Don State Univ., USSR

Geomagn. and Aeron. (USSR), Vol. 13, No. 5, 940-2, 1973 Coden: GEAEA6

Trans of: Geomagn. and Aeron. (USA), Vol. 13, No. 5, 799-801, 1973

Coden: GMARAX

Nearly Vertical Incidence Skywave (NVIS) HF Frequency Assignment Factors AD-771 932 17/2.1 20/14

Army Electronics Command Fort Monmouth, $\mathrm{NJ}$

Descriptive Note: Research and Development Technical Rept.,

Dec 73 35P Perlman, Sol

Rept. No. ECOM-4176

Proj: DA-1-F-262202-A-97

Task: 1-F-262202-A-9701

Average Behavior of the Mid-latitude F-region Parameters $N_{T}, N_{\max }$ and During Geomagnetic Storms

Mendillo, M., Papagiannis, M. D., and Klobuchar, J. A.

J. Geophys. Res. 77:4891, 1972.

The Use of VLF Radio Waves in Ionospheric Research

Bjontegaard, G.; Egeland, A.

Norwegian Inst. Cosmic Phys., Osio

Phys. Norv. (Norway), Vol.6, No. 2, 113-26, 1972 Coden: PHNOAH

Some Effects of the Equatorial Ionosphere on Terrestrial HF Radiocommunication Bradley, P. A.; Eccles, D.; King, J.W.

Radio and Space Res. Station, Slough, England

Telecommun. J. (Engl. Ed.) (Switzerland), Vol. 39, No. 12 717-24 Dec. 1972

Coden: TCJOA6

Properties of VLF Signals

Reder, F. H.

U. S. Army Electronics Command, Fort Monmouth, NJ

Nat. Electronics Conference Inc., et al

Proceedings of the National Electronics Conference, Vol. XXVII, 253-7 1972

9-11 Oct. 1972 Chicago, IL, USA

Nat. Electronics Conference Inc. Oak Brook, IL, USA 
IONOSPHERIC PROPAGATION (RADIO/RADAR, ETC.) --3-C

Propagation and Application of Waves in the Ionosphere

Yeh, K. C.; Liu, C. H.

Univ. Illinois, Urbana-Champaign, USA

Rev. Geophys. and Space Phys. (USA) Vo1. 10, No. 2 631-709 May 1972

Coden: RGPSBL

Reflection Conditions of a Radiovave Propagated Obliquely Through a

Horizontally stratified Ionosphere

Jones, T. B.; Foley, G.

Univ. Leicester, England

J. Atmos. and Terr. Phys. (GB), Vol. 34, No. $5837-44$ May 1972 Coden: JATPA3

Booker Quartic Involving Ion and Temperature Effects

Agarwa 1, D. C.

Univ. Allahabad, India

J. Inst. Eng. (India) Electron. and Telecommun. Eng. Div.

Vol. 52, PT.ET4, No. 7 183-4 March 1972 Coden: JEETA2

Sky-Wave Backscatter - A Means for Observing our Environment at Great

Distances

Croft, T. A.

Stanford Univ., Calif., USA

Rev. Geophys, and Space Phys. (USA) Vol. 10, No. 1 73-155 Feb. 1972

Coden: RGPSBL

Model Studies of the Conversion of Faraday Rotation Measurements from a Geostationary Satellite to Total Electron Content,

Klobuchar, J. A., and Mendillo, M.

Report of the Joint Satellite Studies Group, JSSG Report No. 4,

Florence, Italy, 1971

Ionospheric Total Electron Content Behavior During Geomagnetic Storms

Mendil10, M.

Nature 234:23, 1971

Use of $F$ Layer Theory in Ionospheric Predictions

Rishbeth, H.

UK Sci. Res. Council, Ditton Park, Slough

Proc. Inst. Elec. Eng. (GB) Vol. 118, No. 10 1323-6 0ct. 1971

Coden: PIEEAH

A Brief Review of Scintillation Studies

Hartmann, G. K.

Max-Planck-Inst. Aeronomie, Lindau, Harz, Germany

Radio and Telecommunication Res. Committee of the Council of Sci. Industrial Res., Indian Space Res. Organization

J. Sci. and Ind. Res. (India) Vol. 30, No. 8 414-20 Aug. 1971

Coden: JSTRAC 
IONOSPHERIC PROPAGATION (RADIO/RADAR, ETC.) $--3-c$

A Note on the Applicability of the Booker Theorem to Magnetoactive Plasmas Von Roos, 0 .

Astrophys. Res. Corp., Los Angeles, Calif., USA

Radio Sci. (USA) Vol. 5, No. 4 693-5 April 1970

Propagation of ELF and VLF Waves Near the Earth

Al'pert, Y. A.: Fligel, D. S.

Wood, J. S.

SBN 306-10836-4

1970

Consultants Bureau, London, England

Electron Content Obtained from Faraday Rotation and Phase Path Length

Differences

Garriott, 0. K., daRosa, A. V., and Ross, W. J.

J. Atmos. Terr. Phys. 32-705, 1970

A First-Order Prediction Model of Total Electron Content Group Path

Delay for a Midlatitude Ionosphere

Klobuchar, J. A., and Allen, R. S.

Tech. Report, AFCRL-70-0403, AFCRL, Bedford, MA, 1970

Handbook of Electromagnetic Propagation in Conducting Media

AD-714 006 20/14 Naval Material Command, Washington, DC

Jan 70113 P Kraichman, Martin B.

Effects of Ionospheric Scattering on Very Long Distance Radio Communication Whale, H. A.

1969

Plenum London, England

Polarization Angle of VHF Telemetry Transmitters on ATS-3

Klobuchar, J. A.

ATS Tech. Data Report, Goddard Space Flight Center, Greenbelt, MD, 1969

Omega, Differential OMEGA and O.P.L.E. Future Sea-Transport-, Air-Transportand Meteorological Prediction-Requirements.

AD-832 $262 \quad 17 / 7$

Technisch Documentatie en Informatie Centrum Voor de Krijgsmacht The Hague (Netherlands)

Descriptive Note: Rept. No. 2, Jun 61-Oct 67, Apr 68 24P Bos, H. J.

Rept. No. TDCK-50192

C.C.I.R. Atlas of Ionospheric Characteristics

International Telecommunications Union, Geneva (Switzerland)

International Radio Consultative Committee

C7063C1 Fld: 17B, 20N, 4A GRAI7619 1966 404P

Rept No. CCIR-340

Monitor: 18

Text in French, English, and Spanish 
IONOSPHERIC PROPAGATION (RADIO/RADAR, ETC.) --3-C

Atmospheric Attenuation in Satellite Communications

Holzer, W.

Microwave Journa1, March 1965, p. 119.

A Survey of Ionospheric Effects Upon Earth-Space Radio Propagation Lawrence, R. S., et al.

Proc. IEEE, 52, January 1964.

On the Guided Propagation of Electromagnetic Wave Beams

Goubau, F. Schwering

IRE Trans. Antennas Propagat., Vo1. AP-9, pp. 248-263, May 1961.

Seasonal and Diurnal Variations in the Total Electron Content of the Ionosphere at Invariant Latitude 45 Degrees

Hawkins, G. S. and Klobuchar, J. A.

AFCL-TR-74-0294, June 1974. 
SPS IONOSPHERIC MODIFICATION STUDY $--3-d$

Modification of the Ionosphere by Radiowaves Lelevier, R. E.

Report No.: P-4125 Issued by: Rand Corp., Santa Monica, Calif., USA USGRDR No.: AD-689 662

June 1969 


\section{PROPAGATION EFFECTS IN ARTIFICIALLY HEATED IONOSPHERE--3-e}

The Effects of Artificial Ionospheric Heating on Partial Reflections

Kissick, W. A.

Pennsylvania State Univ., University Park, USA

Complementary Cross Modulation - A New Technique for Ionospheric Modification Studies

Sulzer, M.; Tomko, A.; Ferraro, A. J.; Lee, H. S. Ionosphere Res. Lab., Pennsylvania State Univ., University Park, PA, USA

J. Geophys. Res. (USA) Vol. 81, No. 25 4754-6 1 Sept. 1976 Coden: JGREA2

Investigation of Nonlinear Phenomena When a Powerful Radio Pulse

Is Propagating in the Lower Ionosphere

Gurevich, A. V.: Shlyuger, I. S.

Izv. Vuz Radiofiz. (USSR) Vol. 18, No. 9 1237-60 1975 Coden: IVYRAY

Trans of: Radiophys. and Quantum Electron (USA) Coden: SORPAK

Kinetics of Electrons in a Low-Temperature Molecular Plasma (Ionosphere) Gurevich, A. V.: Milikh, G. M.: Shlyuger, I. S. Zh. Eksp. and Teor. Fiz. (USSR) Vol. 69, No. 5 1640-53 Nov. 1975 Coden: ZETFA7

Ionospheric Modification Induced by High-Power HF Transmitters - A Potential for Extended Range VHF-UHF Communications and Plasma Physics Research Utlaut, W. F. Inst. Telecommunication Sci., U. S. Dept. Commerce, Boulder, CO, USA Proc. IEEE (USA) Vol. 63 No. 7 1022-43 July 1975 Coden: IEEPAD

Effect of the Ionophere on Space Systems and Communications Based on the 1975 Ionosphere Effects Symposium Held in Crystal City, Arlington, ' VA, January 20-22, 1975

$A D-40235104 / 120 / 14$ 17/2.1 Naval Research Lab, Washington, DC 75 512P Goodman, John M.

Radio Frequency Scattering from a Heated Ionospheric, Volume 3, Crosssection Calculations

Minkoff, J.

Radio Science 9, 997-1004, 1974.

VHF and UHF Bistatic Observations of a Region of the Ionosphere Modified by a High Power Radio Transmitter

Carpenter, G. B.

Stanford Res. Inst., Menlo Park, Calif., USA

Radio Sci. (USA) Vol. 9, No. 11 965-9 Nov. 1974 Coden: RASCAD 
Field-Aligned Instability Due to Stimulated Scattering of Intense Radio Saves from Diffusion Quasi-Modes

Goldman, M. V. Univ. Colorado, Boulder, USA Radio Sci. (USA), Vol. 9, No. 11107709 Nov. 1974 Coden: RASCAD

Field-Aligned Scattering from a Heated Region of the IonosphereObservations at $\mathrm{HF}$ and VHF Fialer, P. A.

Stanford Res. Inst., Menlo Park, Cal if., USA

Radio Sci. (USA), Vol. 9, No. 11 923-40 Nov. 1974 Coden: RASCAD

First Observations of RF Backscatter from Field-Aligned Irregularities Produced by Ionospheric Heating

Thome, G. D.: Blood, D. W.

Raytheon Co., Sudbury, MA, USA

Radio Sci. (USA) Vol. 9, No. 11 917-21 Nov. 1974 Coden: RASCAD

HF Phased Array Observations of Heater-Induced Spread-F

Allen, E. M.: Thome, G. D.; Rao, P. B.

Raytheon Co., Sudbury, MA, USA

Radio Sci. (USA) Vo1. 9, No. 11 905-16 Nov. 1974 Coden: RASCAD

HF-VHF Cormunications Experiment Using Man-made Field-aligned

Ionospheric Scatterers

Barry, G. H.

Barry Res. Corp., Palo A1to, CA, USA

Radio Sci. (USA) Vol. 9, No. 11 1025-32 Nov. 1974 Coden: RASCAD

A Model for RF Scattering Field-Aligned Heater-Induced Irregularities Rao, P. B.: Thome, G. D.

Raytheon Co., Sudbury, MA, USA

Radio Sci. (USA) Vol. 9, No. 11 987-96 Nov. 1974 Coden: RASCAD

Observations of Ion-Acoustic Wave Scattering Over Long Oblique Paths

Frank, V. R.

Stanford Res. Inst., Mento Park, CA, USA

Radio Sci. (USA) Vol. 9, No. 11 971-4 Nov. 1974 Coden: RASCAD

Satellite Transmission Studies of Spread-F Produced by Artificial Heating of the Ionosphere

Bowhill, S. A.

Aeronomy Corp., Champaign, IL, USA

Radio Sci. (USA) Vol. 9, No. 11 975-86 Nov. 1974 Coden: RASCAD 
PROPAGATION EFFECTS IN ARTIFICIALLY HEATED IONOSPHERE--3-e

Search for Whistier-Ducts During an Ionospheric Heating Experiment at Boulder, Colorado

AD-A028 581 4/1 20/14 Stanford Univ Calif Stanford Electronics Labs Descriptive Note: Technical Rept., Sep 7422 P Helliwell, R. A.; Smith, R. L.; Seely, N. T.

Rept. No. SU-SEL-74-045, TR-3432-3

Contract: N00014-67-A-0112-0044, N00014-67-A-0112-0012

Ionospheric Heating Analysis

AD-781 178 4/1 Rice Univ Houston Tex

Descriptive Note: Final Technical Rept., Apr 74 107P

Gordon, William E.; Carlson, Herbert C.

Contract: F30602-72-C-0278, ARPA Order-1423

Monitor: RADC TR-74-124

The Angular Distribution of Spread F Returns from an Artificially Modified Ionosphere

Allen, E. M.; Thome, G. D.; Rao, P. B.; Germain, R.L.ST. Raytheon Co., Sudbury, MA, USA

J. Geophys. Res. (USA) Vol. 79, No. 22 3161-9 I Aug. 1974 Coden: JGREA2

Characteristics of Artificially Generated F-Region Irregularities Using

Scintillation Signals

Rufenach, C. L.

NOAA, Boulder, Colo., USA

American Geophys. Union

EOS Trans. Am. Geophys. Union (USA) Vol. 54, No. 111147 Nov. 1973 Coden: EOSTAJ

American Geophysical Union 1973 Fall Annual Meeting (Abstracts Only) 10-13 Dec. 1973 San Francisco, Calif., USA

Kinesonde Observations of Ionosphere Modification by Intense

Electromagnetic Fields from Platteville, Colorado

Wright, J. W.

NOAA, Boulder, Colo., USA

J. Geophys. Res. (USA) Vol. 78, No. 25 5622-35 1 sept. 1973 Coden: JGREA2

Radio Scintillation on Stellar Signals During Artificial Ionospheric

Modification

Rufenach, C. L.

NOAA, Boulder, CO, USA

J. Geophys. Res. (USA) Vo1. 78, No. 25 5611-21 I Sept. 1973 Coden: JGREA2

Further Ionosonde Observations of Ionospheric Modification by a High-

Powered HF Transmitter

Utlaut, W. F.; Violette, E. J.

Inst. Telecommunication Sci., Boulder, CO, USA

J. Geophys. Res. (USA) Vol. 77, No. 34 6804-18 I Dec. 1972 Coden: JGREA2 
PROPAGATION EFFECTS IN ARTIFICIALLY HEATED IONOSPHERE--3-e

Observations of D-Region Modifications at Low and Very Low Frequencies Jones, T. B.: Davies, K.; Wieder, B.

NOAA, Boulder, CO, USA

Nature (GB) Vol. 238, No. 5358 33-4 7 July 1972 Coden: NATUAS

Effect on Ionospheric Heating by Radio Waves on the Absorption of Probing Waves of Different Polarization

Fejer, J. A.

Univ. California, San Diego, La Jolla, USA

J. Geophys. Res. (USA) Vo1. 76, No. 1 285-6 1 Jan. 1971 Coden: JGREA2

Sideband Structure Observed by Topside Sounders

AD-694 871 4/1 17/2 Aeronomy Lab Boulder C0

Feb 69 5P Warnock, J. M. 
EMI $--4-a$

Integrated Circuit Electromagnetic Susceptibility Investigation Phase III IC Susceptibility Handbook - Draft 1

AD-A029 224 9/5 McDonnell Douglas Astronautics Co - East St Louis MO Jun 76 100P Roe, J. M.

Rept. No. MDC-E1515

Contract: N60921-76-C-A030

Proj: XF54-585

Task: XF54-585-001

Monitor: NSWC/DL TR-3506

Electromagnetic Compatibility Study of Conducting Wires

AD-A004 235 9/1 Naval Postgraduate School Monterey Calif

Descriptive Note: Master's Thesis, Dec 74 26P Uluc, Levent

Rept. No. NPS-52AB74121

Improved Electromagnetic Compatibility (EMC) Analyses, Volume 1, Report on Tasks 1 and $3-9$

AD-915 195L 20/14 9/3 9/5 17/2 General Research Corp McLean VA

Operations Analysis

Descriptive Note: Final Rept. Sep 72-Aug 73, Nov 73 208P

Clark, Coleman T.; Doeppner, Thomas W.; Heverly, J. Ross;

Rept. No. OAD-CR-17-Vo1-1

Jones, James L.; Manzavinos, Allen T.

Contract: DAHC19-69-C-0017

Proj: DA-10334

Engineering Design Handbook, Hardening Weapon Systems Against RF Energy AD-894 910 20/14 9/3 Army Materiel Command Washington DC

Descriptive Note: Pamphlet Feb 72 269P

Rept. No. AMCP-706-235

Digital Equipment Susceptibility

AD-894 891 17/2.1 20/14 9/3 Martin Marietta Corp Orlando FL

Descriptive Note: Quarterly Progress Rept. No. 6, 29 Nov 71-27 Feb 72

Jun 72 85P Baxter, Denmer Dix; Wilson, Jay L.;

Rept. No. OR-11864-1 Lecain, James $F$.

Contract: DAAB07-71-C-0013

Proj: $\quad D A-1-5-662701-D-449$

Monitor: ECOM 0013-6

Electromagnetic Interference Environment Measurement and Prediction Considerations

AD-881 937L 17/2 Office of Telecommunications Boulder Colo Inst for

Telecommunication Sciences

Descriptive Note: Technical Memo., Feb 71 93P Disney, Robert T.

Rept. No. OT/ITSTM-28

Monitor: NESTEF 70-135 
EMI--4-a

Interference Notebook, Volume 2

AD-861 063L 17/2 20/14 Atlantic Research Corp Alexandria VA Jansky and Bailey Research and Engineering Dept

Aug 69 258P Baldwin, Thomas E., Jr.; Hyduke, David; Seneker, William P.; Stemple, Harry L.; Them, Albert

Contract: F30602-68-C-0050

Proj: AF-4540

Task: 454002

Monitor: RADC TR-66-1-Vol-2

Compatibility Study of EMI Standards

AD-837 568L 9/3 17/2.1 Naval Electronic Systems Test and Evaluation Facility Patuxent River MD

Descriptive Note: Final Rept., Aug 68 20p Browne, J. E.

Rept. No. NESTEF-68-36 
PNL-2482

UC $-97 a$

\section{OISTRIBUTION}

\begin{tabular}{ll}
$\frac{\text { No. of }}{\text { Copies }}$ & $\frac{\text { No. of }}{\text { Copies }}$ \\
\hline OFFSITE & OFFSITE
\end{tabular}

1 DOE Chicago Patent Group

US Department of Energy

3 Institute for Te? ecommunication

Argonne, IL 60439

A. A. Churm

27 DOE Technical Information Center

7 Argonne National Laboratory $400 \mathrm{~N}$. Capitol Street N.I Washington, DC 20001

CA Sandah1 (1)

9700 South Cass Avenue Argonne, IL 60439

$T$ Wolsko (6)

16 Department of Energy Division of Biomedical and Environmental Research Washington, DC 20545 $T$ Gross (2)

Solar, Geothermal, Electrical and Storage Systems 20 Massachusetts Avenue NW Washington, DC 20545 EH Willis (1)

Division of Solar Technology 600 East Street NW Washington, DC 20545

FA Koomanoff (5) JF Madewell HH Marvin

Division of Technology Overview Rt. 270

Germantown, MD 20545

$R$ Blaunstein (6)

43 National Aeronautics and Space Administration NASA Headquarters Washington, DC 20546

$$
\begin{array}{lll}
H & \text { Calahan (2) } \\
\mathrm{R} & \text { LaRock (1) } \\
\mathrm{S} \text { Manson (2) }
\end{array}
$$

Johnson Space Center Houston, TX 77058

$\begin{array}{ll}L & \text { Bell (3) } \\ C & \text { Covington (4) } \\ H & \text { Davis (1) } \\ O & \text { Garriott (6) } \\ J & \text { Loftus (1) } \\ \text { R Piland (2) }\end{array}$

Marshall Space Flight Center Huntsville, AL 35812
$K$ Fikes
C Guttman (5)
J Murphy (1)
(15) 
No. of

Copies

OFFSITE

$4 \quad$ Planning Research Corporation

7600 0ld Springhouse Road

McLean, VA 22101

C Bain

2 Solar Energy Research Institute

1536 Cole Boulevard

Golden, C0 80401

$P$ Rappaport

ONSITE

1 DOE, Richland Operations Office Federal Building

Richland, WA 99352

HE Ransom

6 Battelle-Northwest

P.0. Box 999

Richland, WA 99352

WJ Bair

KC Davis

$K$ Drumheller

PA Ekstrom

$\mathrm{CL}$ Simpson

RA Stokes

Technical Information Files (5)

Technical Publications (4) 